DOE/ID-10754

U.S. Department of Energy
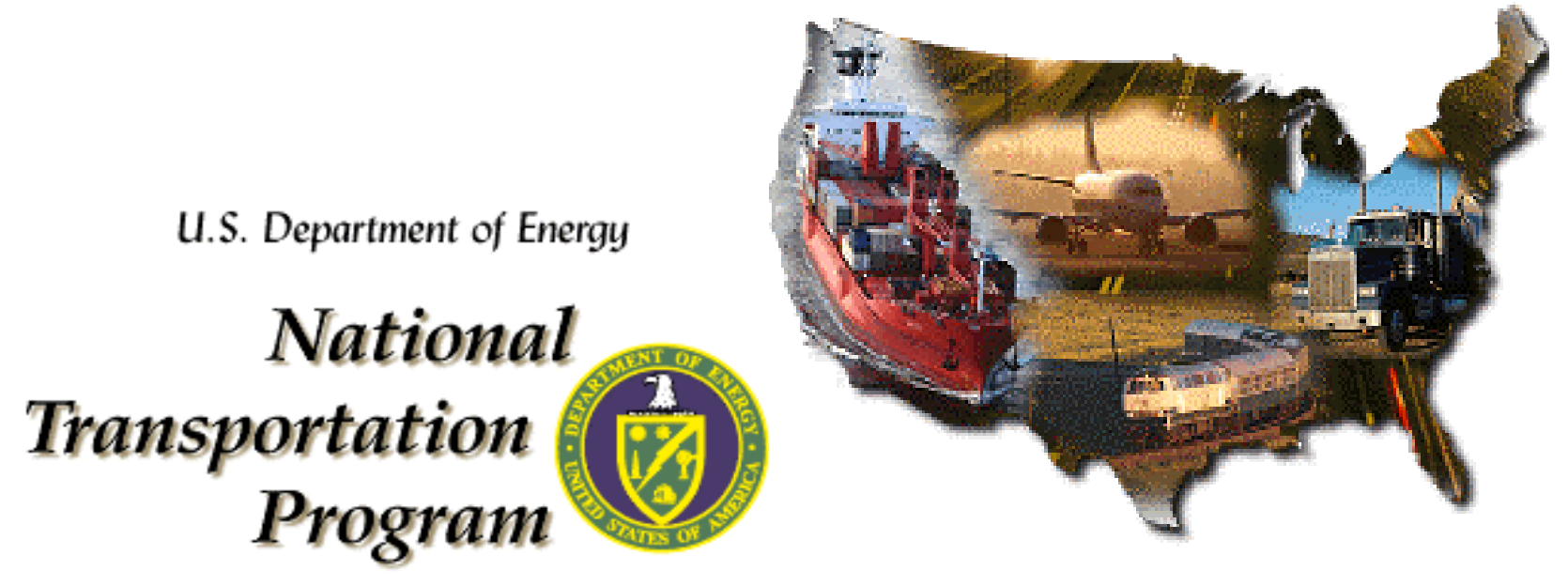

\title{
TRANSPORTATION BASELINE REPORT
}

Prepared by:

National Transportation Program Integration and Planning Bechtel BWXT Idaho, LLC

Idaho National Engineering and Environmental Laboratory P.O. Box 1625

Idaho Falls, ID 83415-1625

December 1, 1999 



\section{TABLE OF CONTENTS}

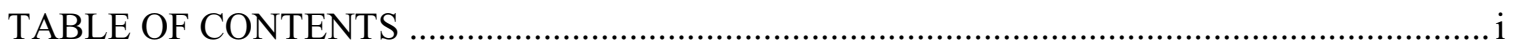

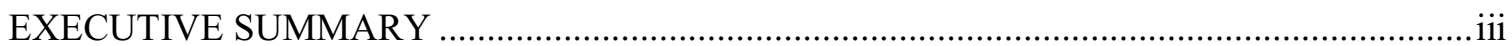

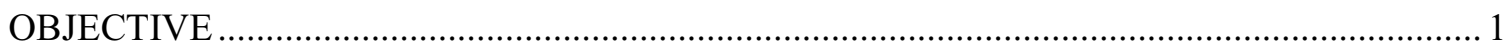

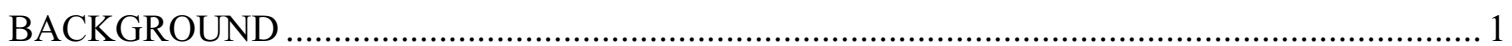

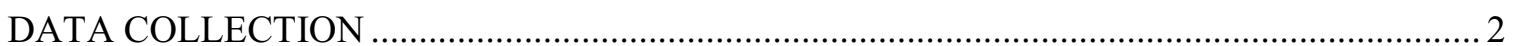

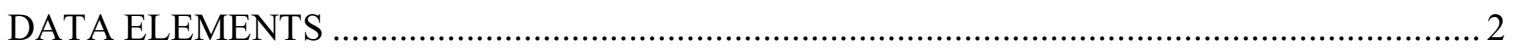

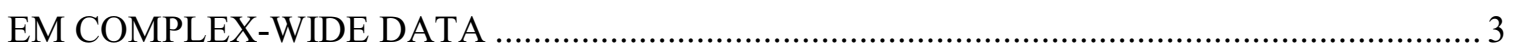

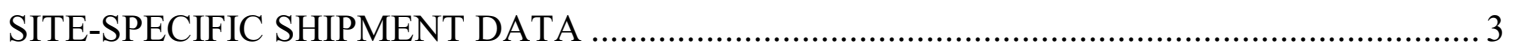

SITE-SPECIFIC VOLUME, WEIGHT AND CANISTER DATA .......................................... 5

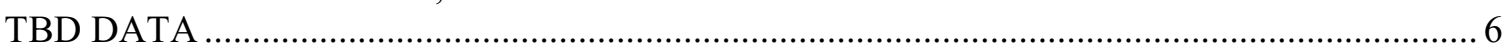

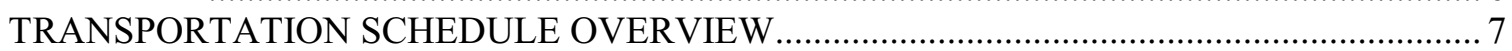

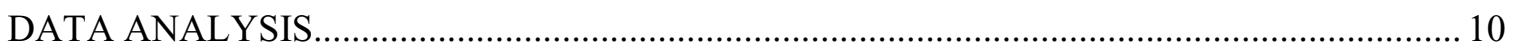

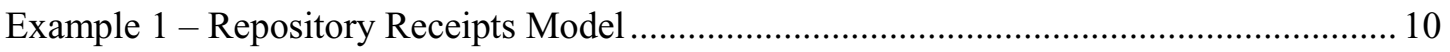

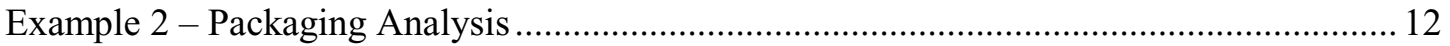

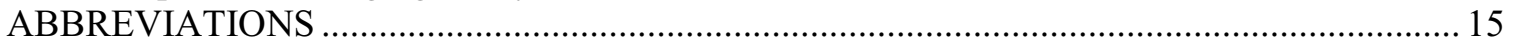

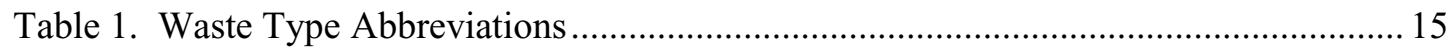

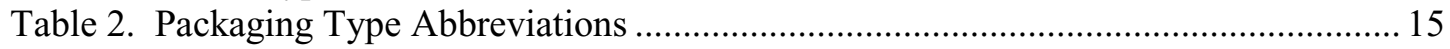

Table 3. DOT Material Class/Category Abbreviations …................................................... 15

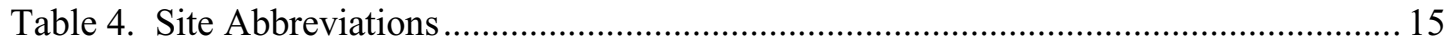

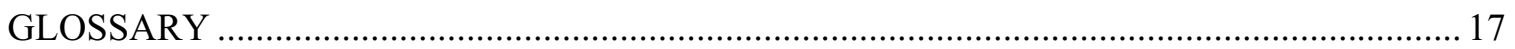

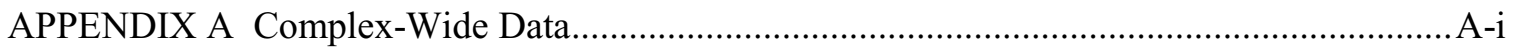

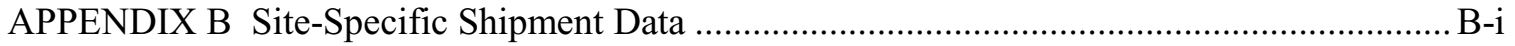

APPENDIX C Site-Specific Volume, Weight and Canister Data ….........................................

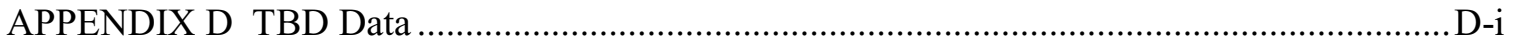

APPENDIX E 1999 Transportation Baseline Schedule Example Graphics................................ E-i

APPENDIX F Data Analysis Examples - Repository Receipts Model; Packaging Analysis ..... F-i 



\section{National Transportation Program 1999 Transportation Baseline Report}

\section{EXECUTIVE SUMMARY}

The National Transportation Program 1999 Transportation Baseline Report presents data that form a baseline to enable analysis and planning for future Department of Energy (DOE) Environmental Management (EM) waste and materials transportation. In addition, this Report provides a summary overview of DOE's projected quantities of waste and materials for transportation. Data presented in this report were gathered as a part of the IPABS Spring 1999 update of the EM Corporate Database and are current as of July 30, 1999. These data were input and compiled using the Analysis and Visualization System (AVS) which is used to update all stream-level components of the EM Corporate Database, as well as TSD System and programmatic risk (disposition barrier) information. Project (PBS) and site-level IPABS data are being collected through the Interim Data Management System (IDMS). The data are presented in appendices to this report. The appendices and their contents are as follows:

- Appendix A: Combined data for the entire DOE complex is presented in Appendix A. Waste to be transported off-site from all facilities during the near term $(1999$ - 2010) and during the entire waste disposition life-cycle are shown. Spent Nuclear Fuel (SNF) quantities were reported in metric tons of heavy metal (MTHM) and shown for the near term and life-cycle. High level waste quantities are reported in terms of numbers of canisters and are presented for the near term and life-cycle. The complex-wide numbers of shipments necessary to transport each material type are presented for the near term and life-cycle.

- $\quad$ Appendix B: Near term and life-cycle shipment data for certain specific sites are presented in Appendix B. Data concerning the yearly numbers of near-term (1999 2010) incoming and outgoing shipments by material type for eleven major DOE sites are presented. In addition, for each site, the life-cycle total number of shipments, by material type and by destination are shown. For incoming shipments, the total number and percentage of near term shipments by material type and by origin are shown.

- Appendix C: Near term and life-cycle volume, weight and canister data for the Major Sites and for the Geologic Repository Disposal are presented in Appendix C.

- $\quad$ Appendix D: Compares numbers of shipments with known origin and destination with those where origin and/or destination is unknown for near term and life-cycle.

- Appendix E: Example of the 1999 Transportation Baseline Schedule.

- Appendix F: Repository Receipts Model and Packaging Analysis. 



\section{National Transportation Program 1999 Transportation Baseline Report}

\section{OBJECTIVE}

The National Transportation Program is tasked with ensuring the availability of safe, efficient and timely transportation for Department of Energy (DOE) materials. In order for the DOE to accomplish its programmatic goals, including ensuring that transportation and packaging functions support execution of each material shipping/disposition campaign, detailed planning is mandatory. The objective of the National Transportation Program 1999 Transportation Baseline Report, (hereafter referred to as this Report) is to present data that form a baseline to enable analysis and planning for future Department of Energy (DOE) Environmental Management (EM) waste and materials transportation. In addition, this Report provides a summary overview of DOE's projected quantities of waste and materials for transportation. No attempt is made in this Report to carry out analysis but some examples of analysis are provided. The data are presented both in graphic form to provide an overview, and numerically to provide detailed information. The baseline reported here is focused on projected, quantified shipping needs based on a forecast of inventories of materials from the Integrated Planning, Accountability, and Budgeting System (IPABS).

\section{BACKGROUND}

Data presented in this report were gathered as a part of the IPABS Spring 1999 update of the EM Corporate Database and are current as of July 30, 1999. IPABS serves as the unifying EM system for planning, budget decisions, oversight of projects, and actions taken to meet EM program objectives. The stream-level disposition data elements required to support this corporate data system have been identified through an extensive field review and concurrence process. The elements are documented in the IPABS-IS Data Requirements (12/18/98) and are now managed through a formal change control process under the EM Chief Information Officer.

Stream Disposition Data (SDD) document the planned baseline disposition paths for waste, contaminated media and spent nuclear fuel. These baseline disposition paths define the work scope required to move waste, media, and spent fuel from their current condition to their "end state". Various levels of uncertainty in baseline disposition plans can be expressed as "TBD" (To Be Determined) data entries for a stream's Source Activity (ER strategy only), Destination Activity (e.g., treatment), Destination Site, or Destination Treatment, Storage, and Disposal (TSD) System. The 12/21/98 Guidance requires that all disposition destination information (especially inter-site transfers) must be consistent with existing DOE Policies, Records of Decision, and agreements with stakeholders.

Disposition Maps are graphical representations (reports) of a site's baseline planning data related to managing wastes, contaminated media, and spent nuclear fuel. They show the planned progression from current status through treatment and disposal. Data are included for each step in the disposition path. A stream is dispositioned when it enters the next TSD system or is transferred to another site, program, or waste type. Final disposition (end state) occurs when a stream is disposed, recycled, or otherwise no longer requires active management. Baseline 
Disposition Maps were adopted to support integration activities and the Draft 2006 Plan (now Accelerating Cleanup, Paths to Closure). The Spring 1999 IPABS SDD update is intended to capture data specified in the IPABS requirements listed above for the following (unclassified data only):

- Stream-level planning data for FY 1999 through the life-cycle for each individual stream.

- FY 1998 year-end stream quantities (“actuals").

- Planned disposition activities for:

- EM waste

- $\quad$ EM contaminated media

- DOE spent nuclear fuel

- DOE newly generated waste, pending further discussions among EM, Defense Programs (DP), Nuclear Energy (NE), and Science (SC), previously known as "Energy Research".

- There is an on-going separate data collection for information on buried TRU waste. The summary-level information provided here should be consistent with that being developed for the more detailed buried TRU waste data call.

\section{DATA COLLECTION}

The data reported here were collected using the Analysis and Visualization System (AVS). The AVS is used to update all stream-level components of the EM Corporate Database, as well as TSD System and programmatic risk (disposition barrier) information. Project (PBS) and site-level IPABS data are being collected through the Interim Data Management System (IDMS). Development of the AVS was based on lessons learned from the 1998 Paths to Closure process, which relied on manual drawing of disposition maps and collection of underlying quantity data using spreadsheets. The AVS was developed with the following goals in mind:

- Simplify and improve the quality of data entry (e.g., through use of valid value "pick lists" and internal logic checks)

- Improve configuration control by automatically producing maps directly from the data

- Improve the ability to coordinate proposed intersite transfers by making data visible to other sites and providing intersite data comparison reports.

\section{DATA ELEMENTS}

The following are the specific, transportation-related data elements, their definitions and related information:

- Material Category identifies the DOT material category (ref. 49 CFR 173.403) that is applicable to all, or part, of the disposition quantity for the reporting period.

- Package Type identifies the planned or most probable DOT package type to be used in the reporting period for the disposition quantity within each specified Material Category.

- Capacity is the volume in cubic meters (to three significant figures) of the stream that can be placed in the Package Type.

- Mode is the planned or most probable transportation mode to be used in the reporting period for the disposition quantity that is within the specified Material Category and Package Type/Capacity. 
- \# of Shipments is the number of shipments during the reporting period that are planned for the disposition quantity of the stream that is within the specified combination of Material Category, Package Type/Capacity, and Mode. For the rail mode, each rail car is considered a shipment. For the truck mode, a single trailer is considered a shipment.

- Percent is the percentage of the disposition quantity for the reporting period that is within the specified combination of Material Category, Package Type/Capacity, and Mode.

\section{EM COMPLEX-WIDE DATA}

Combined data for the entire DOE EM complex are presented in Appendix A as follows:

- Quantities by Material Type: Waste volumes in cubic meters (M3) that are to be transported off-site from all facilities during the near term (1999 - 2010), and during the entire waste disposition life-cycle are shown in Figures 7 and 8, respectively.

- Certain material types could not be reported in terms of volume and are, therefore, illustrated separately. Some hazardous waste (HAZ) quantities were reported in metric tons (MT) rather than cubic meters and are shown for the near term and life-cycle, respectively, in Figures 9 and 10. Spent Nuclear Fuel (SNF) quantities were reported in metric tons of heavy metal (MTHM) and shown for the near term and life-cycle respectively in Figures 11 and 12. High level waste quantities are reported in terms of numbers of canisters and are presented for the near term and life-cycle respectively in Figures 13 and 14.

- Shipments by Material Type: The complex-wide numbers of shipments necessary to transport each material type are presented for the near term and life-cycle respectively in Figures 15 and 16. One shipment is defined for reporting purposes as the movement of one truck load or one rail car load from origin to destination.

- Shipments by Transportation Mode: Complex-wide numbers of shipments by transportation mode are shown for the near term and life-cycle respectively in Figures 17 and 18.

- Numbers of Packagings: The complex-wide projected numbers of packagings to be used, by packaging type and by year, are shown for the near term and life-cycle respectively in Figures 19 and 20.

- Shipments by DOT Material Class: The yearly number of shipments, by DOT Material Class, are shown for the near term and life-cycle respectively in Figures 21 and 22.

Note: The term "EM \& Non-EM" is used in the figures in the appendices. Non-EM refers to waste/materials which are either newly generated or waste/materials which do not belong to EM, but are being managed at an EM site and may be dispositioned with EM waste/materials.

\section{SITE-SPECIFIC SHIPMENT DATA}

Near term and life-cycle shipment data for specific sites are presented in Appendix B as follows:

- Major Sites: Data concerning the yearly numbers of near-term (1999 - 2010) incoming and outgoing shipments by material type for eleven major DOE sites are presented in bar graphs in Figures 23 through 39. In addition, for each site, the life-cycle total number of shipments, 
by material type and by destination are shown in pie charts. For incoming shipments, the total number and percentage of near term shipments by material type and by origin are shown. Figure 1 below explains how to read the graphs for the major sites in Appendix B. Note that for Rocky Flats, shipment data was not provided and in its place, volume information is reported in Figure 61 (Appendix C). The eleven major sites are as follows:

- Fernald Environmental Management Project

- Hanford Site

- Idaho National Engineering and Environmental Laboratory

- Los Alamos National Laboratory

- Nevada Test Site

- Oak Ridge Reservation

- Rocky Flats Environmental Technology Site

- Sandia National Laboratory

- Savannah River Site

- Waste Isolation Pilot Plant

- West Valley Demonstration Project

- Geological Repository Disposal Site Data: In Figure 40, incoming shipment data for the Geological Repository Disposal (GRD) site are presented. This combines IPABS data, which are as yet very incomplete, with data gathered in conjunction with Integrated Repository Receipts Workshops conducted during FY 1999.

- Major Sites vs. All Other: Figures 41 through 44 offer a composite reporting for the eleven major sites combined, and for all other sites combined. Figure 45 shows that the eleven major sites account for $71 \%$ of the complex-wide, near-term outgoing shipments and $21 \%$ of the complex-wide, near-term incoming shipments. 


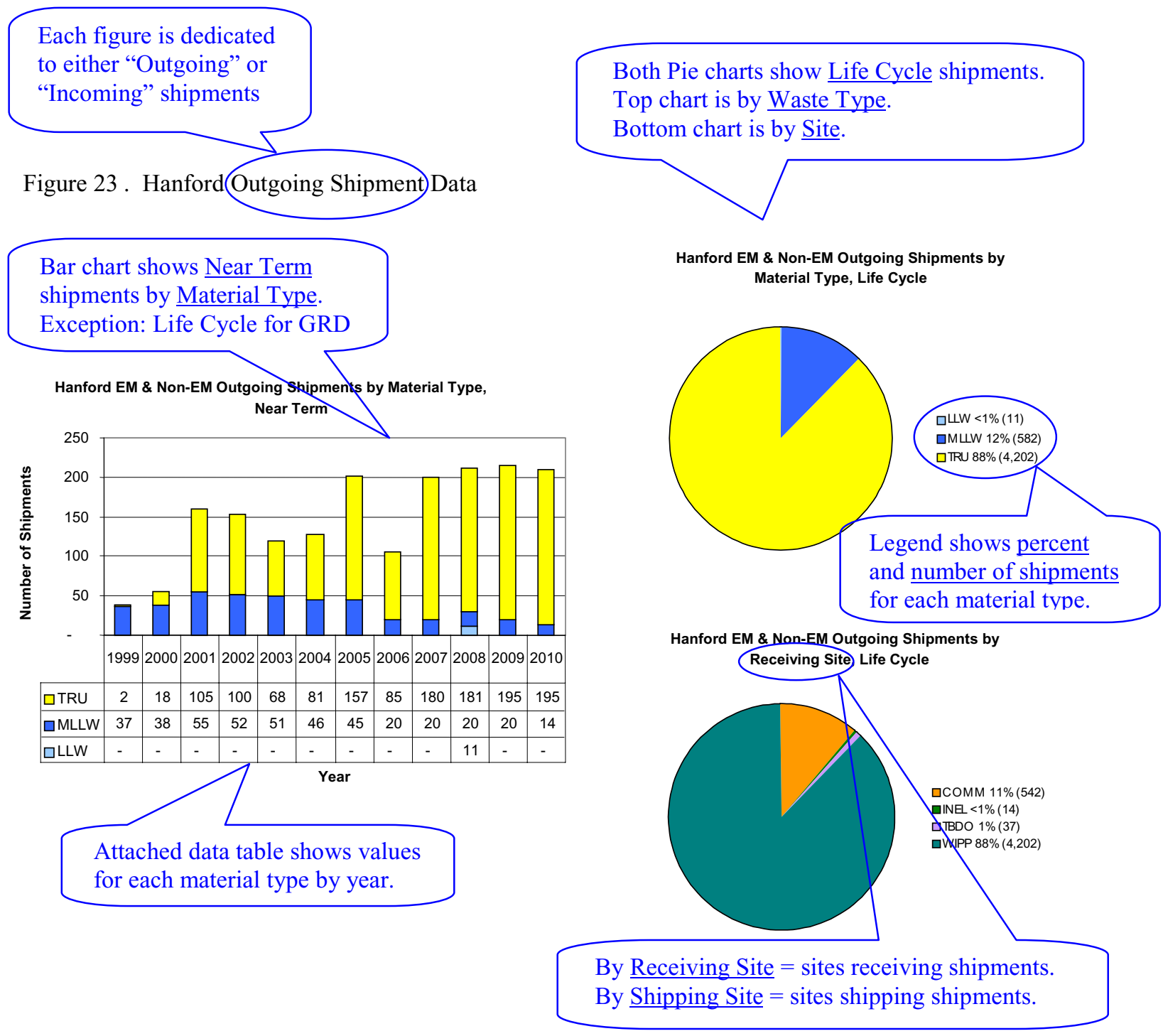

Figure 1. Explanation of Site-Specific Shipment Data in Appendix B.

\section{SITE-SPECIFIC VOLUME, WEIGHT AND CANISTER DATA}

Near term and life-cycle volume, weight and canister data for the Major Sites and for the Geologic Repository Disposal are presented in Figures 46 through 72 (Appendix C). Certain material types could not be reported in terms of volume (i.e., cubic meters (M3 or $\left.\mathrm{m}^{3}\right)$ ), therefore, they were reported in units of weight (i.e., metric tons of heavy metal (MTHM)) for SNF or in number of canisters (NC) for High Level Waste (HLW). The purpose in presenting this information is to show the best possible transportation picture.

Appendices B and C complement each other to present a more accurate view of the planned transportation activities for the specified sites. Appendix B presents shipment data for the material streams that have shipment data in the database. Appendix $\mathrm{C}$ presents volume, weight and canister data for material streams that do not have shipment data. For example, if a material stream has shipment data, the information is presented in Appendix B, but not in Appendix C. If 
a material stream does not have shipment data, then the volume, weight or canister information is presented in Appendix C, but not in Appendix B. Figure 2 below explains how to read the graphs for the major sites in Appendix C.

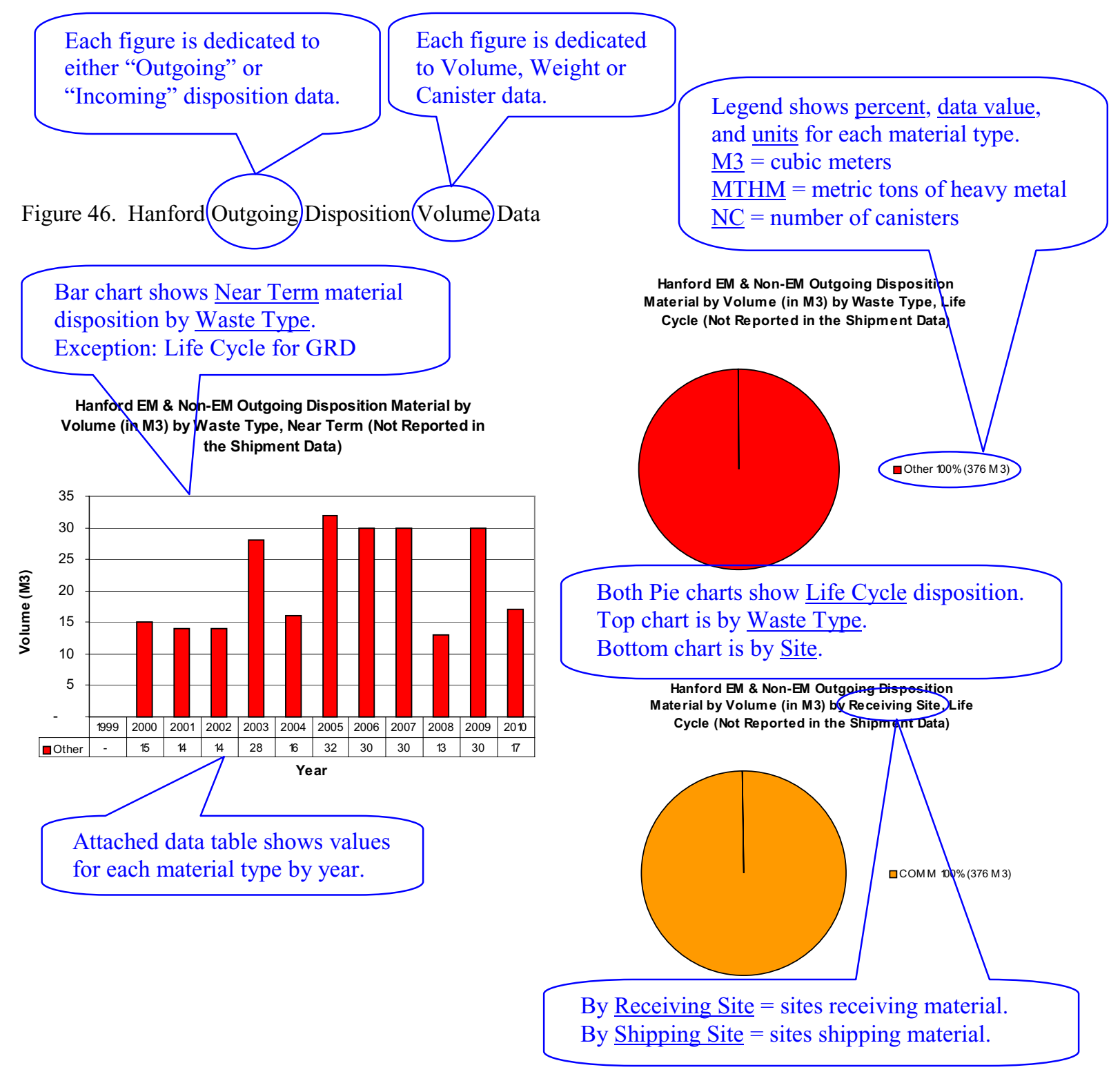

Figure 2. Explanation of Site-Specific Disposition Volume, Weight or Canister Data in Appendix C.

\section{TBD DATA}

Figures 73 and 74 in Appendix D depict a complex-wide shipment origin-destination pairing of "unknown" (TBD) sites and "Known" sites for near term and life-cycle, respectively. Figure 73 shows the following for near term shipments: 
- $76 \%$ will be shipped from a known site to a known site

- $23 \%$ will be shipped from a known site to a TBD site

- $1 \%$ will be shipped from a TBD site to a known site

- Less than $1 \%$ will be shipped from a TBD site to a TBD site

Figure 74 shows the following for life-cycle shipments:

- $\quad 73 \%$ will be shipped from a known site to a known site

- $13 \%$ will be shipped from a known site to a TBD site

- $14 \%$ will be shipped from a TBD site to a known site

- Less than $1 \%$ will be shipped from a TBD site to a TBD site

By comparing Figures 73 and 74, it should be noted that there is an increase in the "TBD to Known" value as the time frame changes from near term to life-cycle. The increase is due to only two waste streams with shipments from TBD to WIPP. These waste streams comprise 19,424 of the 19,449 shipments (i.e., $99.9 \%$ ) of the "TBD to Known" category.

\section{TRANSPORTATION SCHEDULE OVERVIEW}

The following is an overview of the 1999 Transportation Baseline Schedule. The 1999 Transportation Baseline Schedule shows a view of the transportation activities of DOE EM wastes/materials. It can be used to identify areas where stakeholder interface is needed and to communicate to stakeholders the quantity/schedule of shipments going through their areas. Potential bottlenecks in the transportation system can be identified; the number of packagings needed and the capacity needed at receiving facilities can be planned. Although it is limited to the 7/30/99 version of SDD captured in the AVS, the 1999 Transportation Baseline Schedule provides a visualization of DOE EM transportation activities for the 11 major sites and the Geologic Repository Disposal (GRD). For the 1999 Transportation Baseline Schedule, the 11 major sites are:

Fernald Environmental Management Project

Hanford Site

Idaho National Engineering and Environmental Laboratory

Los Alamos National Laboratory

Nevada Test Site

Oak Ridge Reservation

Rocky Flats Environmental Technology Site

Sandia National Laboratory

Savannah River Site

Waste Isolation Pilot Plant

West Valley Demonstration Project

The information presented is for Mixed/Low Level Waste (M/LLW), Transuranic (TRU) waste, High Level Waste (HLW), and Spent Nuclear Fuel (SNF) waste/material streams. Information used for the GRD map includes data gathered in conjunction with the Integrated Repository Workshop conducted during FY 1999.

One of the transportation related data elements captured in the AVS is "Number of Shipments." At the waste stream level, the number of shipments for each year was captured, 
indicating a high level schedule of planned shipments. The following is a definition for "Number of Shipments" from the AVS:

- \# of Shipments is the number of shipments during the reporting period that are planned for the disposition quantity of the stream that is within the specified combination of Material Category, Package Type/Capacity, and Mode. For the rail mode, each rail car is considered a shipment. For the truck mode, a single trailer is considered a shipment.

The "number of shipments" data element was entered into the AVS by each site. It is not derived by the AVS using waste/material volumes. The 1999 Transportation Baseline Schedule focuses on the number of shipments. However, volume schedule data are presented where shipping information was not available.

The waste stream shipment schedule information was combined for each waste type, to show a high-level shipping schedule for that particular waste type from a given site (e.g., number of LLW shipments for the reporting period). The "waste type annual number of shipments" for each site was used as the schedule of shipments to/from the site. The "annual number of shipments" were combined and used as the "total life-cycle number of shipments." Examples of how these numbers were used in the 1999 Transportation Baseline Schedule are as follows:

The 1999 Transportation Baseline Schedule map (Figure 3) shows a high level view of incoming/outgoing shipments for the specified site. The total life-cycle number of shipments from 7/30/99 SDD is indicated for each site with its accompanying volume.

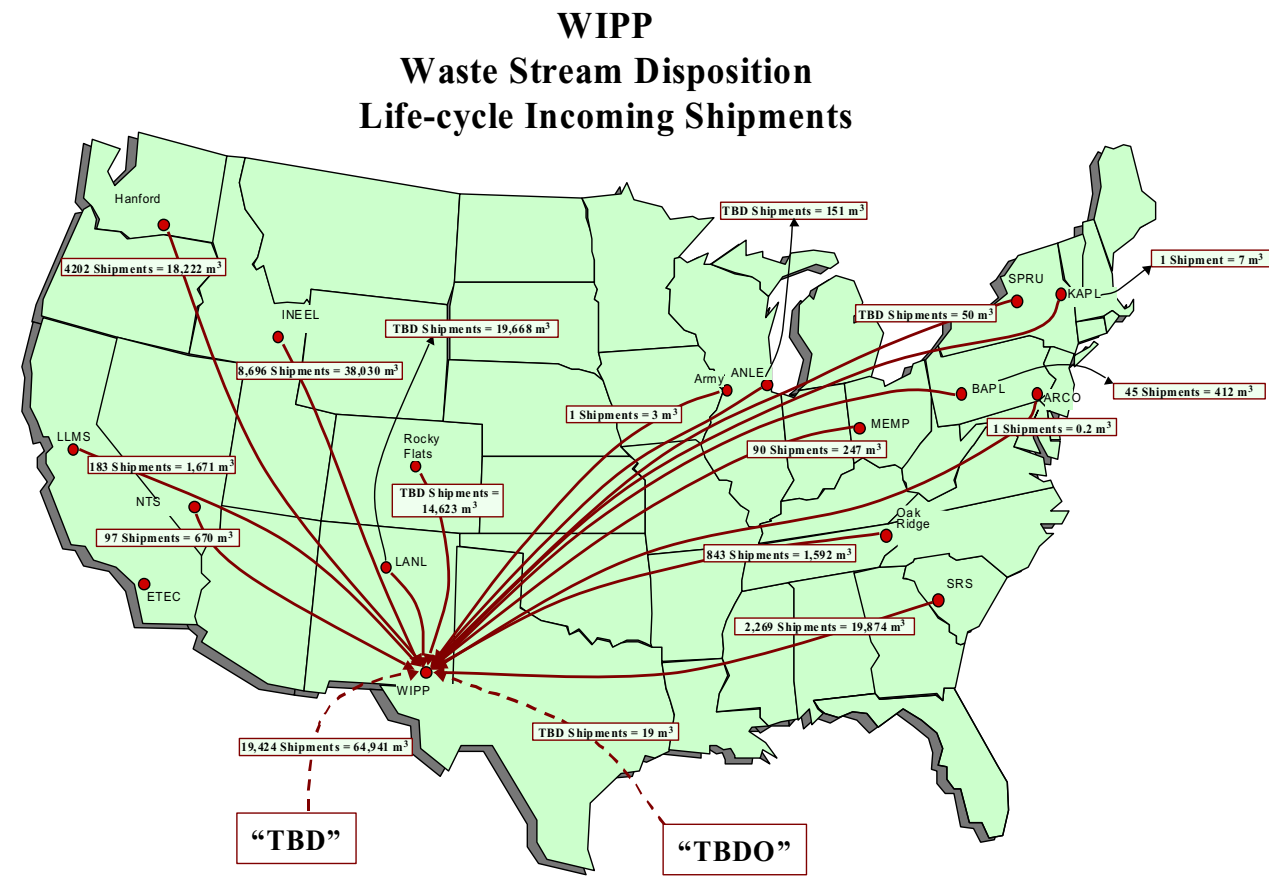

Figure 3. Transportation Baseline Schedule Map. 
An information box appears on (or near) the red arrow for each origin-destination pair. Volumes for the waste/material streams with shipping information are displayed (Figure 4).

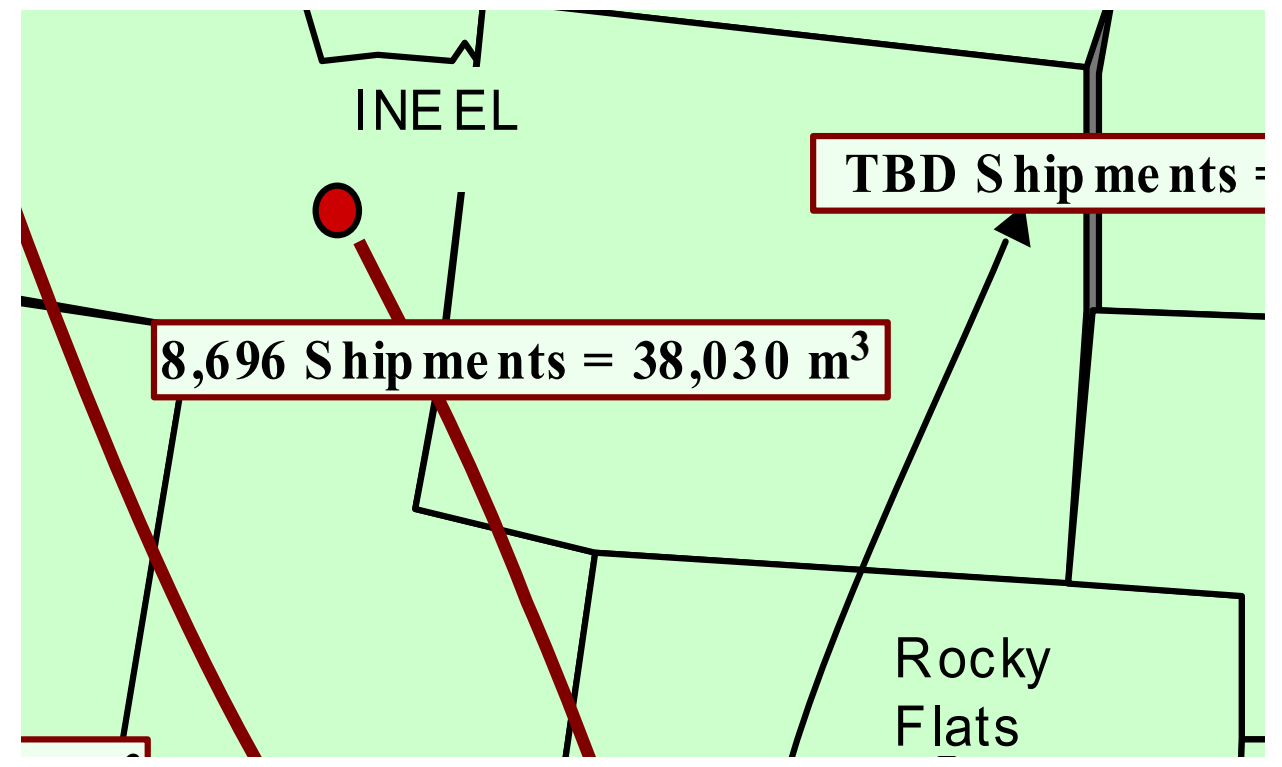

Figure 4. Volume and Number of Shipments as reported in IPABS SDD.

If a waste/material stream volume is provided in the SDD and no shipping information is provided, it is indicated as "TBD Shipments" (Figure 5).

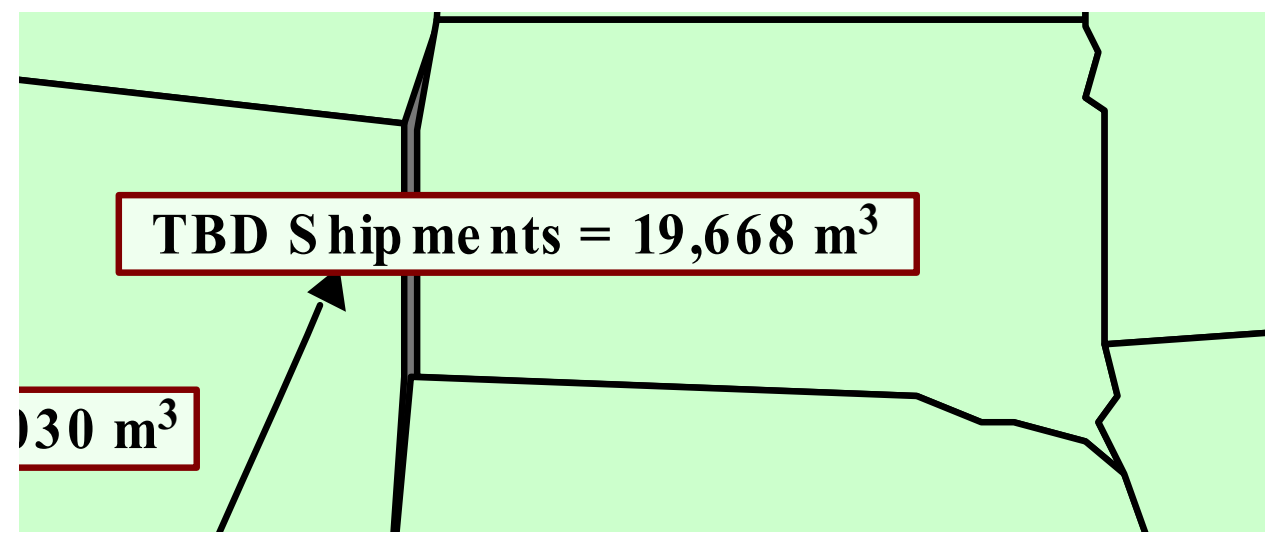

Figure 5. Volume reported in IPABS SDD without Number of Shipments. 
If some of the waste/material streams have shipping information in IPABS SDD and some do not, both are displayed in separate lines in the information box. Figure 6 is an example of an origin-destination pair where the SDD contains the number of shipments for $38,030 \mathrm{~m}^{3}$, but has $19,668 \mathrm{~m}^{3}$ with no shipping information.

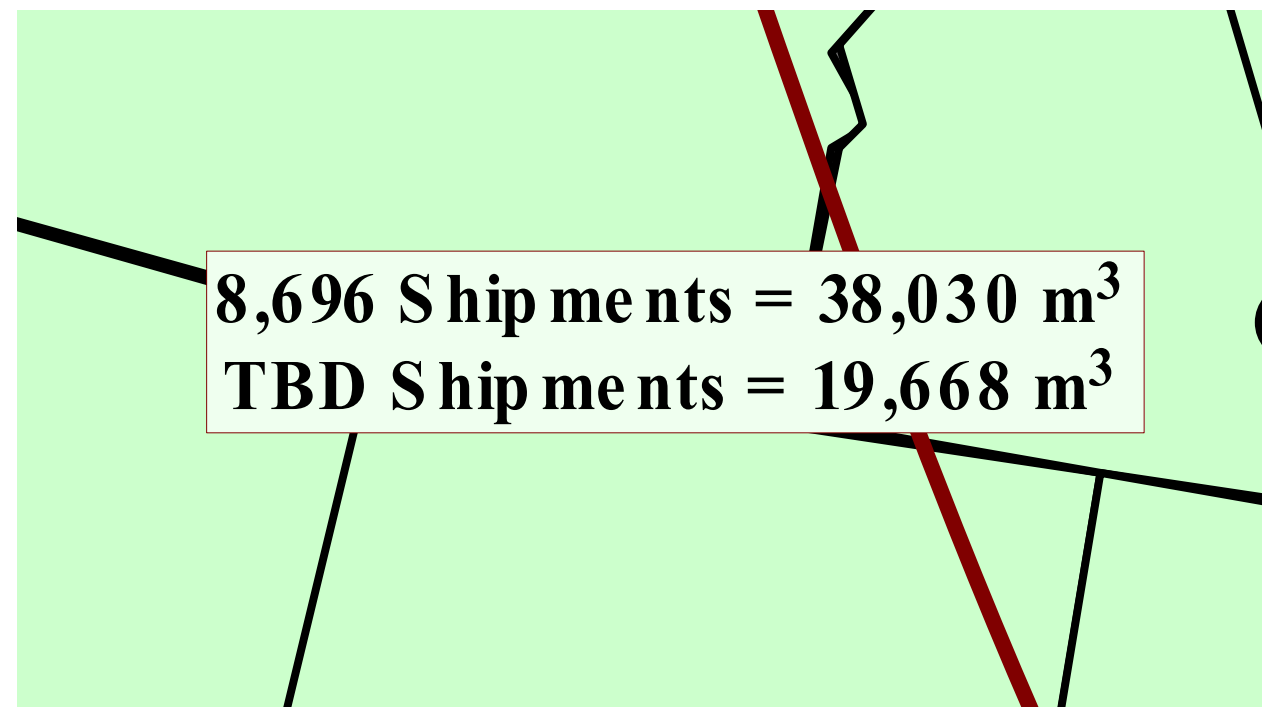

Figure 6. Volume reported in IPABS SDD with no Number of Shipments.

The data in the information boxes are displayed in the graphs that follow the Transportation Baseline Schedule map.

An example of the 1999 Transportation Baseline Schedule graphics is included in Appendix E (Figures 75 through 91).

The "Number of Shipments" data element captured in the IPABS data was used as a high level shipping schedule. It was used to obtain the total life-cycle number of shipments for a given site. That information is graphically displayed as EM transportation activities for a given site. A graph compiling all shipments to/from a site by origin/destination was developed. The combination of these pieces of information provides a graphical view of where the shipments are going, where they are from, and the planned schedule of shipments.

\section{DATA ANALYSIS}

Data analysis is beyond the scope of this report, however, two examples are provided to demonstrate the potential uses of the data. The following two examples are the Repository Receipts Model and Packaging Analysis.

\section{Example 1 - Repository Receipts Model}

The baseline data presented in this report, particularly as visualized using the methodology outlined in the Transportation Schedule Overview section, provides a method of viewing the planned shipping schedule for individual sites and the complex as a whole. When the composite schedule is viewed (e.g., Figures 7 and 8 in Appendix A) it is readily apparent that the current baseline does not optimize the shipping schedule for best use of capital and operational resources. 
Such optimization requires that all variable interactions and relationships be analyzed concurrently. The following is a discussion of an existing mathematical model for HLW and SNF shipments to the GRD, and how it has been used to develop an alternative Integrated Shipping Schedule.

DOE EM SNF and HLW shipments to the GRD require integration to ensure shipping resources are efficiently used and interim storage requirements are minimized. Effective integration uses many variables that, when combined, create a system that is difficult to grasp without a computational device. A spreadsheet model has, therefore, been developed that allows alternative shipping scenarios to be deployed and the resulting effects on shipping resources and site interim storage to be observed.

The model uses assumptions and data sets developed at three 1999 workshops attended by representatives for SNF and HLW from the following sites:

\section{Hanford Site \\ Idaho National Engineering and Environmental Laboratory \\ Oak Ridge Reservation \\ Savannah River Site \\ West Valley Demonstration Project \\ United States Navy}

The developed assumptions are:

1. SNF and HLW are packaged into 10 or 15 -foot standard canisters

2. Co-disposal of 1 SNF canister with 5 HLW canisters in a waste package at the repository

3. Priority for co-disposal is like length with like length (e.g. $15 \mathrm{ft}$. HLW with $15 \mathrm{ft}$. SNF, $10 \mathrm{ft}$. HLW with $10 \mathrm{ft}$. SNF) but co-disposal of $15 \mathrm{ft}$. HLW with $10 \mathrm{ft}$. SNF is also allowed

4. All DOE HLW will be disposed in the GRD (no canister limit)

5. GRD facility can emplace $160 \mathrm{DOE}$ waste packages per year

6. Lag storage at the GRD is limited to 1100 canisters

7. The main cost avoidance issues are new storage facilities

At workshops attended by representatives from the above sites, data was collected in the following two categories: 1) generation rates and 2) shipping rates. Generation rates are expressed as years of operation for vitrification of HLW, and years of packaging SNF into standard canisters. Shipping rates are in numbers of canisters scheduled to be sent to the GRD. These two data categories may then be used to generate a complex-wide shipping schedule including interim storage needs. Because each site created its schedule independently, there is an opportunity to improve the complex-wide schedule and minimize interim storage needs by using modeling as a tool.

The model is designed like a checking account with deposits (in), withdrawals (out) and a balance. Within the model, there are two categories of accounts: 1) site and 2) GRD. The site account includes generation (in), shipping (out), and interim storage (balance). The GRD account includes the shipping portion of the site accounts as deposits (in), emplacement (out), and lag storage (balance). The rule set governing the emplacement of SNF and HLW into the GRD was generated from the assumptions listed above. Treating the data in this manner produces the desired interim storage output for the individual sites and the GRD. 
Figure 92 (Appendix F) is a "stacked area" graphical representation of lag storage at the GRD as generated by the baseline schedule. In a stacked area graph, the canister types are "stacked" or summed together forming the overall curve. For example, in the peak storage year 2034 the numbers of canisters for each canister type are as shown in the following table:

\begin{tabular}{|lr|}
\hline Canister Type & Amount \\
\hline RL-MCO & 92 \\
$15 \mathrm{ft}$ SNF & 300 \\
$10 \mathrm{ft}$. SNF & 465 \\
$15 \mathrm{ft}$ HLW & 2,042 \\
$10 \mathrm{ft} . \mathrm{HLW}$ & 437 \\
\hline Total & $\mathbf{3 , 3 3 6}$ \\
\hline
\end{tabular}

As can be seen, in the baseline scenario, canisters accumulate in large numbers at the lag storage facility because the sites do not ship in proportions conducive to the five and one codisposal rule. Under current plans, during the first 15 years of proposed GRD operation, $15 \mathrm{ft}$. SNF arrives with $10 \mathrm{ft}$. HLW. These two types are not co-disposable and so they accumulate at the lag storage facility while waiting for compatible canisters to arrive. This problem is then compounded through the following years of operation. This can be corrected by arranging the arrival of HLW and SNF in a schedule that allows for earlier co-disposal. Figure 93 shows that when shipping schedules are aligned so that the correct blend of HLW and SNF canisters arrive at the GRD, the lag storage requirement is reduced.

The model also generates interim storage requirements for the individual sites. Figure 94 shows the projected baseline interim storage requirements at the Hanford Site. (The blue line, labeled "Storage Need", refers to the dynamic, actual storage need in any given year while the red line, labeled "Planned Storage", shows the capacity of the planned storage facility and when it is to be built). In this case, Hanford plans on building a storage facility with a capacity for 12,200 canisters around the year 2016 to accommodate the peak actual storage need in the year 2030 .

Figure 95 shows the projected Hanford Site interim storage need for the integrated shipping scenario outlined above. Here, the proposed integrated schedule produces a mutually beneficial situation, in that there is a reduced need for interim storage at the Hanford Site because the GRD is willing to take Hanford $15 \mathrm{ft}$. HLW sooner in order to co-dispose with incoming $15 \mathrm{ft}$. SNF. For some of the other sites, the proposed integrated schedule generates somewhat increased or unchanged interim storage needs, but over-all it is clearly beneficial.

Through the efforts of the complex-wide representatives, a solution has been developed that shows value added for both EM and RW. Modeling has proven to be a useful tool for decisionmakers in developing an alternative for an Integrated Shipping Schedule. The relationships involved with changing a shipping schedule at one site can be seen propagating through the complex-wide system. Once cause-and-effect is understood, resources can be used more efficiently.

\section{Example 2 - Packaging Analysis}

The data provided should allow for analysis of EM Transportation problems or gaps. As an example, data concerning anticipated packaging needs is entered by site, but can be viewed from the EM complex-wide perspective. Packaging requirements were given by year and by package type for both the near term and the life-cycle. Numbers of packagings required are estimated 
from the data submitted by dividing the capacity of the packaging to be used into the volume of the waste to be transported. No correction is applied for outage or other factors.

In general, requirements for packaging types other than Type B are readily fulfilled using standard, commercially available packagings. Efforts are being made to develop DOE standards for some attributes of certain LLW packagings (see Evaluation of the Container Working Group Long-Term Recommendation Related Standardization of Waste Containers and Adoption of Transport Packaging Policy dated June 1999), but no difficulty is foreseen in obtaining adequate supplies of these packagings once the standards are in place. Most packagings other than Type B that are used for waste disposal are used only once and are disposed of along with their contents. The data, as currently collected, however, does not distinguish such "one-way" packagings from packagings that are reused. Still, needs for packagings other than Type B are not expected to present an insurmountable barrier to the transportation of any waste type.

Figures 96 and 97 in Appendix F show the numbers of Type B packagings calculated to be necessary to transport each waste type by years. These calculations simply divide waste quantity by packaging capacity to arrive at a number of packagings. Type B packagings, however, are almost invariably reused so that the actual number of Type B packagings required to transport a quantity of waste over the course of a year would be considerably less than that calculated in this way. The IPABS data call requests Type B packaging inventory information. Currently, however, this data has not been fully collected, nor is there complete information concerning quantities of SNF and HLW to be transported. The most complete data is for TRU waste, where it appears that between the years 2004 and 2015, approximately 2000 shipments a year will be made. This information can be useful in estimating the requirements for TRUPACT II Type B containers during peak shipping years although there is insufficient information in the IPABS data to do so accurately here. As an example of the type of analysis that can be performed, a minimum requirement can be estimated making the following assumptions:

1) Each shipment consists of three (3) TRUPACT II containers.

2) WIPP will receive shipments $X$ days per year.

3) The total round trip time for a TRUPACT II container will be Y days.

4) Shipping will be coordinated among the sites for optimum usage of containers.

For instance, if $X=360$ (WIPP receives shipments 360 days a year) and $Y=6$ (an average of two days each in transit to and from WIPP and a day each for loading and unloading), WIPP would receive an average of about 6.4 shipments a day in 19 TRUPACT II containers. This then would require six (6) sets of 19 TRUPACT II containers or a minimum of 114 . With more complete information in the future, similar calculations will be possible for other waste types and packagings. 



\section{ABBREVIATIONS}

Table 1. Waste Type Abbreviations

\begin{tabular}{|c|l|}
\hline Waste Type Code & \multicolumn{1}{|c|}{ Waste Type Name } \\
\hline HAZ & Hazardous Waste \\
\hline HLW & High Level Waste \\
\hline LLW & Low Level Waste \\
\hline MLLW & Mixed Low Level Waste \\
\hline Other & $\begin{array}{l}\text { Other Waste Types (i.e., 11e2 By-product Waste, Sanitary Waste, } \\
\text { Unspecified Waste) }\end{array}$ \\
\hline SNF & Spent Nuclear Fuel \\
\hline TRU & Transuranic Waste \\
\hline
\end{tabular}

Table 2. Packaging Type Abbreviations

\begin{tabular}{|c|l|}
\hline Packaging Type Code & \multicolumn{1}{c|}{ Packaging Type Name } \\
\hline IP & Industrial Packaging (rad) \\
\hline POP & Performance Oriented Packaging (non-rad) \\
\hline HAZSPEC & Special Hazardous Material Packaging (non-rad) \\
\hline STP & Strong Tight Packaging/Excepted Packaging (rad) \\
\hline TBD & To Be Determined \\
\hline Type A & Type A Packaging (rad) \\
\hline Type B & Type B Packaging (rad) \\
\hline
\end{tabular}

Table 3. DOT Material Class/Category Abbreviations

\begin{tabular}{|c|l|}
\hline $\begin{array}{c}\text { DOT Material Category } \\
\text { Code }\end{array}$ & \multicolumn{1}{|c|}{ DOT Material Category Name } \\
\hline EXS & Exempted/Special Form \\
\hline LMQ & Limited Quantity \\
\hline LSA-I, LSA-II, LSA-III & Low Specific Activity - Type I, - Type II, - Type III, respectively \\
\hline NLA & Non-LSA Type A \\
\hline NLB & Non-LSA Type B \\
\hline NRD & Non-Radioactive/Non-Hazardous \\
\hline NRH & Non-Radioactive Hazardous \\
\hline SCO-I, SCO-II & Surface Contaminated Objects - Type I, - Type II, respectively \\
\hline TBD & To Be Determined \\
\hline
\end{tabular}

Table 4. Site Abbreviations

\begin{tabular}{|c|l|}
\hline Site Code & \multicolumn{1}{|c|}{ Site Name } \\
\hline AEMP & Ashtabula Environmental Management Project \\
\hline AMES & Ames Laboratory \\
\hline ANLE & Argonne National Laboratory - East \\
\hline ANLW & Argonne National Laboratory - West \\
\hline ARCO & ARCO Medical Products Company \\
\hline ARMY & U.S. Army Material Command \\
\hline BAPL & Bettis Atomic Power Laboratory \\
\hline BRNL & Brookhaven National Laboratory \\
\hline CEMP (BCLJ) & Columbus Environmental Management Project - West Jefferson \\
\hline CNS & Charleston Naval Shipyard \\
\hline
\end{tabular}




\section{ABBREVIATIONS}

\begin{tabular}{|c|c|}
\hline Site Code & Site Name \\
\hline COMM & Commercial Site - TBD \\
\hline CWM & Chemical Waste Management \\
\hline DOE & DOE Site - TBD \\
\hline DSSI & Diversified Scientific Services, Inc. \\
\hline ENVR & Envirocare \\
\hline ETEC & Energy Technology Engineering Center \\
\hline FEMP & Fernald Environmental Management Project \\
\hline GEAT & General Atomics \\
\hline GRD & Geologic Repository Disposal \\
\hline HASI & Hanford Site \\
\hline INEL, INEEL & Idaho National Engineering and Environmental Laboratory \\
\hline KAPL & Knolls Atomic Power Laboratory - Schenectady \\
\hline KESS & Knolls Atomic Power Laboratory - Kesselring \\
\hline KWIN & Knolls Atomic Power Laboratory - Windsor \\
\hline LABL & Lawrence Berkeley National Laboratory \\
\hline LANL & Los Alamos National Laboratory \\
\hline LL & Laidlaw \\
\hline LLMS & Lawrence Livermore National Laboratory - Main Site \\
\hline LRRI & Lovelace Respiratory Research Institute \\
\hline MEMP & Miamisburg Environmental Management Project \\
\hline MINS & Mare Island Naval Shipyard \\
\hline MURR & Missouri University Research Reactor \\
\hline NAVY & Naval Reactors Site - TBD \\
\hline NNS & Norfolk Naval Shipyard \\
\hline NRF & Naval Reactor Facility \\
\hline NVTS, NTS & Nevada Test Site \\
\hline ORR, ORTN & Oak Ridge Reservation \\
\hline PAPL & Pantex Plant \\
\hline PGDP & Paducah Gaseous Diffusion Plant \\
\hline PHNS & Pearl Harbor Naval Shipyard \\
\hline PNS & Portsmouth Naval Shipyard \\
\hline PORT & Portsmouth Gaseous Diffusion Plant \\
\hline PPPL & Princeton Plasma Physics Laboratory \\
\hline PSNS & Puget Sound Naval Shipyard \\
\hline RFTS & Rocky Flats Environmental Technology Site \\
\hline SARS, SRS & Savannah River Site \\
\hline SEG & GTS Duratek (formerly, Scientific Ecology Group) \\
\hline SK & SafetyKleen \\
\hline SNLN & Sandia National Laboratories - NM \\
\hline SPRU & Separations Process Research Unit \\
\hline TBD & To Be Determined \\
\hline TBDO & To Be Determined/Off-Site \\
\hline WIPP & Waste Isolation Pilot Plant \\
\hline WVDP & West Valley Demonstration Project \\
\hline
\end{tabular}




\section{GLOSSARY}

$11 \mathrm{e} 2$

Excepted Package

\section{Exempted/ \\ Special Form \\ (EXS)}

Hazardous
Material

High Level

Radioactive Waste

\section{Industrial \\ Packaging (IP)}

IP-1

IP-2
$11 \mathrm{e} 2$ by-product material is (1) any radioactive material (except special nuclear material) yielded in or made radioactive by exposure to the radiation incident to the process of producing or utilizing special nuclear material, and (2) the tailings or wastes produced by the extraction or concentration of uranium or thorium from any ore processed primarily for its source material content (42 USC 2014, 10 CFR 20.1003).

Excepted package means a packaging together with its excepted Class 7 (radioactive) materials as specified in 49 CFR Part 173.421-173.426 and 173.428 .

Special Form is a Class 7 (radioactive) material that meets the conditions listed in 49 CFR Part 173.403.

A substance or material, which has been determined by the Secretary of Transportation to be capable of posing an unreasonable risk to health, safety, and property when transported in commerce, and which has been so designated. The term includes hazardous substances, hazardous wastes, marine pollutants, and elevated temperature materials as defined in this section, materials designated as hazardous under the provisions of Sec. 172.101 of this subchapter, and materials that meet the defining criteria for hazard classes and divisions in Part 173 of this subchapter (49 CFR 171.8).

(A) The highly radioactive material resulting from the reprocessing of spent nuclear fuel, including liquid waste produced directly in reprocessing and any solid material derived from such liquid waste that contains fission products in sufficient concentrations; and (B) other highly radioactive material that the Commission consistent with existing law, determines by rule requires permanent isolation (42 USC 10101, 10 CFR 72.3, 10 CFR 960.2).

Industrial packaging meets the requirements of 49 CFR Part 173.410 and 173.411. Industrial packages are categorized in 49 CFR Part 173.411 as either IP-1, IP-2 or IP-3

An IP-1 packaging must meet the general design requirements prescribed in 49 CFR Part 173.410.

An IP-2 packaging must meet the general design requirements prescribed in 49 CFR Part 173.410 and when subjected to the tests specified in Part 173.465 (c) and (d) or evaluated against these tests by any of the methods authorized by Part 173.461 (a), must prevent:

(i) Loss or dispersal of the radioactive contents; and

(ii) A significant increase in the radiation levels recorded or calculated at the external surfaces for the condition before the test. 


\section{GLOSSARY}

IP-3

Limited Quantity

Low Level

Radioactive Waste

Low Specific

Activity (LSA)

LSA-I

LSA-II
Each IP-3 packaging must meet the requirements for an IP-1 and an IP2, and must meet the requirements specified in Part 173.412 (a) through Part 173.412 (j).

Limited quantity of Class 7 (radioactive) material means a quantity of Class 7 (radioactive) material not exceeding the materials package limits specified in Part 173.425 and conforming to requirements specified in Part 173.421.

Radioactive material that (A) is not high-level radioactive waste, spent nuclear fuel, Transuranic waste, or by-product material as defined in section 2014(e)(2) of this title; and (B) the NRC Commission, consistent with existing law, classifies as low level radioactive waste (42 USC 10101, 10 CFR 62.2).

Low Specific Activity (LSA) material means Class 7 (radioactive) material with limited specific activity that satisfies the descriptions and limits set forth below. Shielding materials surrounding the LSA material may not be considered in determining the estimated average specific activity of the package contents. LSA material must be in one of three groups, LSA-I, LSA-II or LSA-III.

LSA-I materials are:

(i) Ores containing only naturally occurring radionuclides (e.g., uranium, thorium) and uranium or thorium concentrates of such ores; or

(ii) Solid unirradiated natural uranium or depleted uranium or natural thorium or their solid or liquid com-pounds or mixtures; or

(iii) Class 7 (radioactive) material, other than fissile material, for which the $\mathrm{A}_{2}$ value is unlimited; or

(iv) Mill tailings, contaminated earth, concrete, rubble, other debris, and activated material in which the Class 7 (radioactive) material is essentially uniformly distributed and the average specific activity does not exceed $10^{-6} \mathrm{~A}_{2} / \mathrm{g}$.

LSA-II materials are:

(i) Water with tritium concentration up to $0.8 \mathrm{TBq} /$ liter $(20.0 \mathrm{Ci} / \mathrm{liter})$; or (ii) Material in which the Class 7 (radioactive) material is distributed throughout and the average specific a-activity does not exceed $10^{-4} \mathrm{~A}_{2} / \mathrm{g}$ for solids and gases, and $10^{-5} \mathrm{~A}_{2} / \mathrm{g}$ for liquids. 


\section{GLOSSARY}

LSA-III

Mixed Waste

Non-EM Waste

Non Radioactive, Hazardous (NRH)

Non Radioactive, Non Hazardous (NRD)

\section{Performance \\ Oriented \\ Packaging (POP)}

LSA-III materials are solids (e.g., consolidated wastes, activated materials) that meet the requirements of Part 173.468 and which:

(i) The Class 7 (radioactive) material is distributed throughout a solid or a collection of solid objects, or is essentially uniformly distributed in a solid compact binding agent (such as concrete, bitumen, ceramic, etc.); and

(ii) The Class 7 (radioactive) material is relatively insoluble, or it is intrinsically contained in a relatively insoluble material, so that, even under loss of packaging, the loss of Class 7 (radioactive) material per package by leaching when placed in water for seven days would not exceed $0.1 \mathrm{~A}_{2}$; and

(iii) The average specific activity of the solid does not exceed $2 \times 10^{-3}$ $\mathrm{A}_{2} / \mathrm{g}$ (49 CFR 173.403, 10 CFR 71.4).

Waste that contains both hazardous waste and source special nuclear, or by-product material subject to the Atomic Energy Act of 1954 (42 U.S.C. 2011 et seq., 42 USC 6903).

Waste/materials which are either newly generated or waste/materials which do not belong to EM, but are being managed at an EM site and may be dispositioned with EM waste/materials.

Material that is a hazardous waste per 40 CFR Part 261.3 (RCRA), which is not managed as a radioactive material.

Material that is not regulated or managed as either radioactive or RCRA Hazardous.

Performance Oriented Packagings must meet certain requirements for non-bulk packagings for hazardous materials. Standards for these packagings are based on the UN Recommendations. POP specifications are found in 49 CFR Subpart L. 


\section{GLOSSARY}

SCO-I

SCO-II

Special Hazardous Material Packaging (non-rad) (HAZSPEC)

Spent Nuclear Fuel
SCO-I is a solid object on which:

(i) The non-fixed contamination on the accessible surface averaged over $300 \mathrm{~cm}^{2}$ (or the area of the surface if less than $300 \mathrm{~cm}^{2}$ ) does not exceed $4 \mathrm{~Bq} / \mathrm{cm}^{2}\left(10^{-4}\right.$ microcurie $\left./ \mathrm{cm}^{2}\right)$ for beta and gamma and low toxicity alpha emitters, or $0.4 \mathrm{~Bq} / \mathrm{cm}^{2}\left(10^{-5}\right.$ microcurie $\left./ \mathrm{cm}^{2}\right)$ for alpha emitters;

(ii) The fixed contamination on the accessible surface averaged over 300 $\mathrm{cm}^{2}$ (or the area of the surface if less than $300 \mathrm{~cm}^{2}$ ) does not exceed $4 \mathrm{x}$ $10^{-4} \mathrm{~Bq} / \mathrm{cm}^{2}\left(1.0\right.$ microcurie $\left./ \mathrm{cm}^{2}\right)$ for beta and gamma and low toxicity alpha emitters, or $4 \times 10^{-3} \mathrm{~Bq} / \mathrm{cm}^{2}\left(0.1\right.$ microcurie $\left./ \mathrm{cm}^{2}\right)$ for all other alpha emitters; and

(iii) The non-fixed contamination plus the fixed contamination on the inaccessible surface averaged over $300 \mathrm{~cm}^{2}$ (or the area of the surface if less than $300 \mathrm{~cm}^{2}$ ) does not exceed $4 \times 10^{-4} \mathrm{~Bq} / \mathrm{cm}^{2}\left(1\right.$ microcurie $\left./ \mathrm{cm}^{2}\right)$ for beta and gamma and low toxicity alpha emitters, or $4 \times 10^{-3} \mathrm{~Bq} / \mathrm{cm}^{2}$ $\left(0.1 \mathrm{microcurie} / \mathrm{cm}^{2}\right)$ for all other alpha emitters.

SCO-II is a solid object on which the limits for SCO-I are exceeded and on which:

(i) The non-fixed contamination on the accessible surface averaged over $300 \mathrm{~cm}^{2}$ (or the area of the surface if less than $300 \mathrm{~cm}^{2}$ ) does not exceed $400 \mathrm{~Bq} / \mathrm{cm}^{2}\left(10^{-2}\right.$ microcurie $\left./ \mathrm{cm}^{2}\right)$ for beta and gamma and low toxicity alpha emitters or $40 \mathrm{~Bq} / \mathrm{cm}^{2}\left(10^{-3}\right.$ microcurie $\left./ \mathrm{cm}^{2}\right)$ for all other alpha emitters;

(ii) The fixed contamination on the accessible surface averaged over 300 $\mathrm{cm}^{2}$ (or the area of the surface if less than $300 \mathrm{~cm}^{2}$ ) does not exceed $8 \mathrm{x}$ $10^{-5} \mathrm{~Bq} / \mathrm{cm}^{2}\left(20\right.$ microcurie $\left./ \mathrm{cm}^{2}\right)$ for beta and gamma and low toxicity alpha emitters, or $8 \times 10^{-4} \mathrm{~Bq} / \mathrm{cm}^{2}\left(2\right.$ micro-curies $\left./ \mathrm{cm}^{2}\right)$ for all other alpha emitters; and

(iii) The non-fixed contamination plus the fixed contamination on the inaccessible surface averaged over $300 \mathrm{~cm}^{2}$ (or the area of the surface if less than $300 \mathrm{~cm}^{2}$ ) does not exceed $8 \times 10^{-5} \mathrm{~Bq} / \mathrm{cm}^{2}\left(20\right.$ microcuries $\left./ \mathrm{cm}^{2}\right)$ for beta and gamma and low toxicity alpha emitters, or $8 \times 10^{-4} \mathrm{~Bq} / \mathrm{cm}^{2}$ (2 microcuries $/ \mathrm{cm}^{2}$ ) for all other alpha emitters (49 CFR 173.403, 10 CFR 71.4).

The term "hazardous material" is common terminology in several functional categories throughout transportation. However, the phrase "special hazardous material" identified in the AC/PC database is not. Therefore, an assumption has been made that "special hazardous material" packaging will be defined simply as, packaging authorized or allowed by the DOE for the transport of hazardous material.

Fuel that has been withdrawn from a nuclear reactor following irradiation, the constituent elements of which have not been separated by reprocessing (42 USC 10101, 10 CFR 960.2).

Strong Tight Packaging must meet minimum packaging requirements as specified in 49 CFR Part 173.24 and 173.24a (non-bulk), or $173.24 \mathrm{~b}$ (bulk). 


\section{GLOSSARY}

Surface

Contaminated

Object (SCO)

Transuranic Waste

Type A Packaging

Type A Quantity

Type B Packaging

Type B Quantity
Surface Contaminated Object (SCO) is a solid object which is not itself radioactive but which has Class 7 (radioactive) material distributed on any of its surfaces. SCO must be in one of two groups, SCO-I or SCO-II.

Material contaminated with elements that have an atomic number greater than 92, including neptunium, plutonium, americium, and curium, and that are in concentrations greater than $10 \mathrm{nCi} / \mathrm{g}$, or in such other concentrations as the Nuclear Regulatory Commission may prescribe to protect the public health and safety (42 USC 2014).

Type A packaging meets the requirements of 49 CFR Part 173.410 and 173.412 and is designed to retain the integrity of containment and shielding under normal conditions of transport as demonstrated by the tests set forth in Part 173.465 or Part 173.466, as appropriate. A Type A package does not require Competent Authority Approval.

A "Type A quantity" is a quantity of Class 7 (radioactive) material, the aggregate radioactivity which does not exceed $A_{1}$ for special form Class 7 (radioactive) material or $\mathrm{A}_{2}$ for normal form Class 7 (radioactive) material. $A_{1}$ and $A_{2}$ values are given in 49 CFR Part 173.435 or are determined in accordance with Part 173.433 (49 CFR 173.403, 10 CFR 71.4).

Type B packaging is designed to retain the integrity of containment and shielding when subjected to the normal conditions of transport and hypothetical accident test conditions set forth in 10 CFR Part 71.

A “Type B quantity" is a quantity of material greater than a Type A quantity (49 CFR 173.403, 10 CFR 71.4). 

Appendix A

Complex-Wide Data 



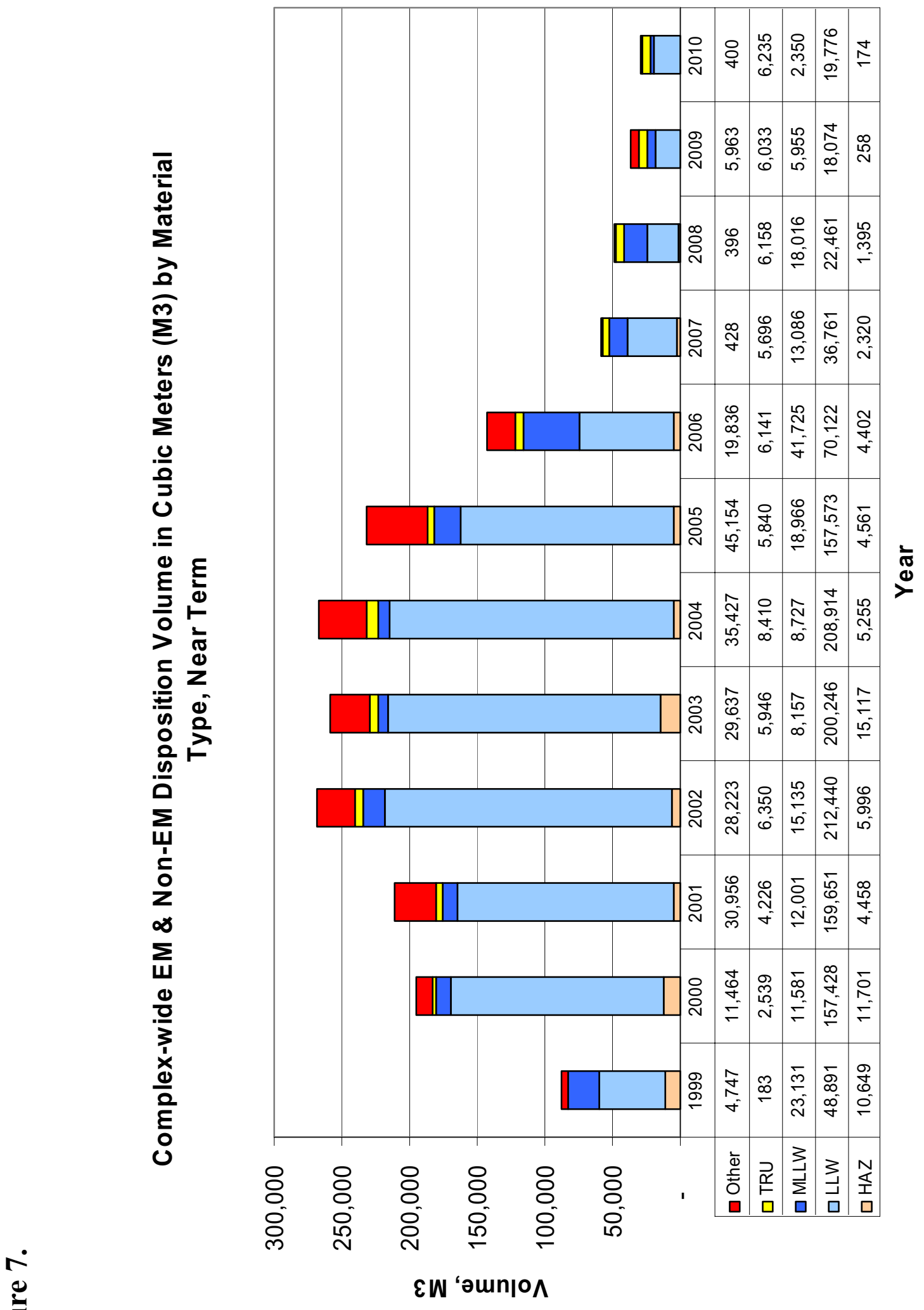




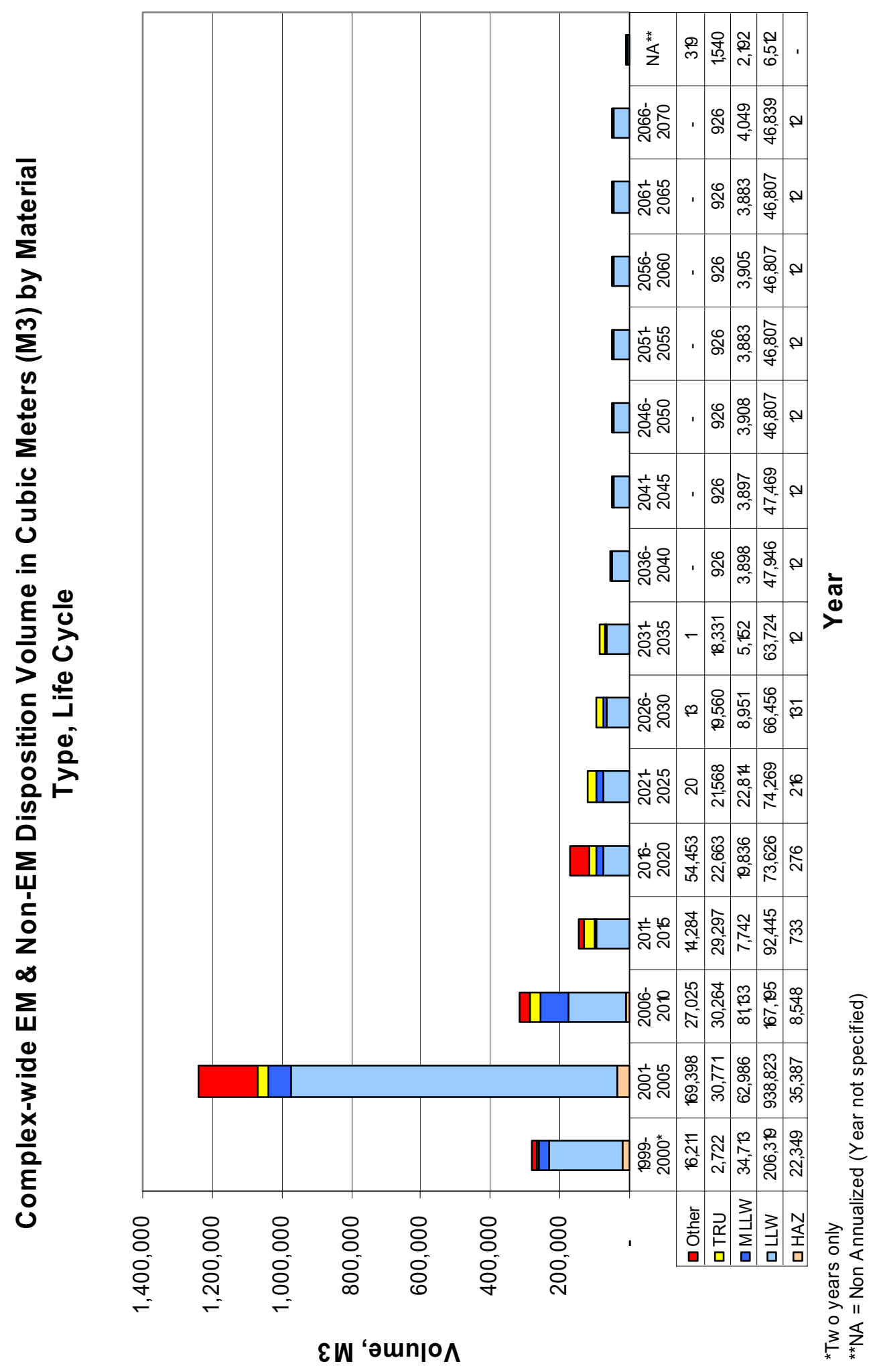




\section{Figure 9.}

Complex-wide EM \& Non-EM Disposition Waste in Metric Tons (MT) by Material Type, Near Term

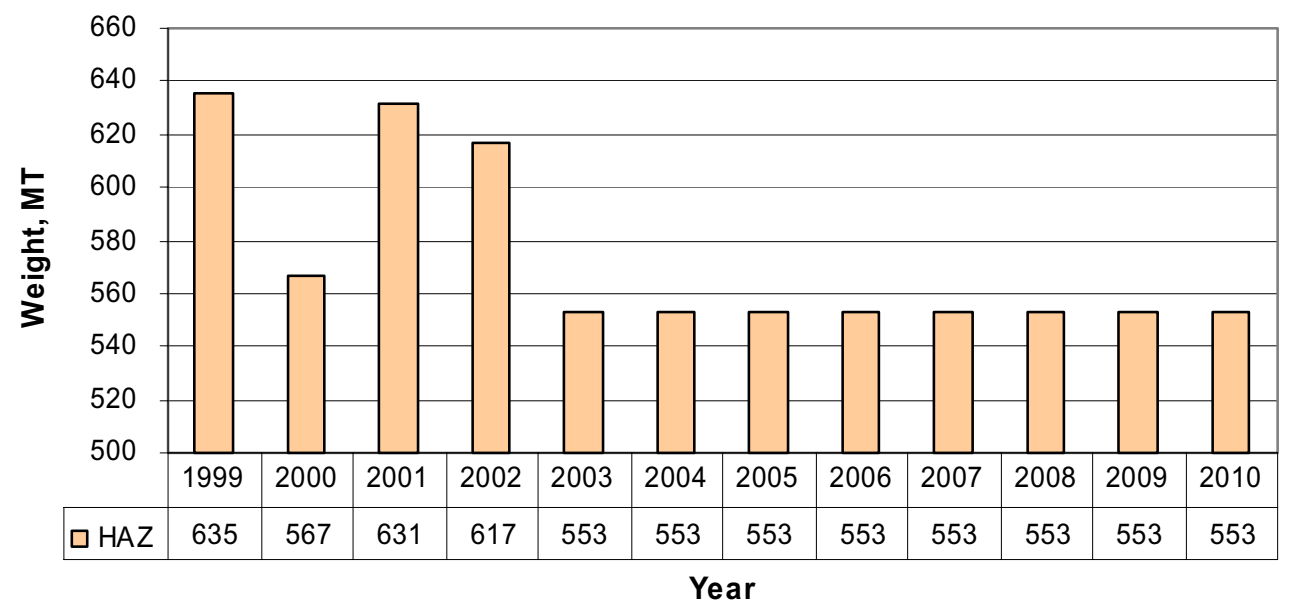

\section{Figure 10.}

\section{Complex-wide EM \& Non-EM Disposition Waste in Metric Tons (MT) by Material Type, Life Cycle}

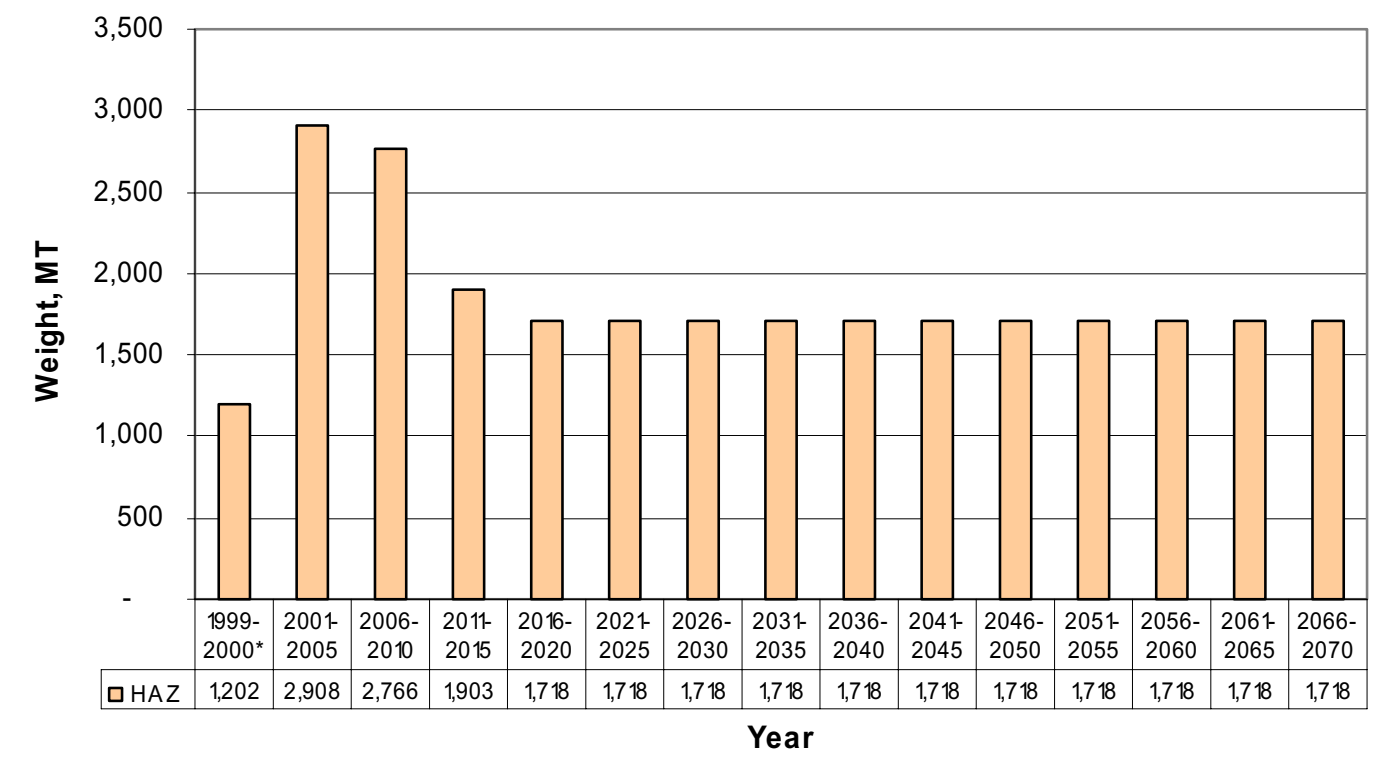

*Two years only 


\section{Figure 11.}

Complex-wide EM \& Non-EM Disposition Waste in Metric Tons of Heavy Metal (MTHM) by Material Type, Near Term

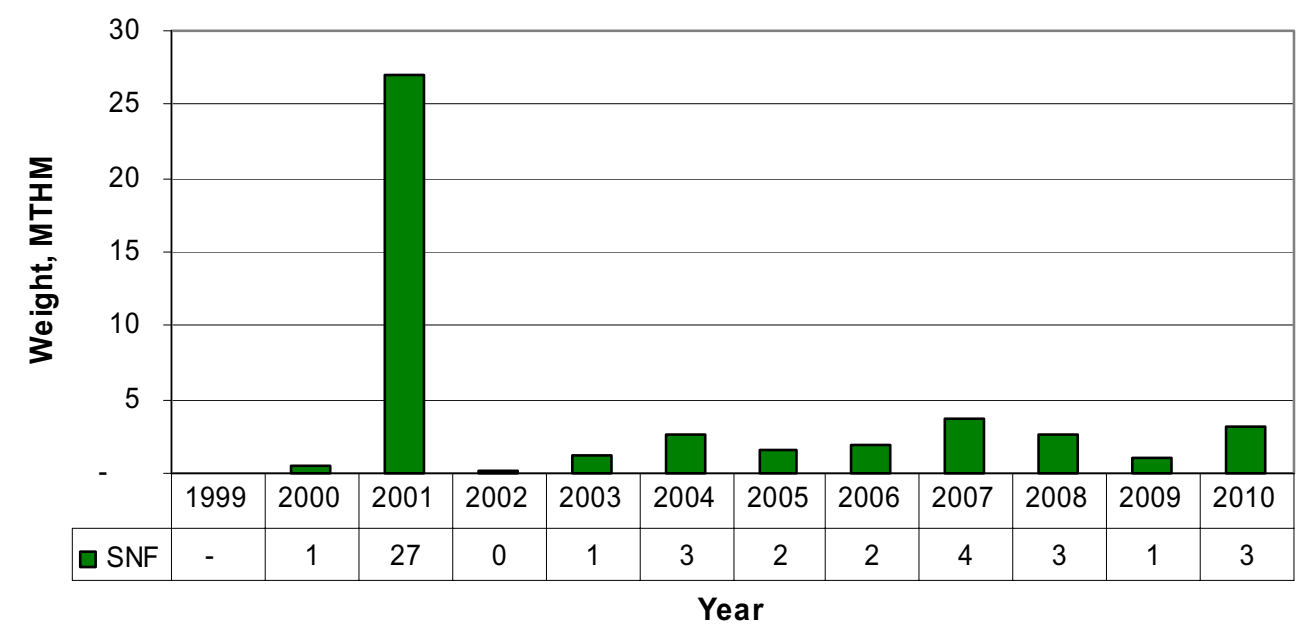

\section{Figure 12.}

Complex-wide EM \& Non-EM Disposition Waste in Metric Tons of Heavy Metal (MTHM) by Material Type, Life Cycle

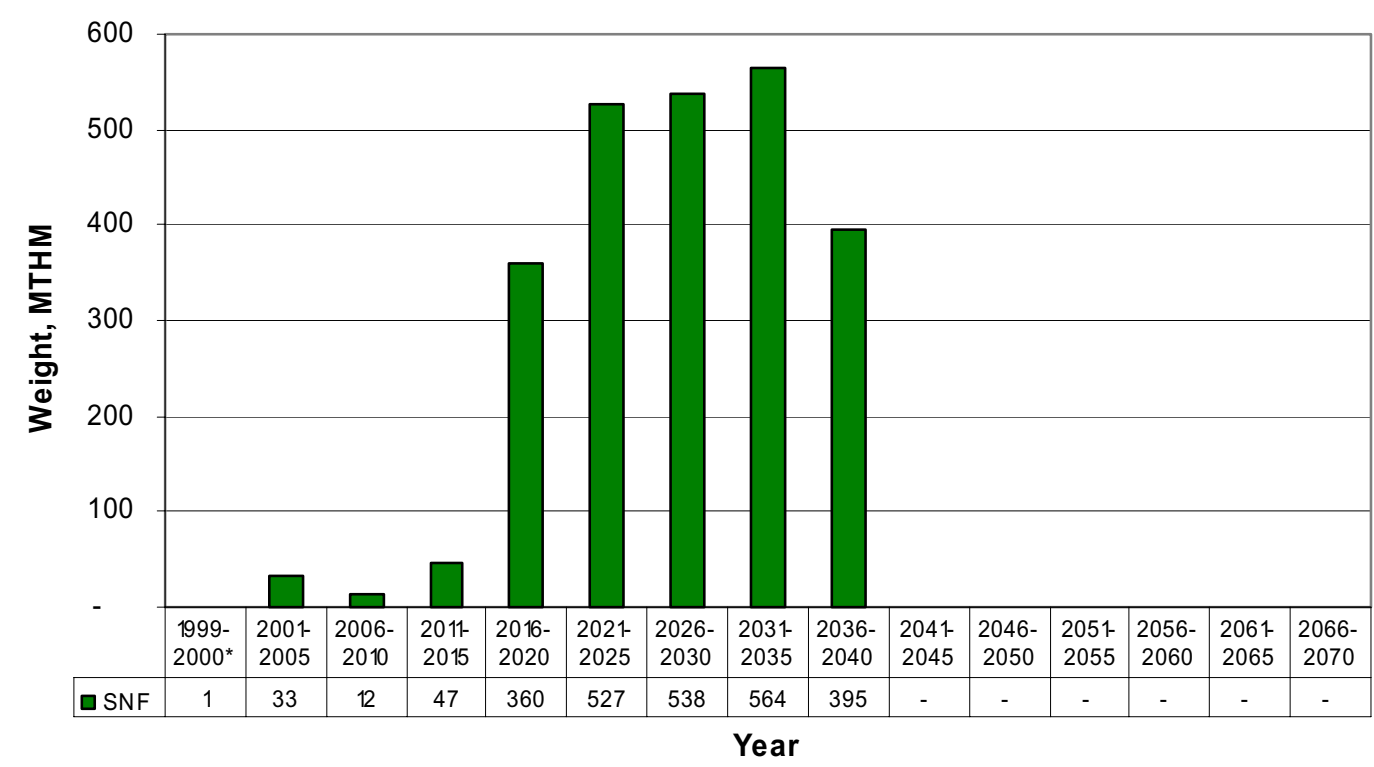

*Two years only 


\section{Figure 13.}

Complex-wide EM \& Non-EM Disposition Waste in Number of Canisters (NC) by Material Type, Near Term

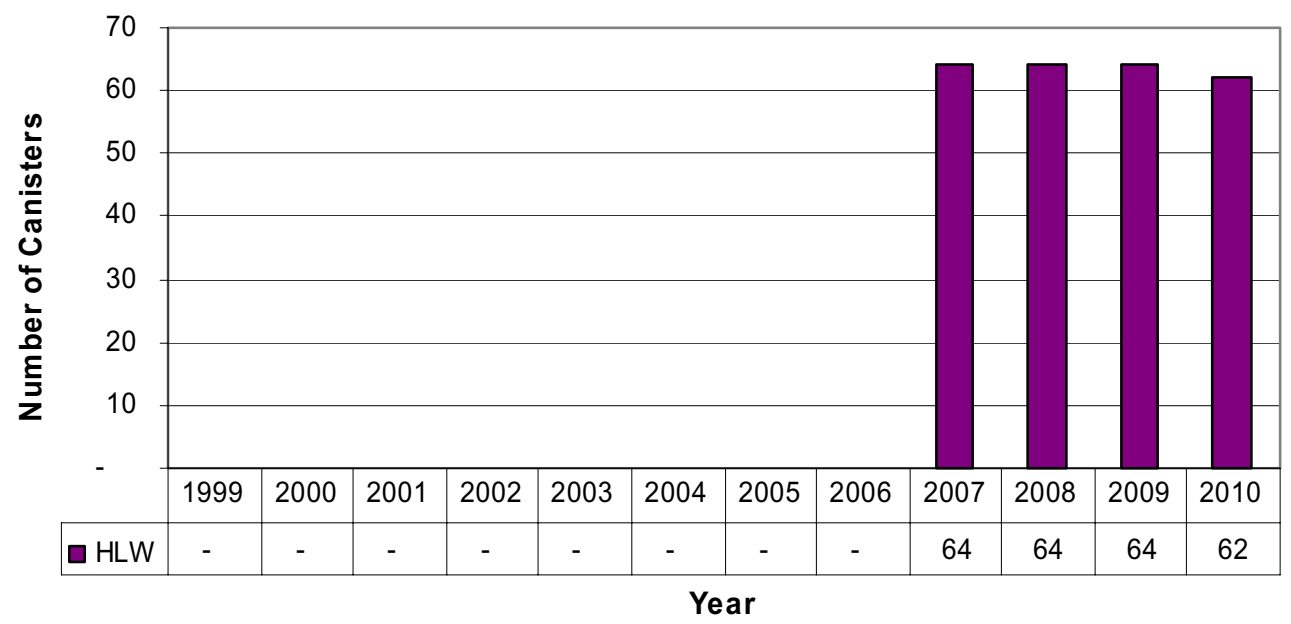

\section{Figure 14.}

Complex-wide EM \& Non-EM Disposition Waste in Number of Canisters (NC) by Material Type, Life Cycle

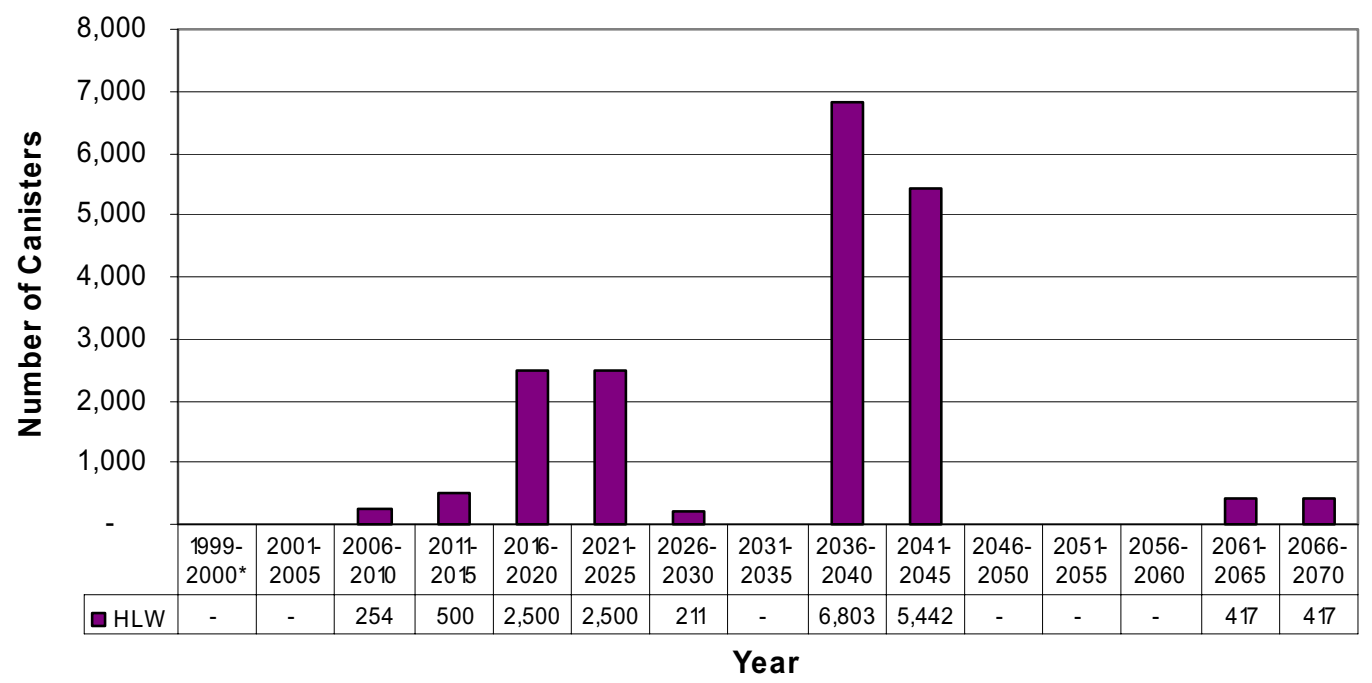

${ }^{*}$ Two years only 


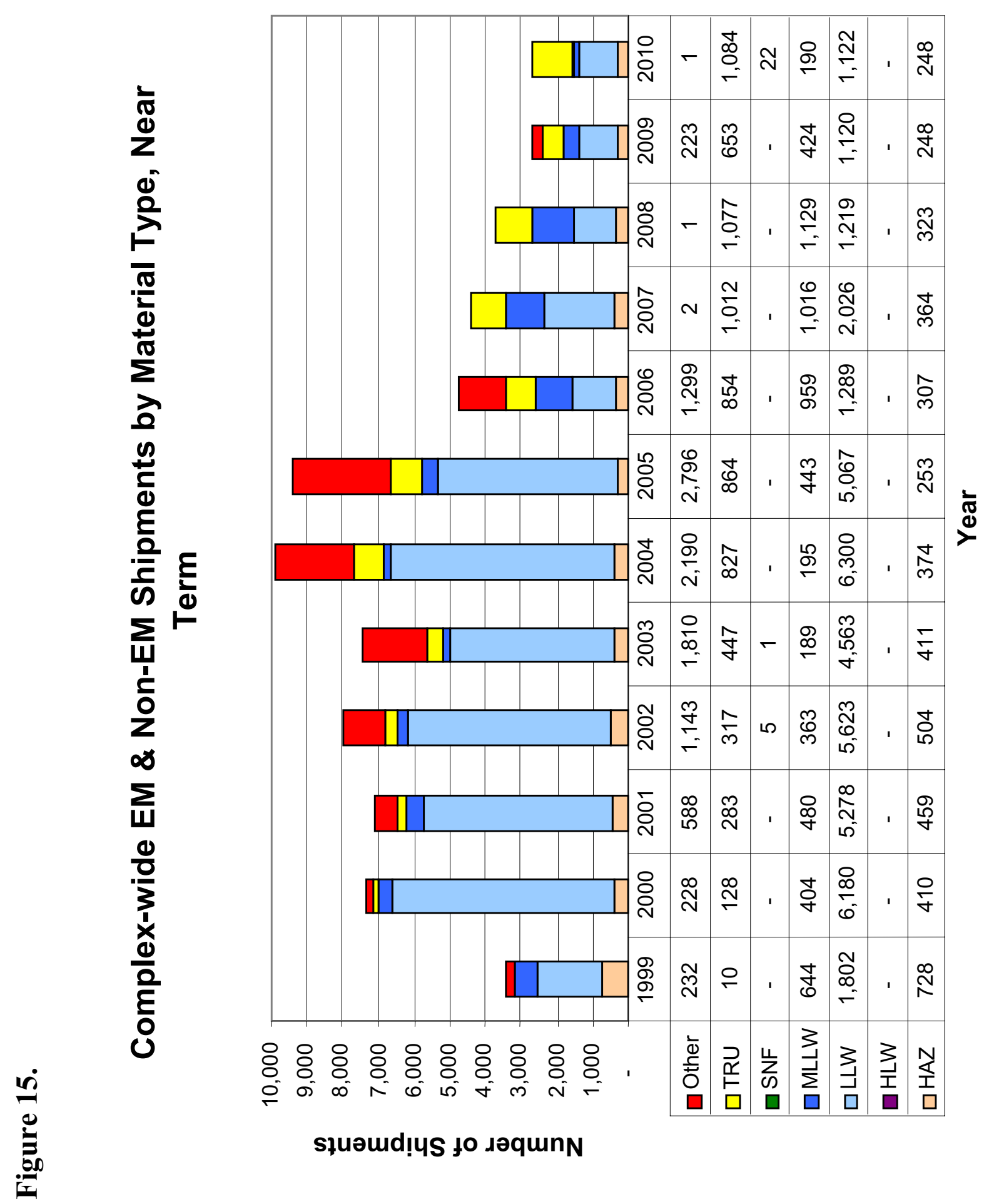




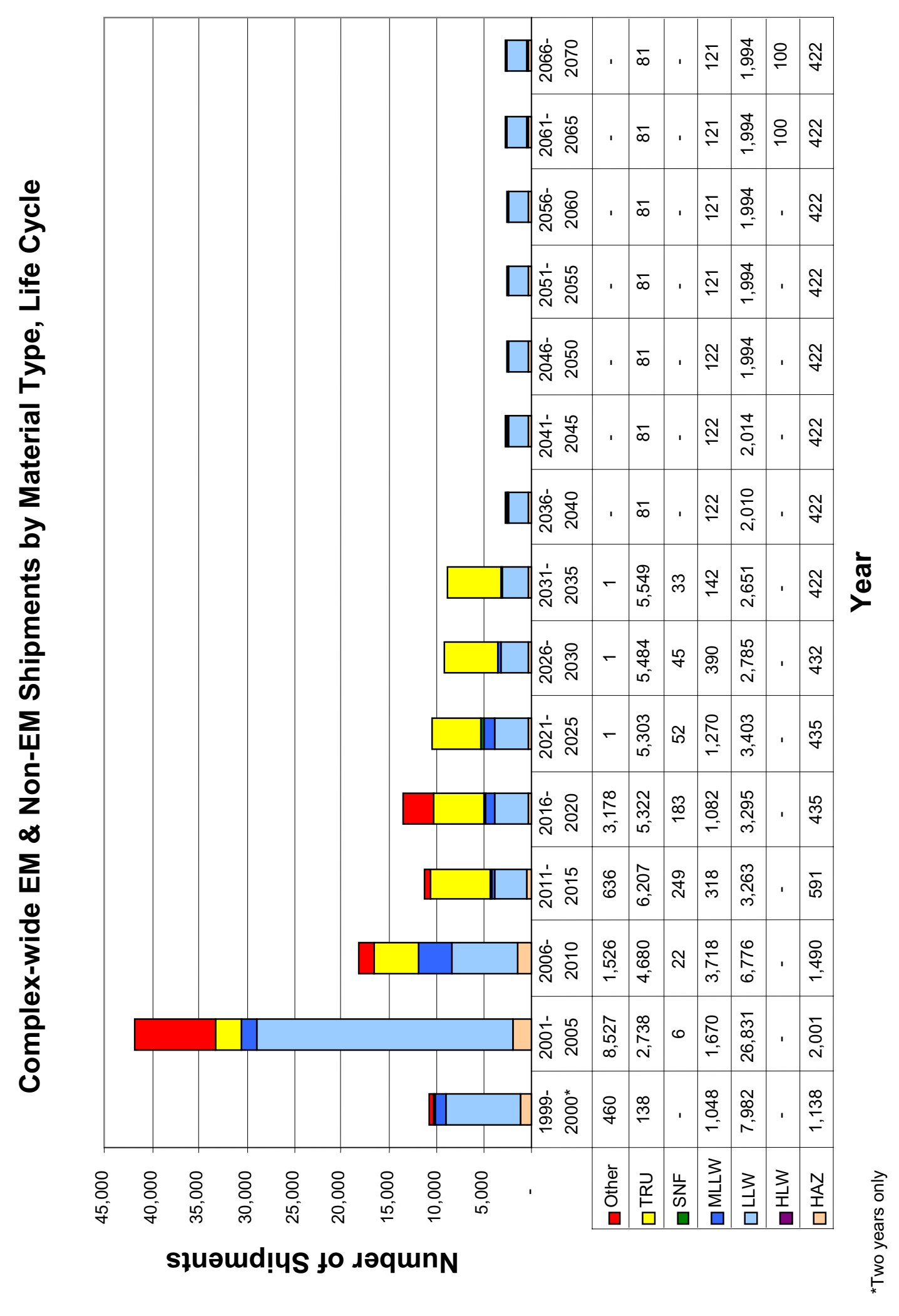




\section{Figure 17.}

\section{Complex-wide Shipments by Transportation Mode, Near Term}

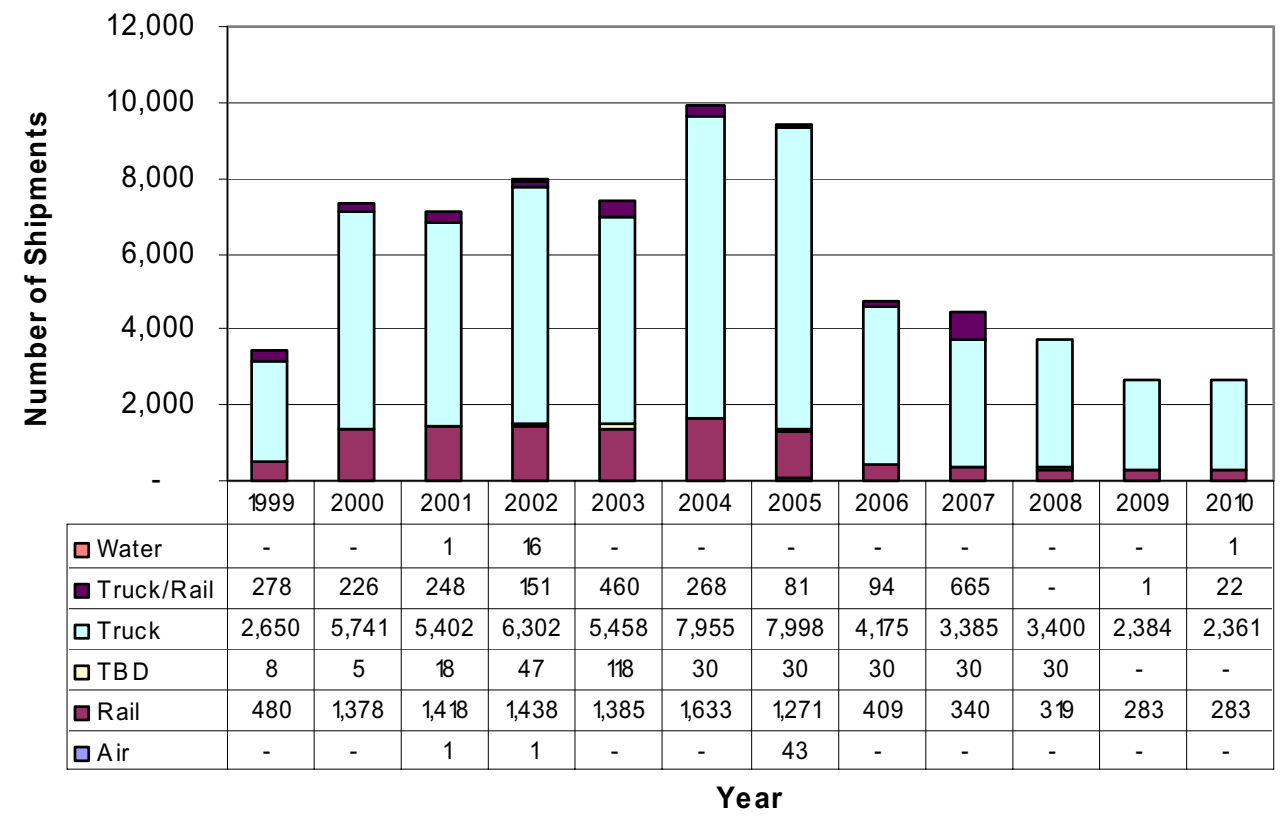

Figure 18.

Complex-wide Shipments by Transportation Mode, Life Cycle

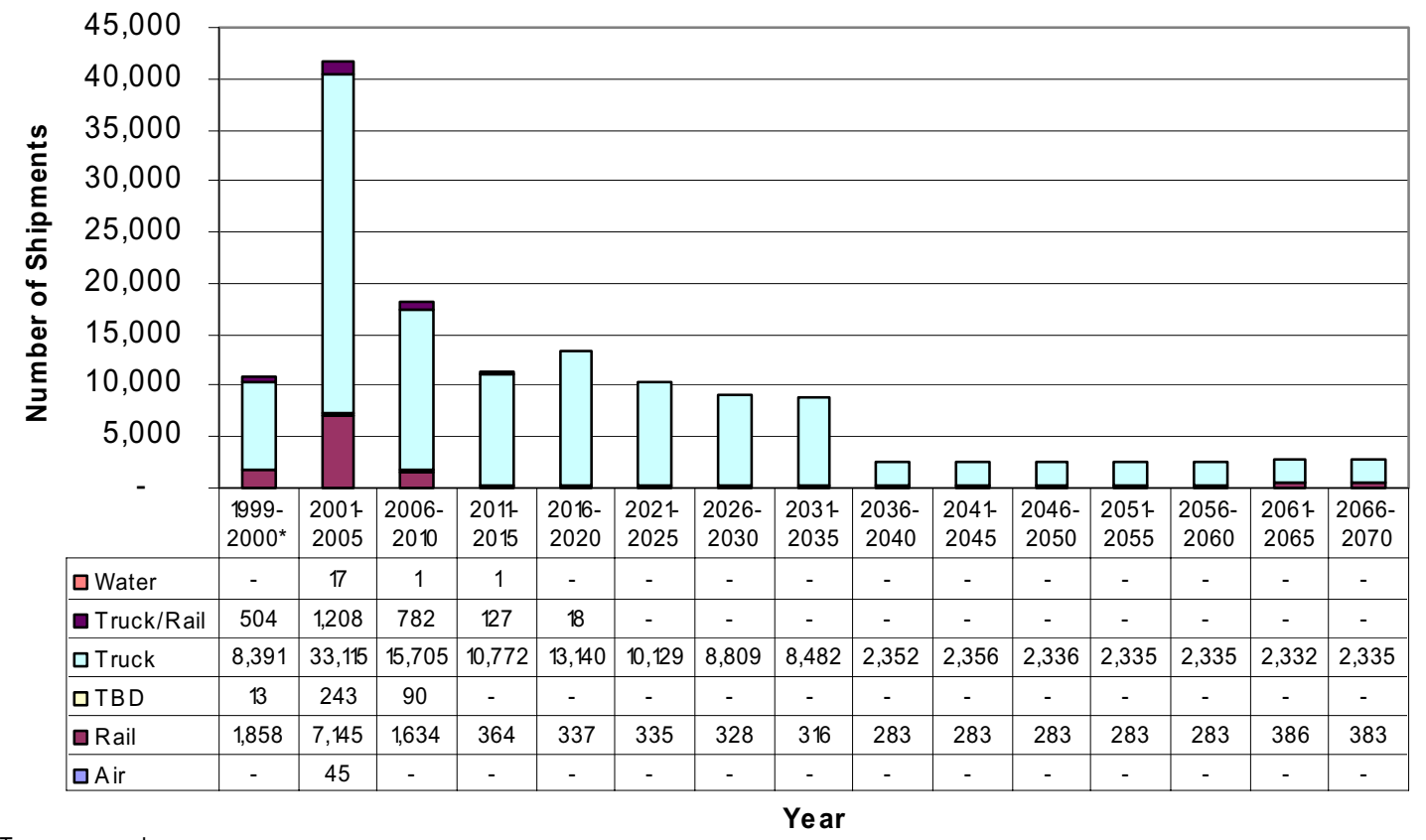

*Two years only 


\section{Figure 19.}

Complex-wide Number of Packagings by Packaging Type, Near Term

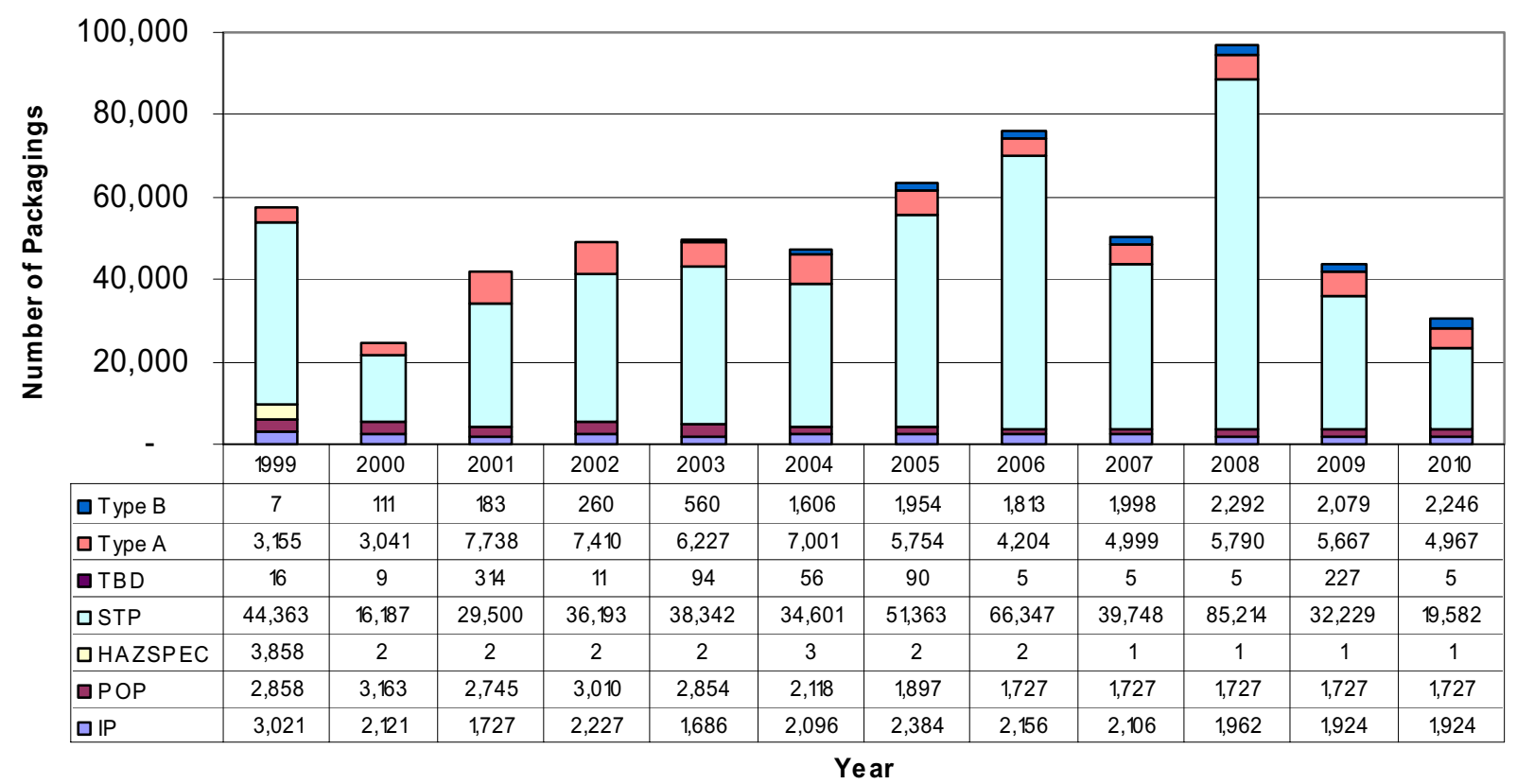

Figure 20.

Complex-wide Number of Packagings by Packaging Type, Life Cycle

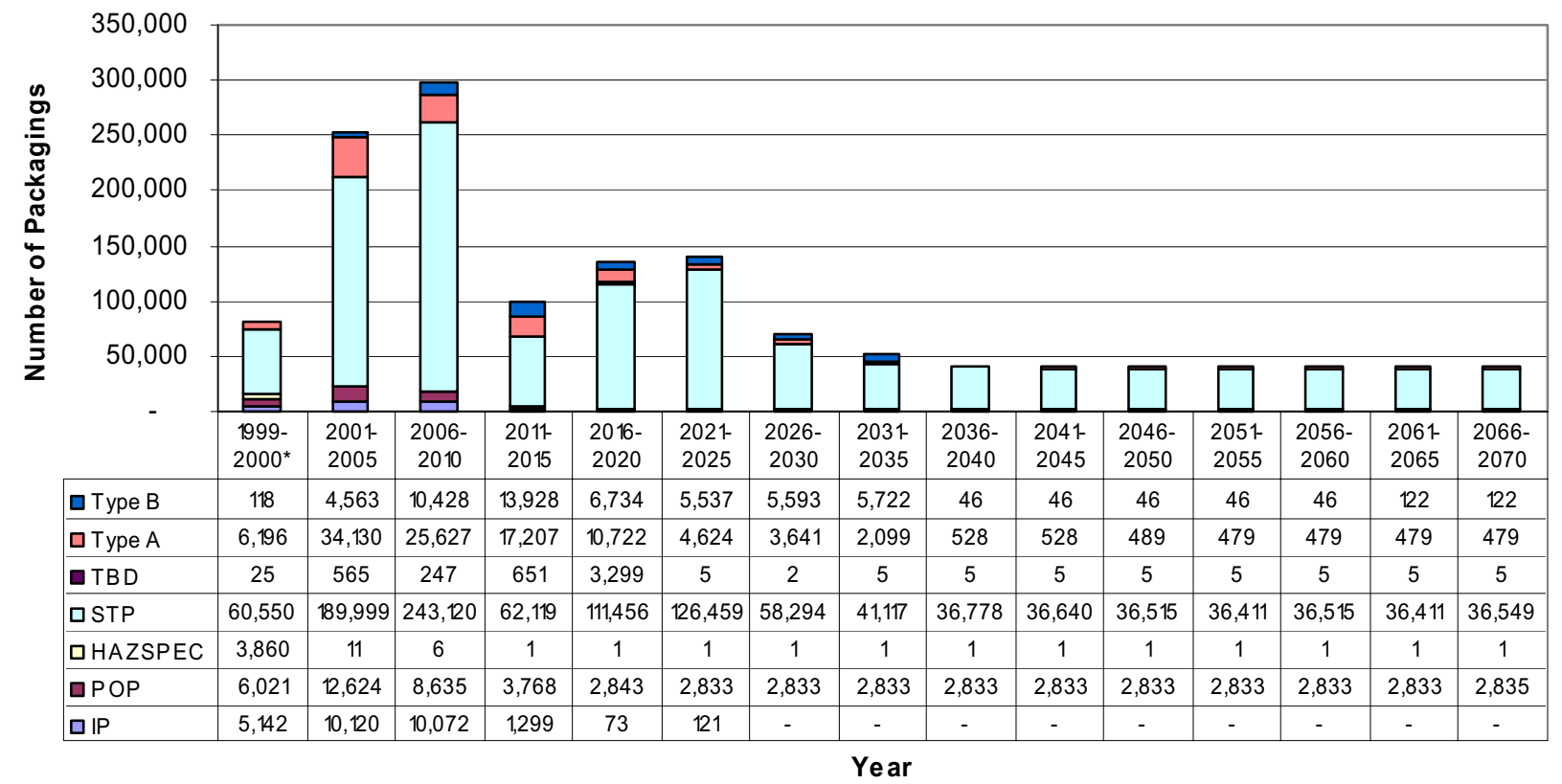

*Tw o Years Only 


\section{Figure 21.}

\section{Complex-wide Shipments by DOT Material Class, Near Term}

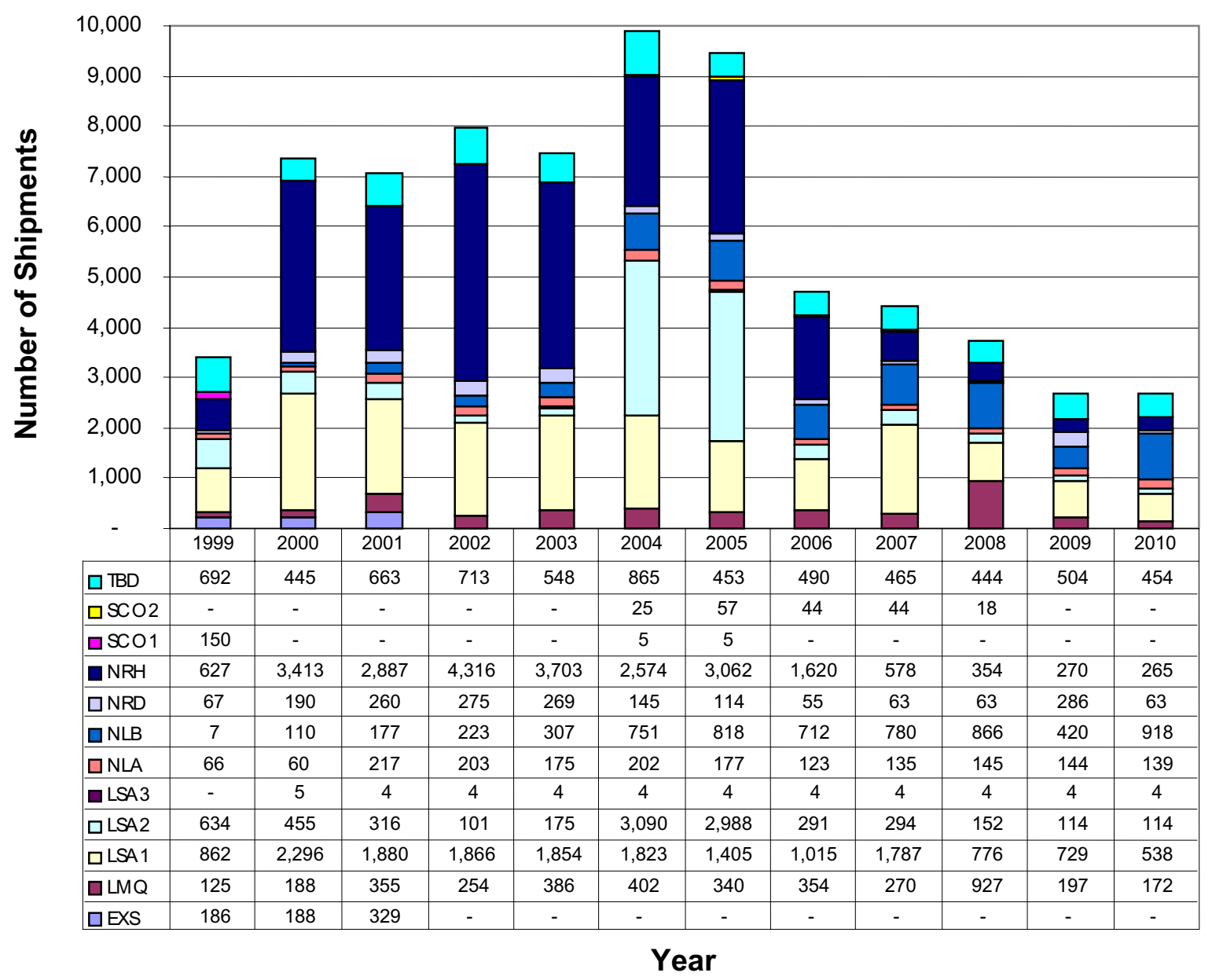




\section{Figure 22.}

\section{Complex-wide Shipments by DOT Material Class, Life Cycle}

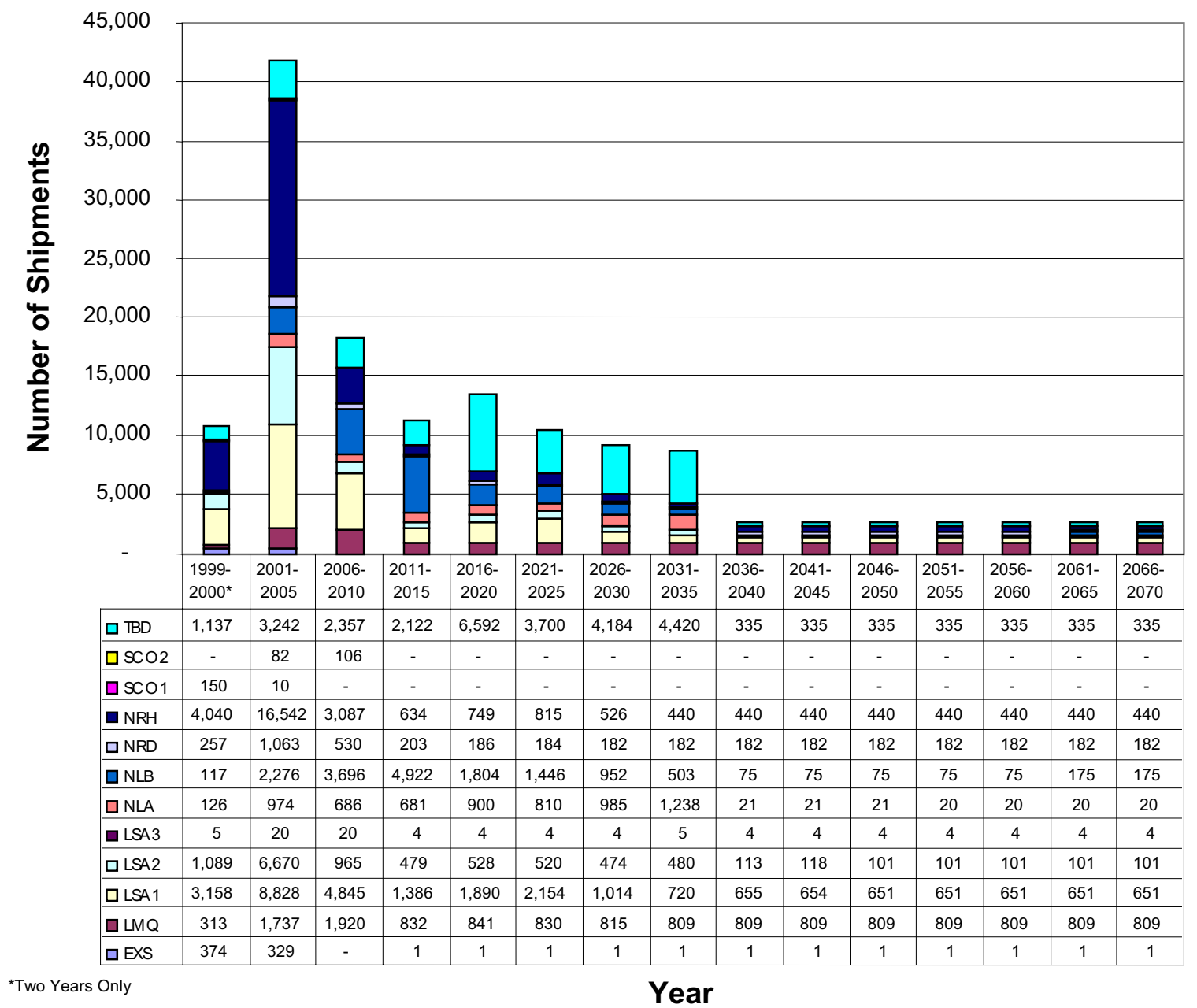





\section{Appendix B}

Site-Specific Shipment Data 


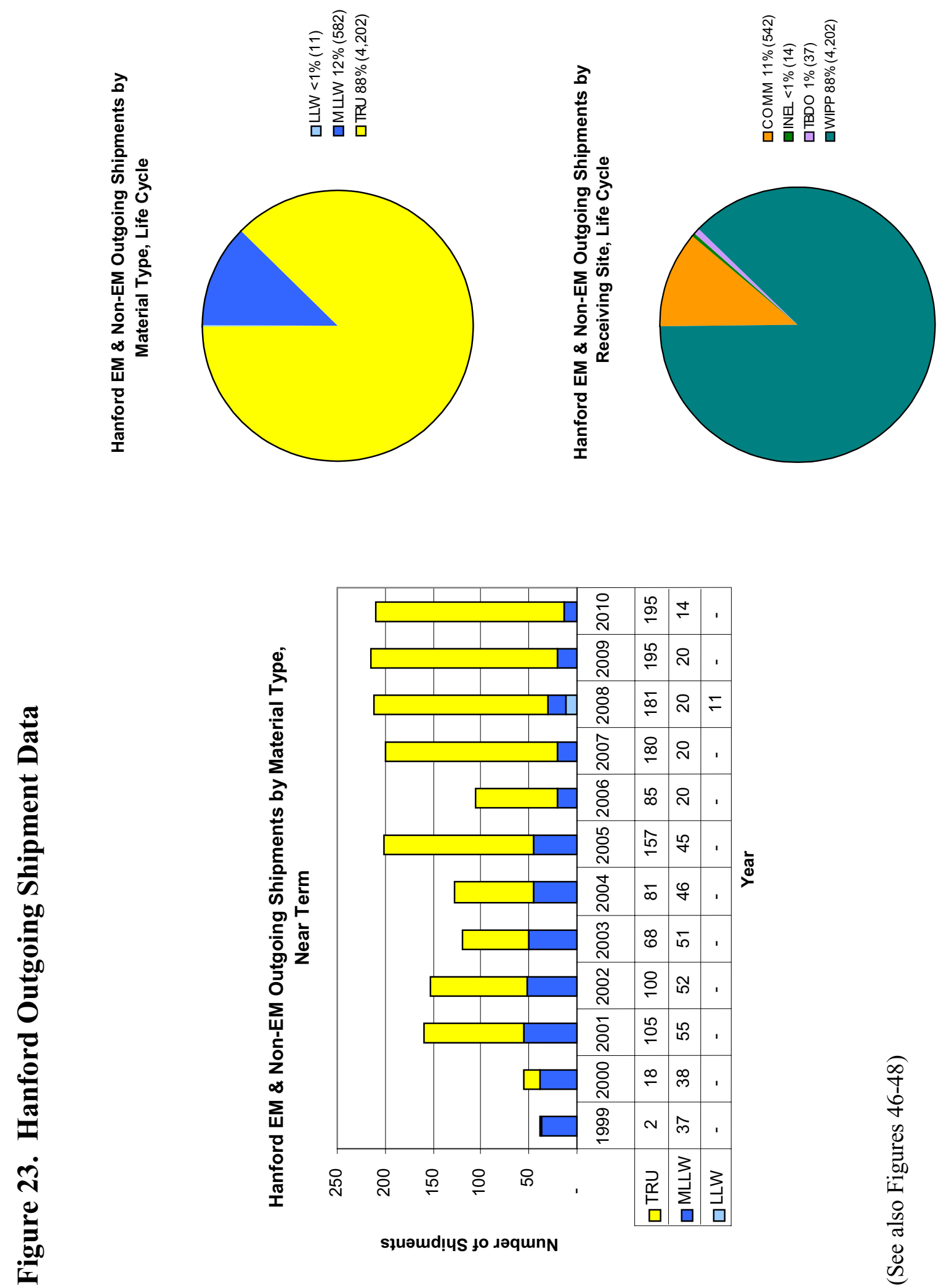

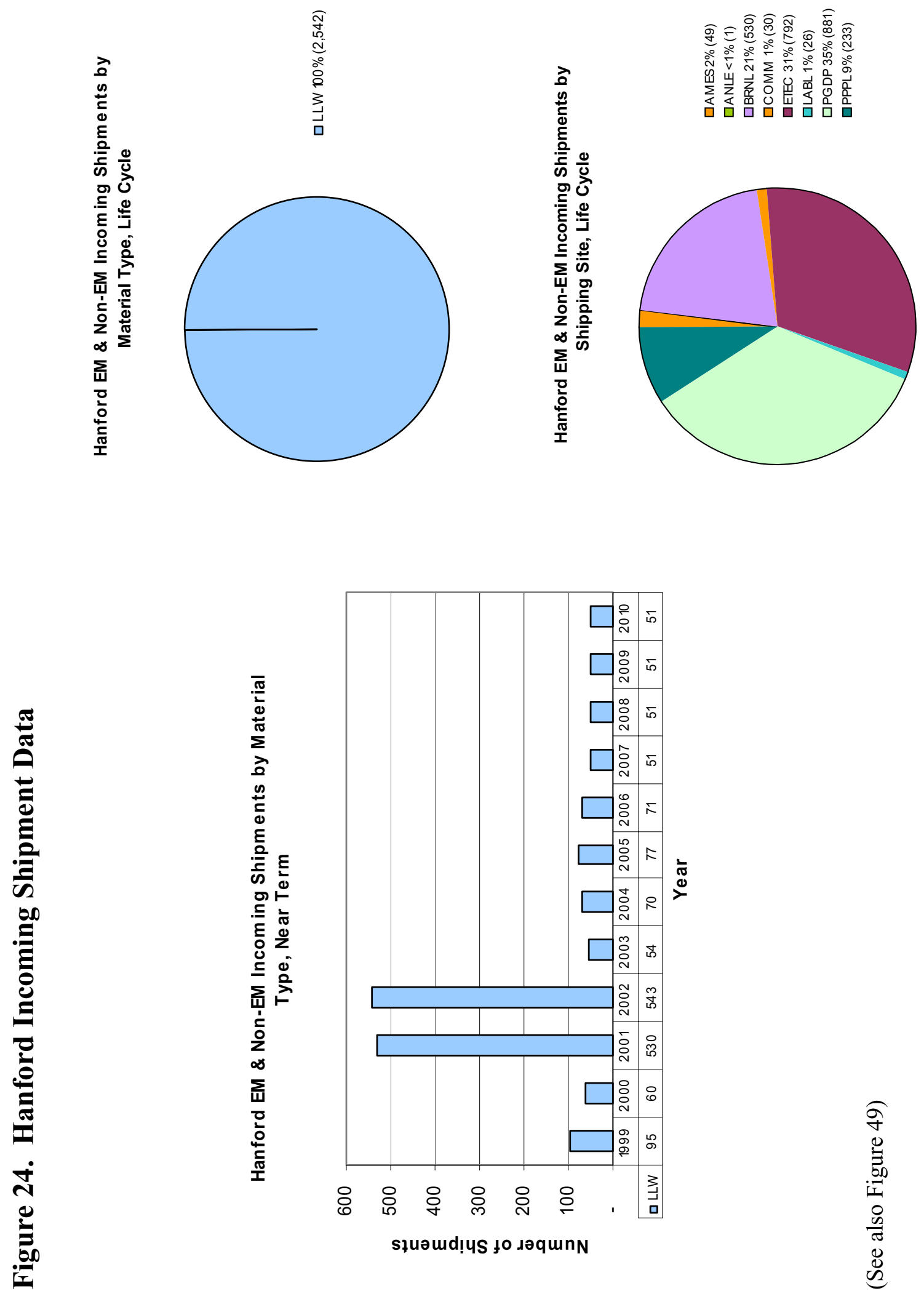

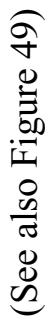



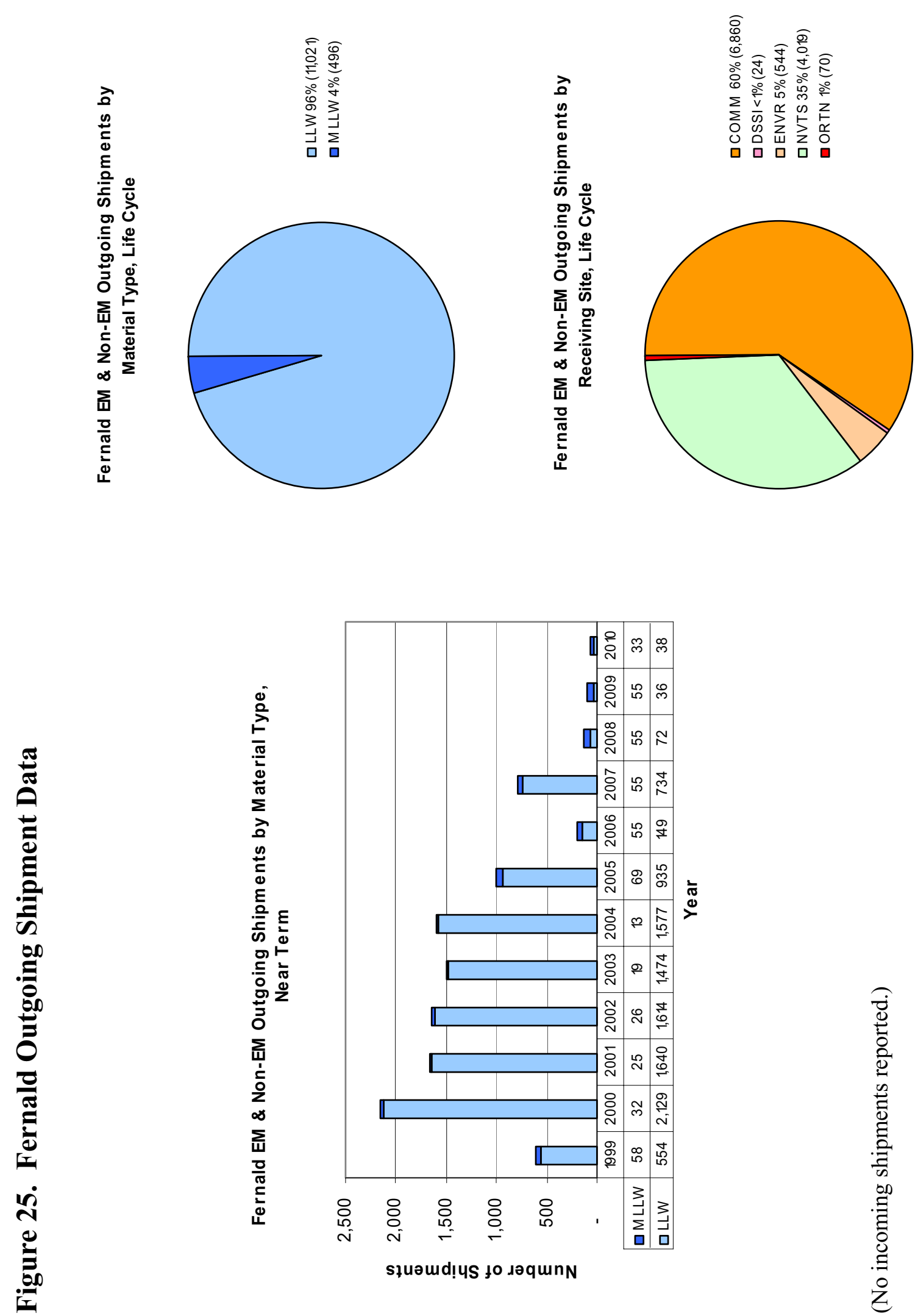

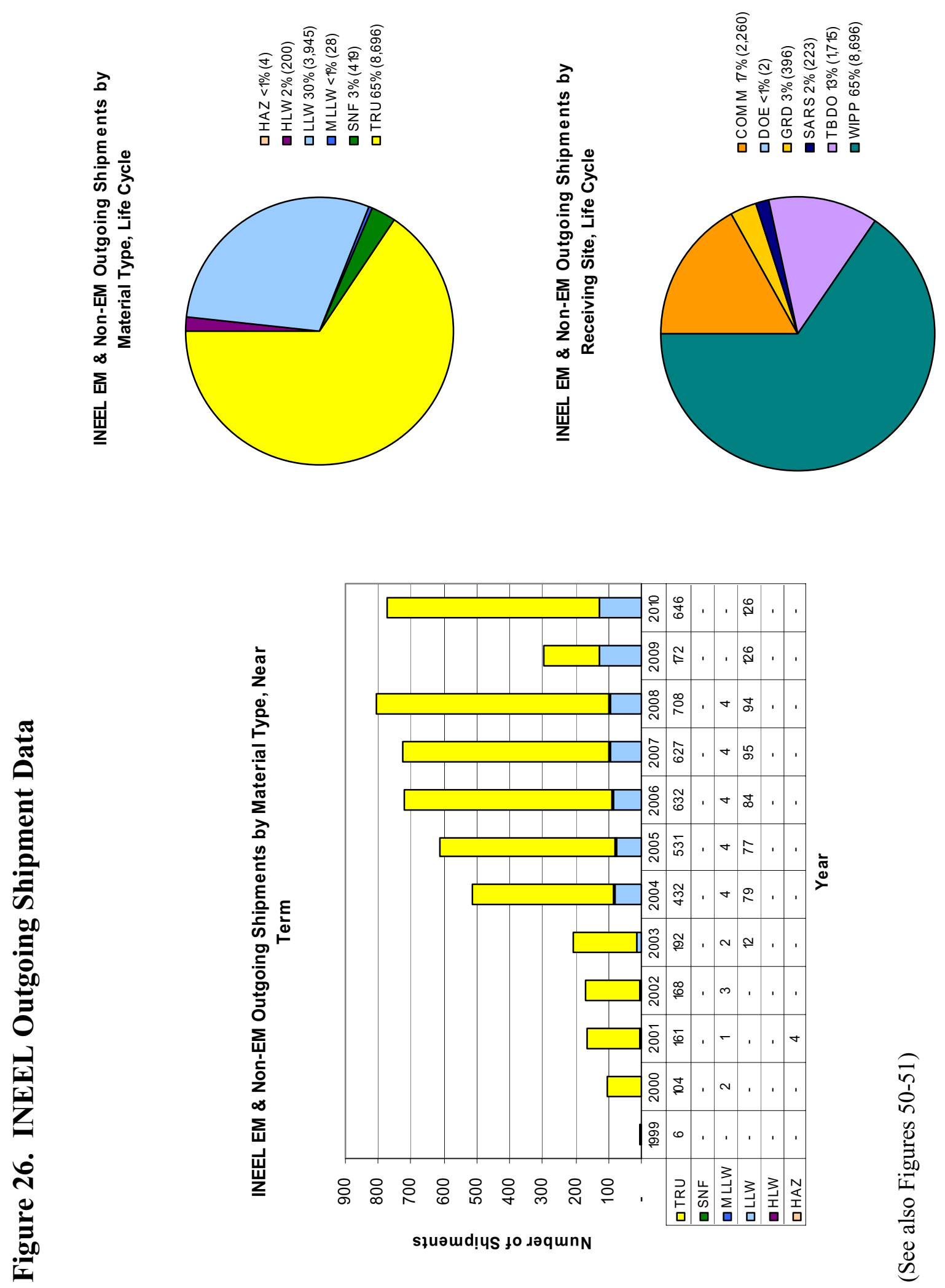

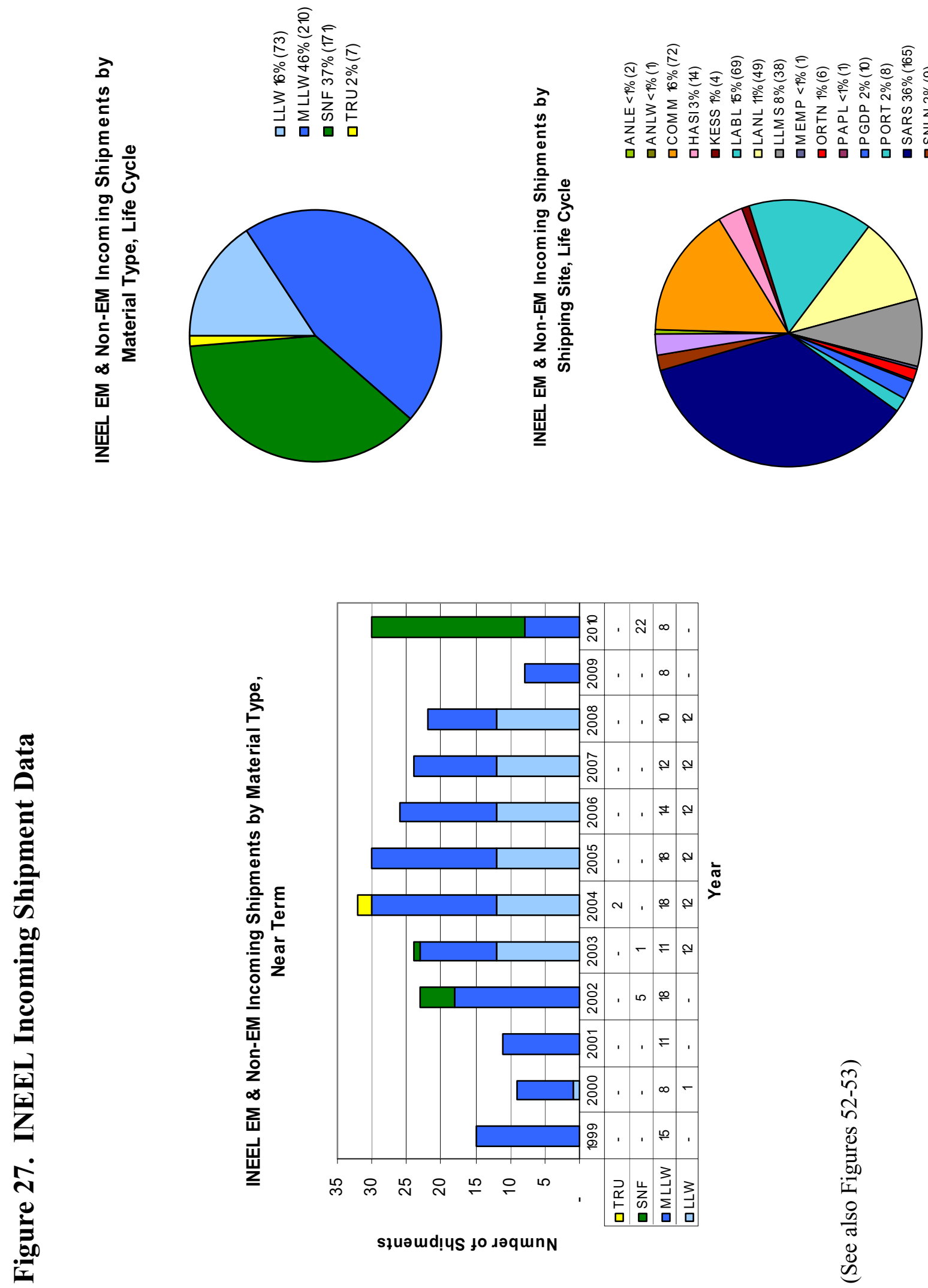

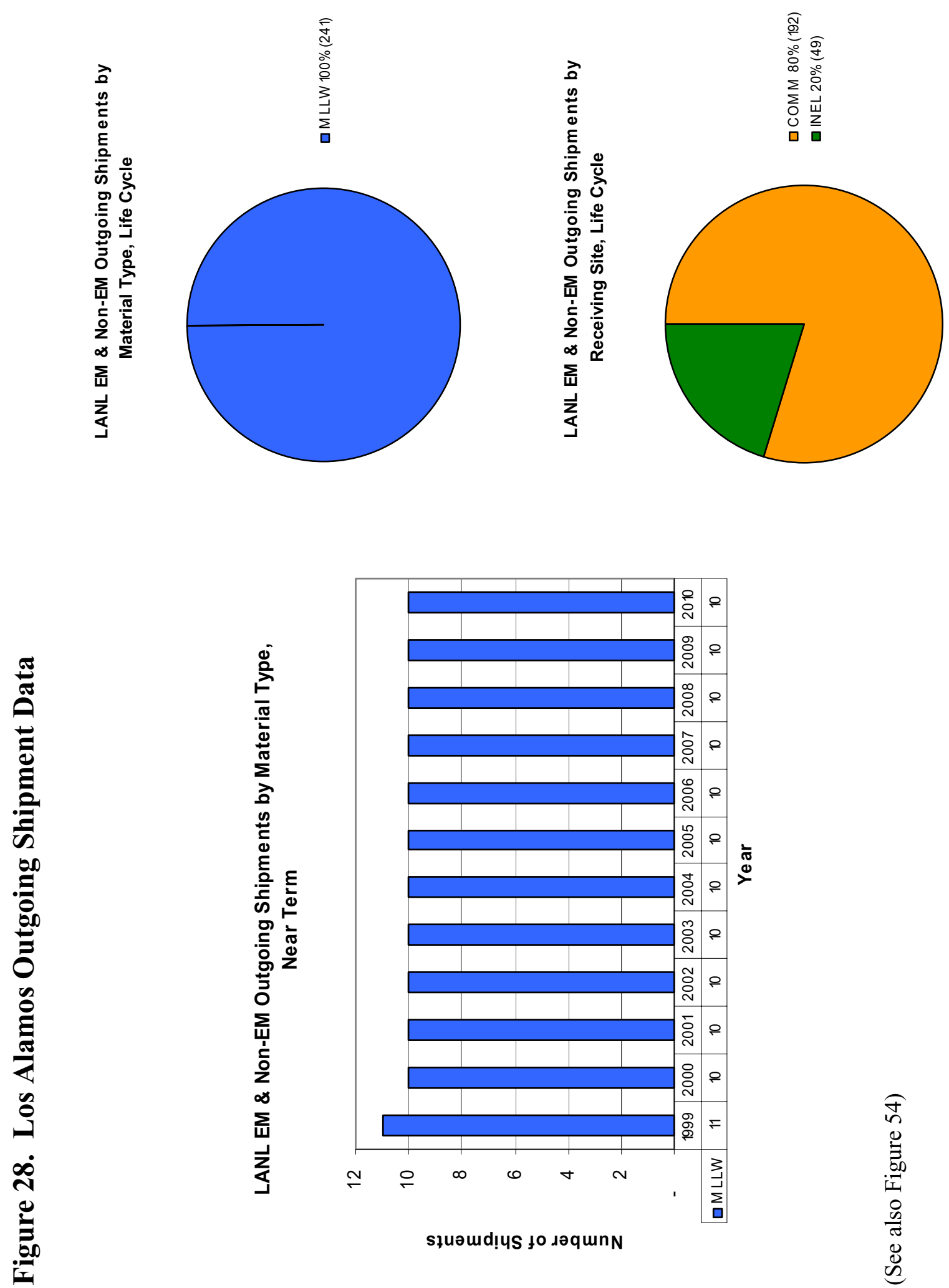

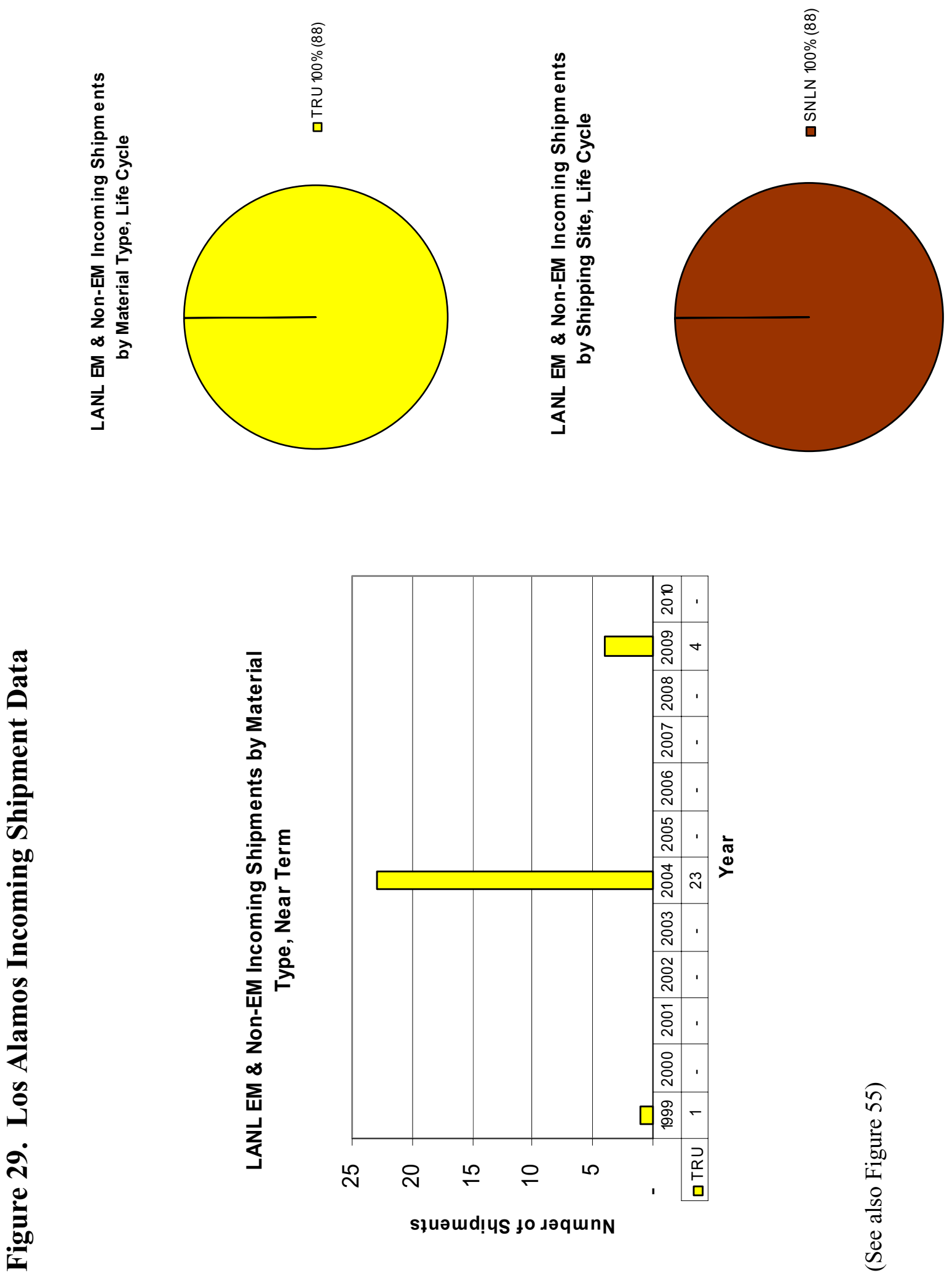

0
$n$
0
0
0
0
0
0
$\pi$
0
0
0 

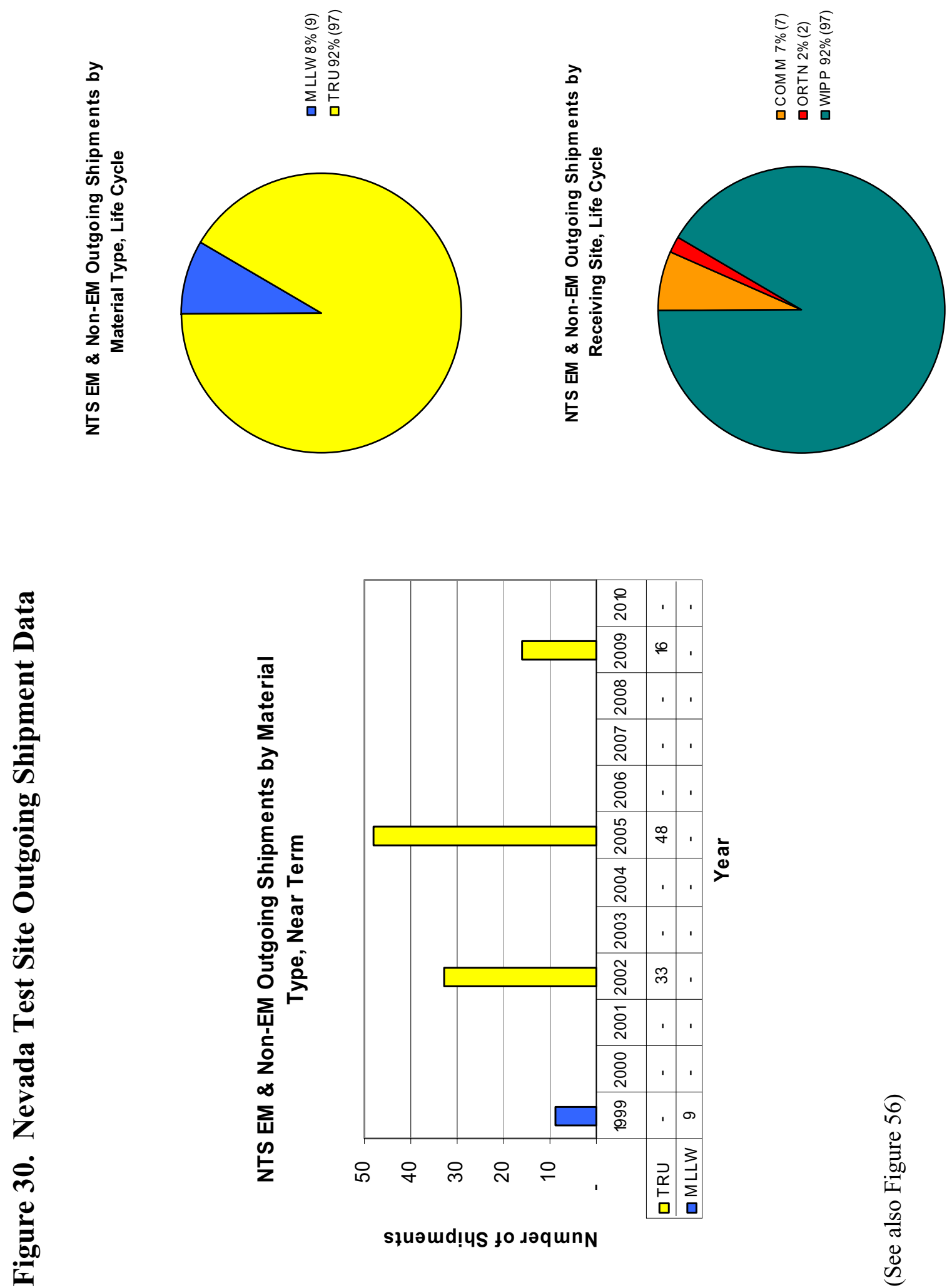

$\sigma$
0
0
0
0
0
0
0
0
0
0
0
0 

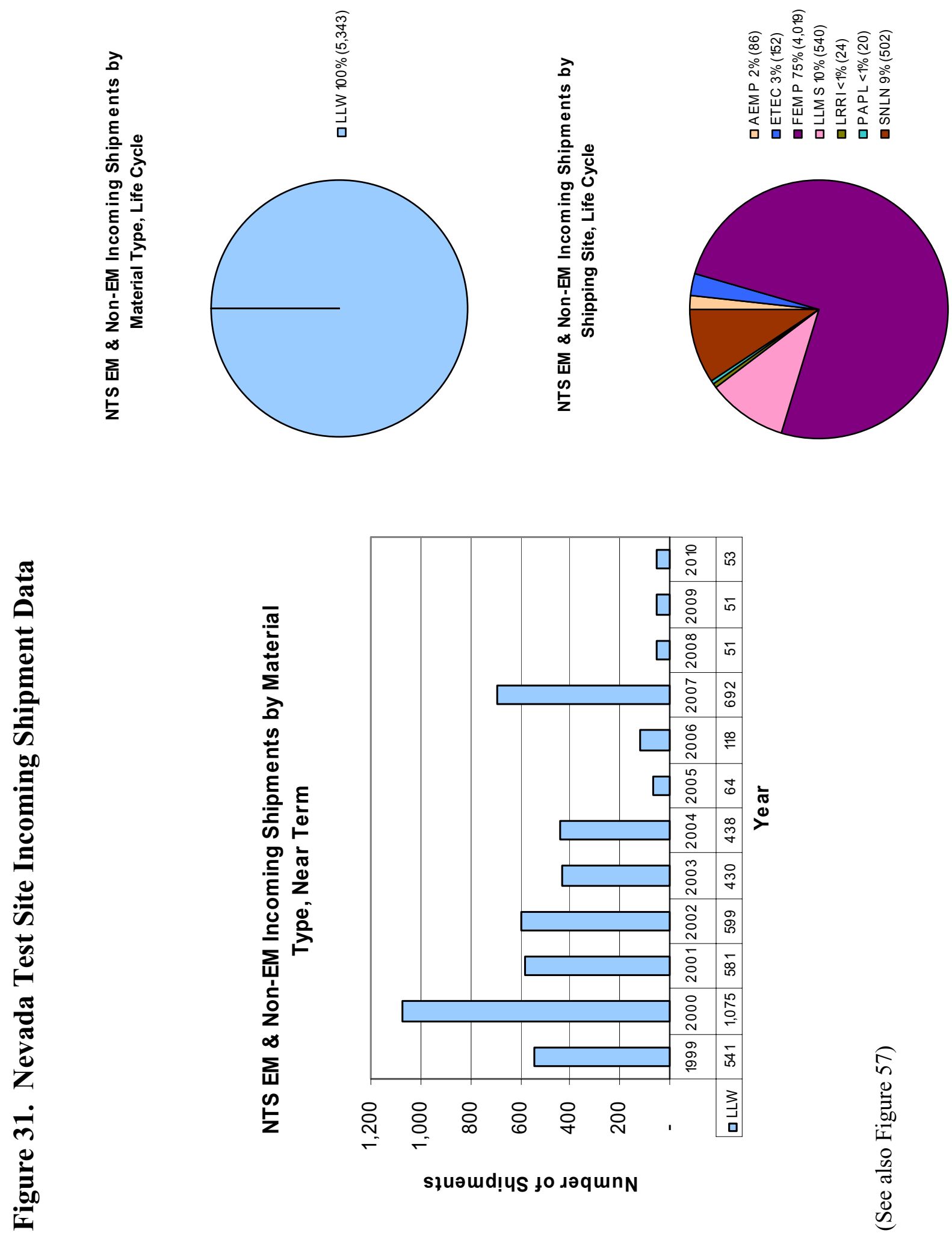

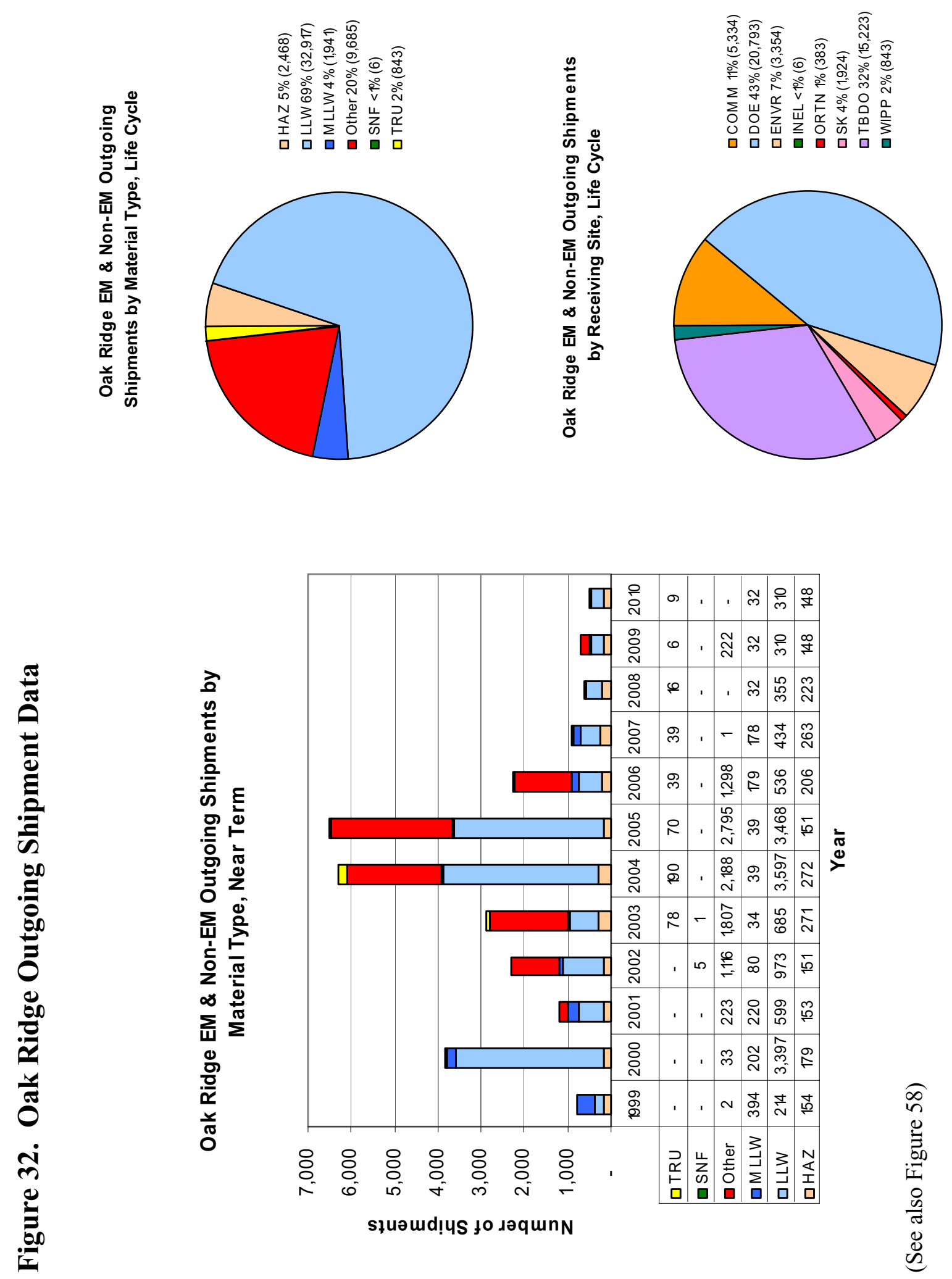

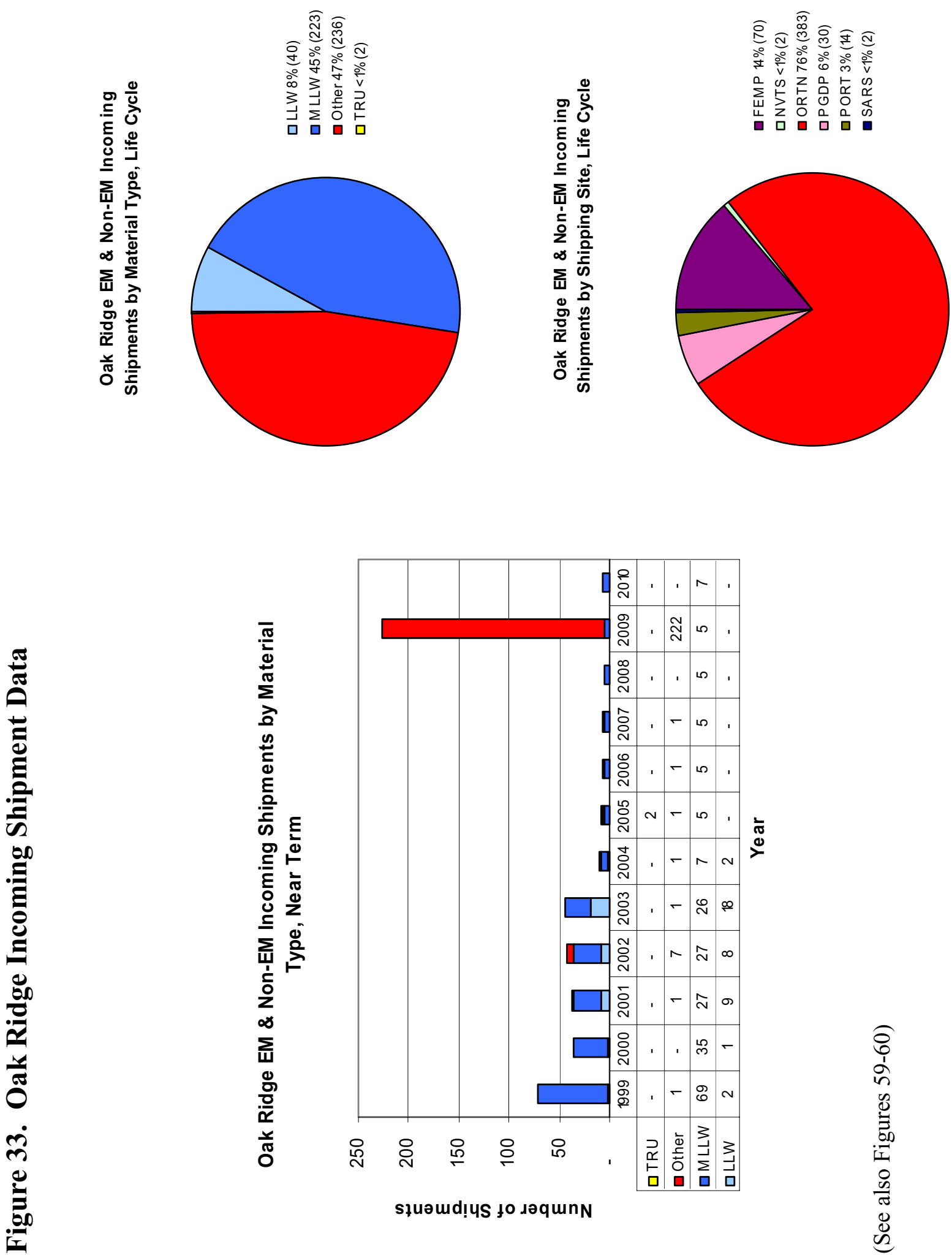

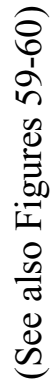



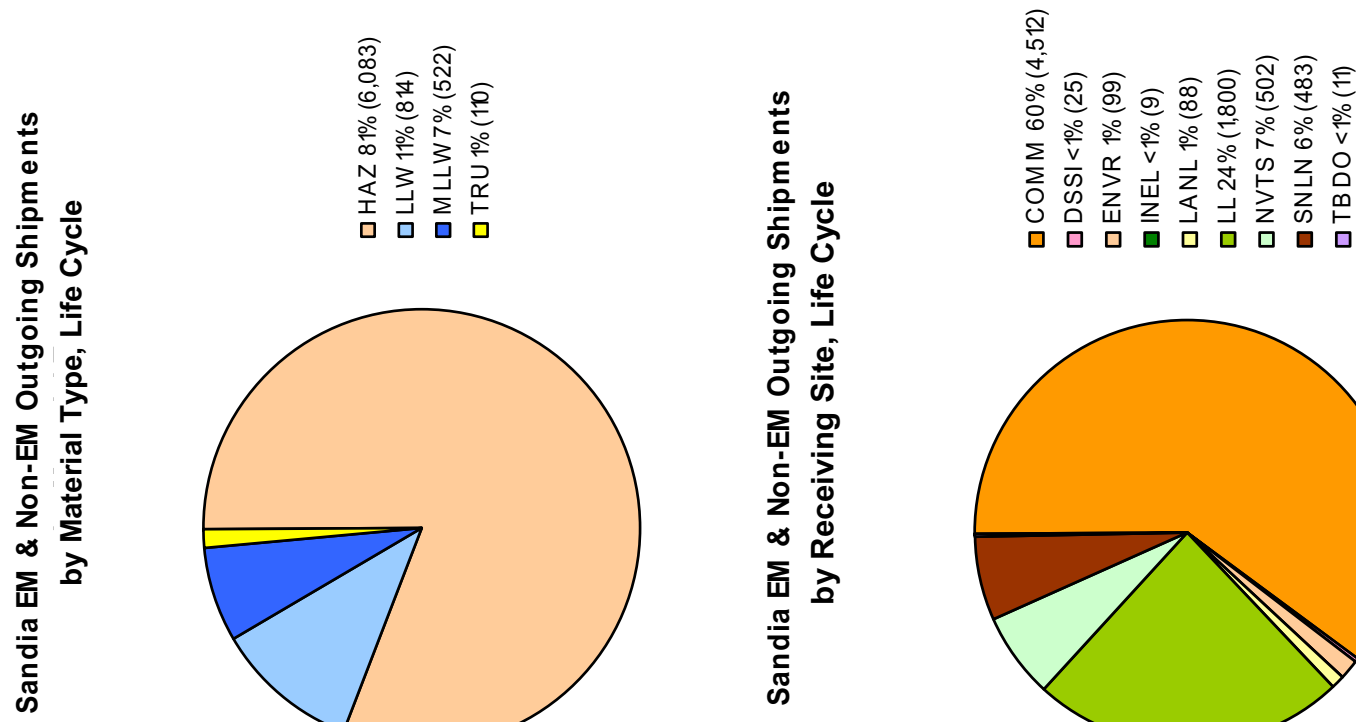

שี
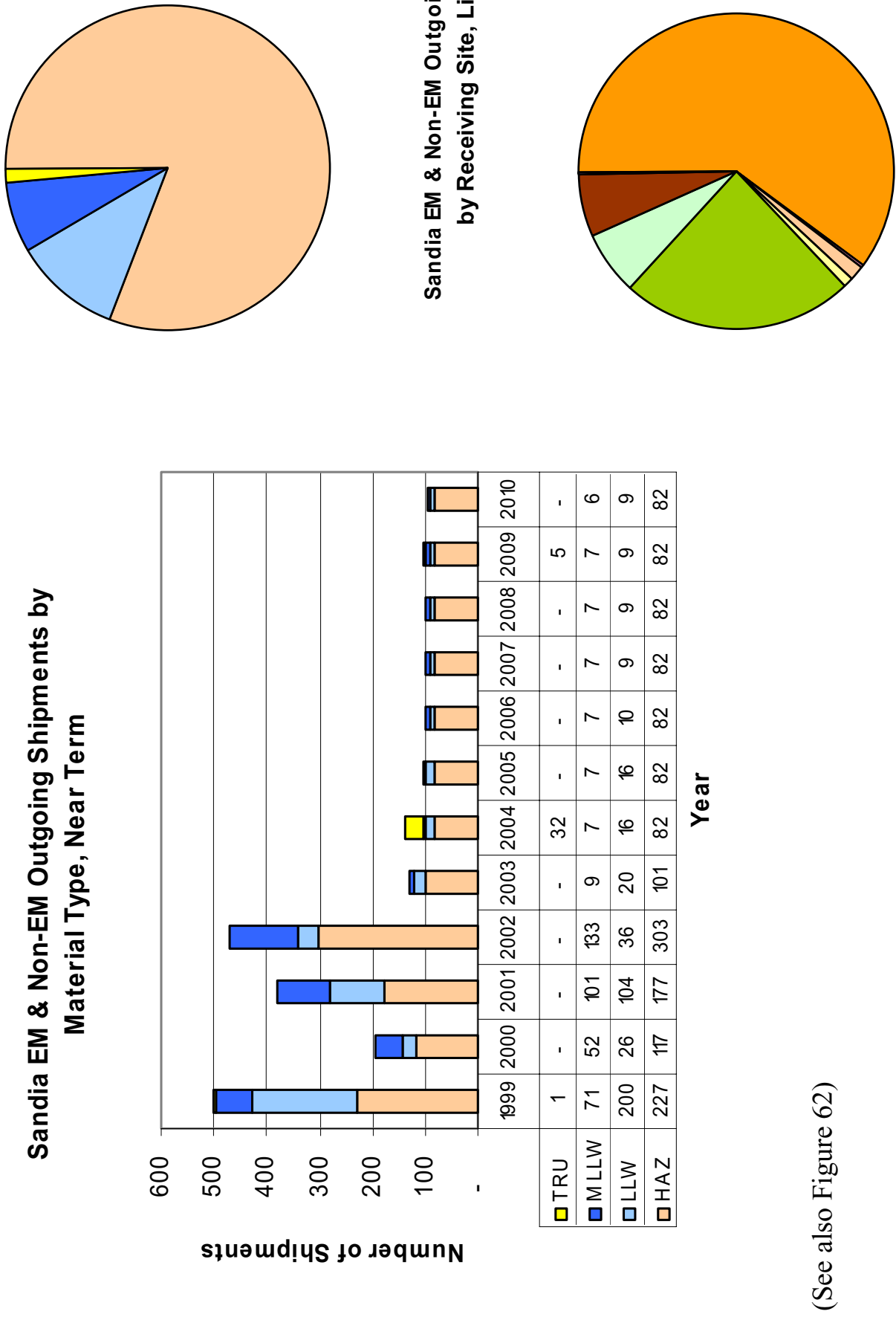

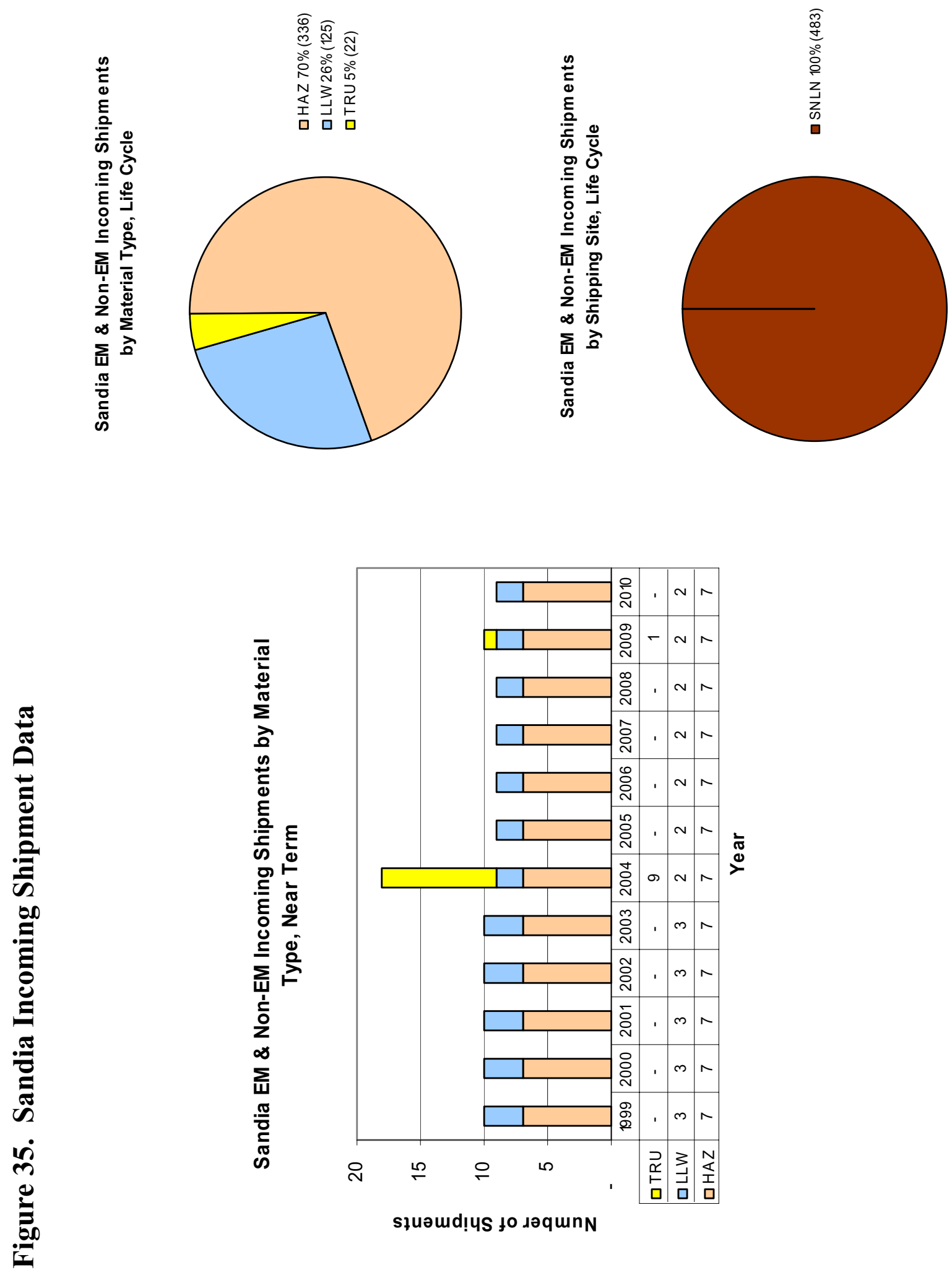

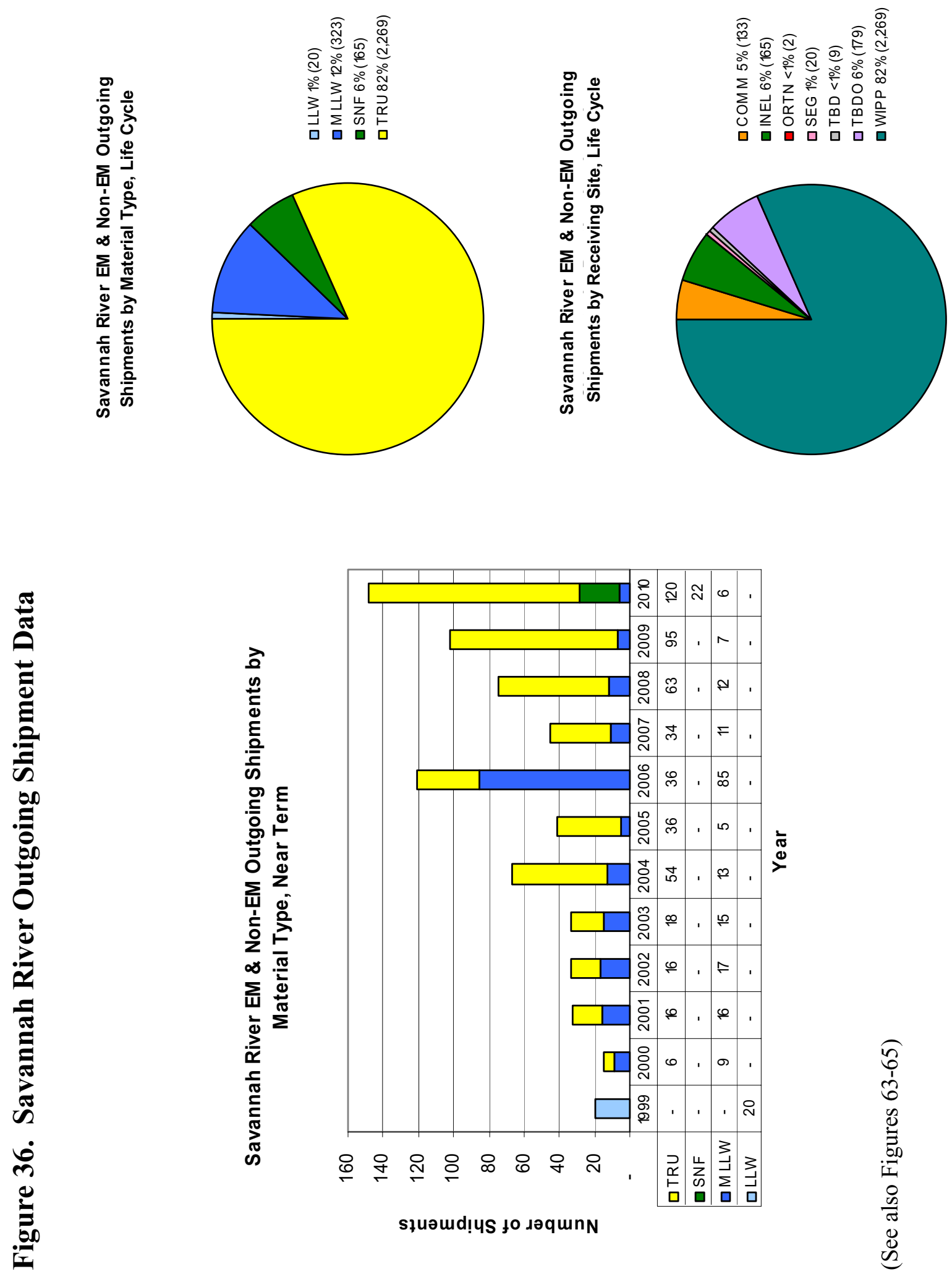

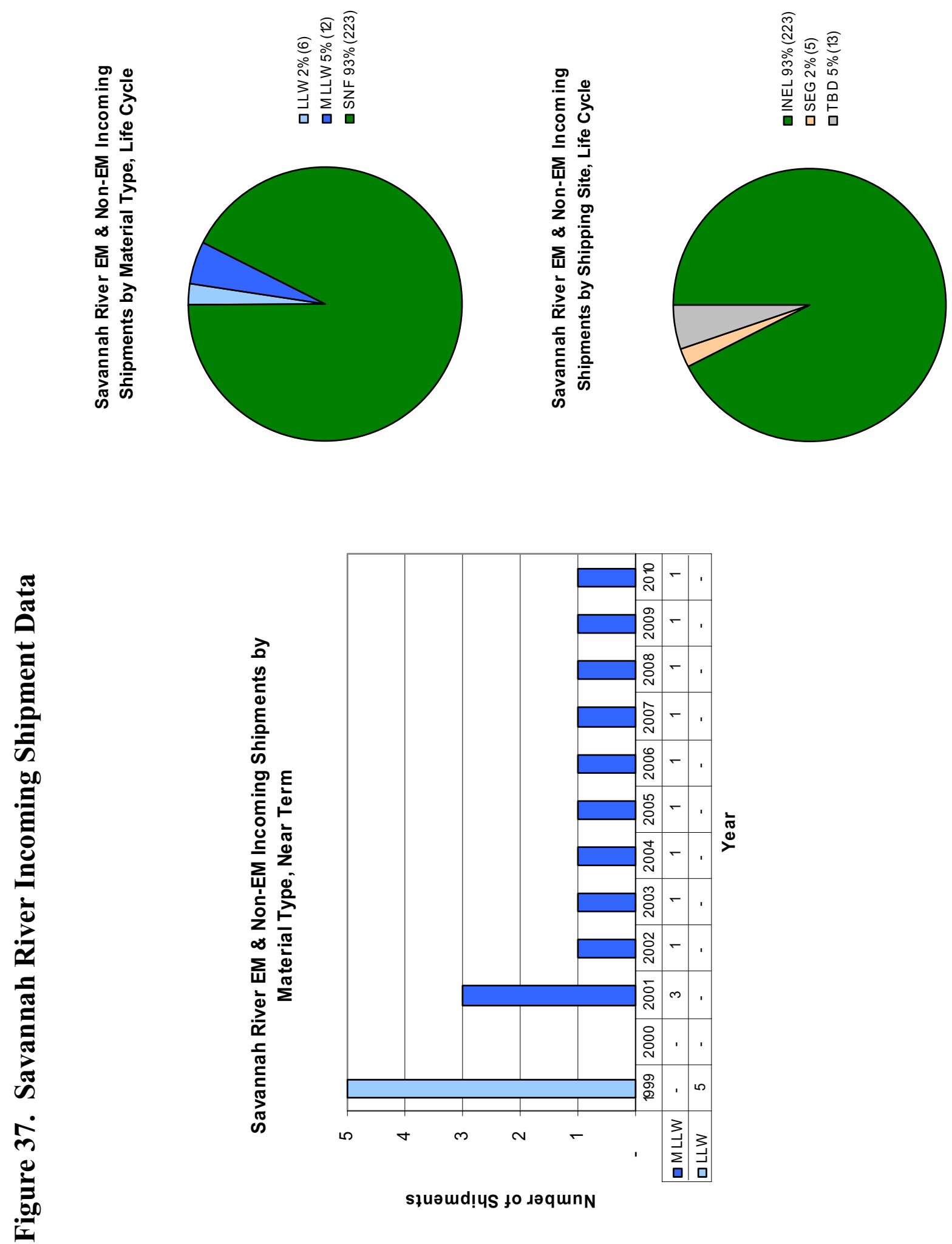

słuəud!̣s to dəqunN 


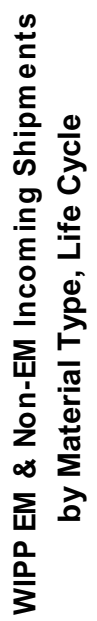

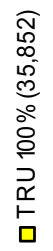
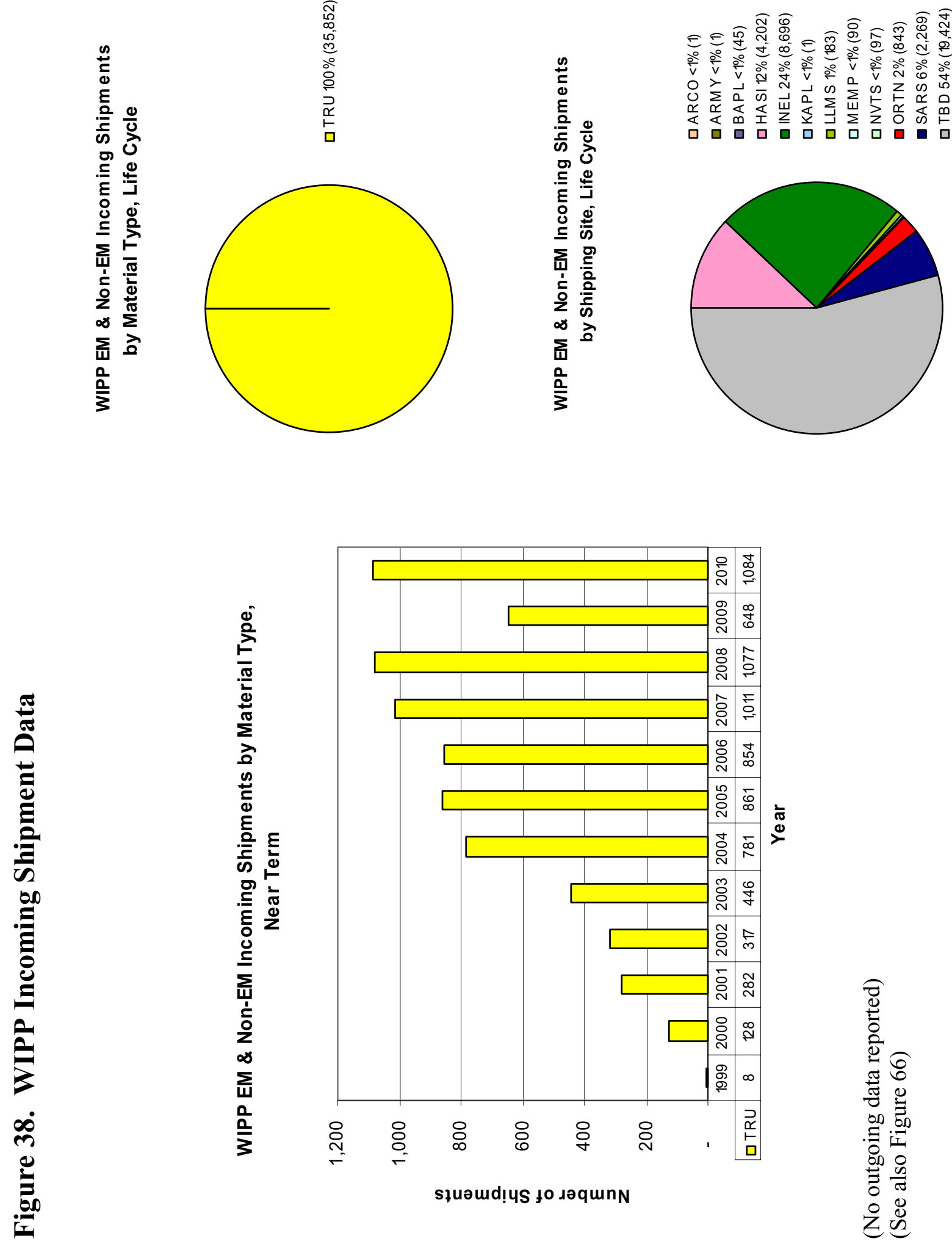

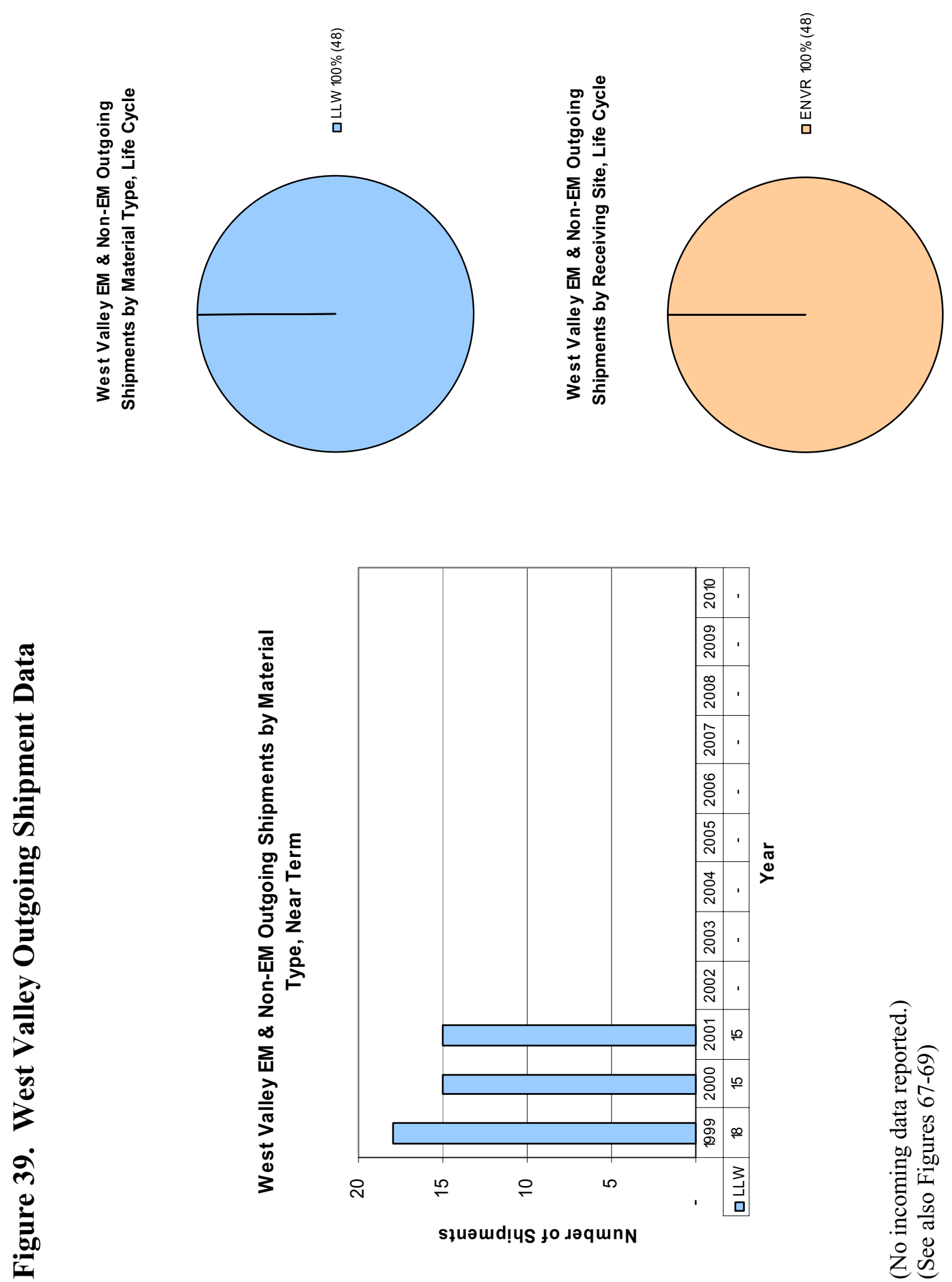


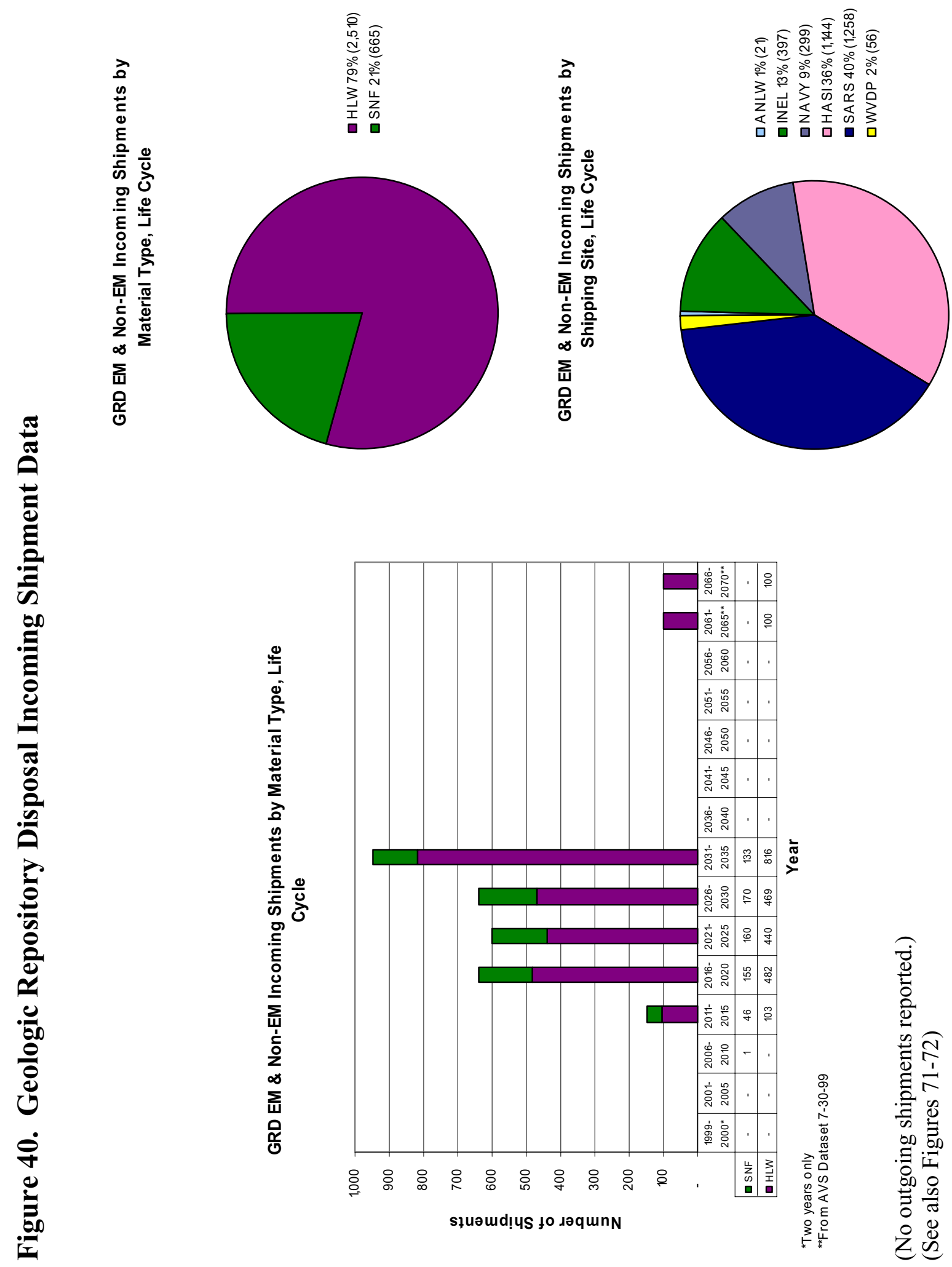




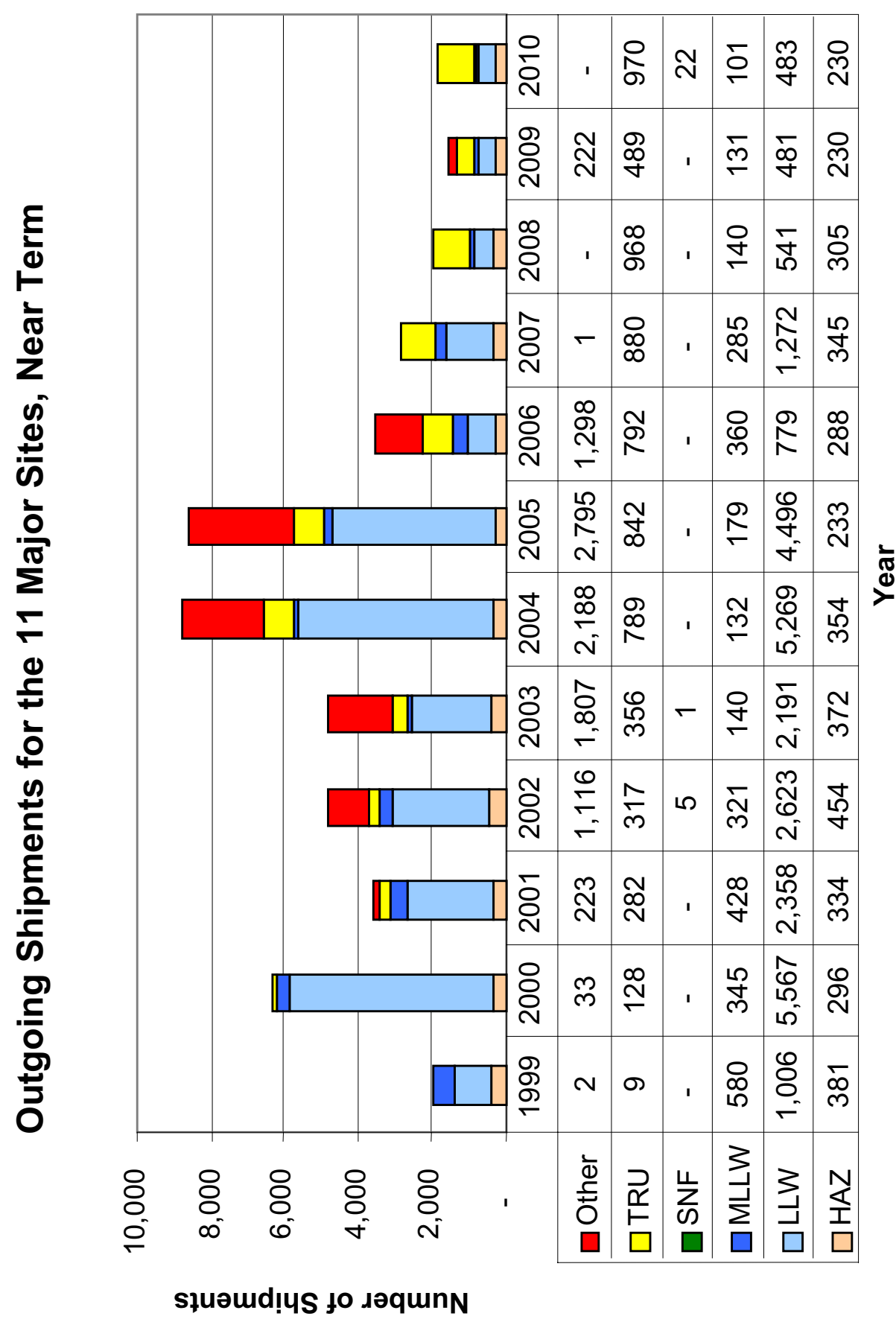




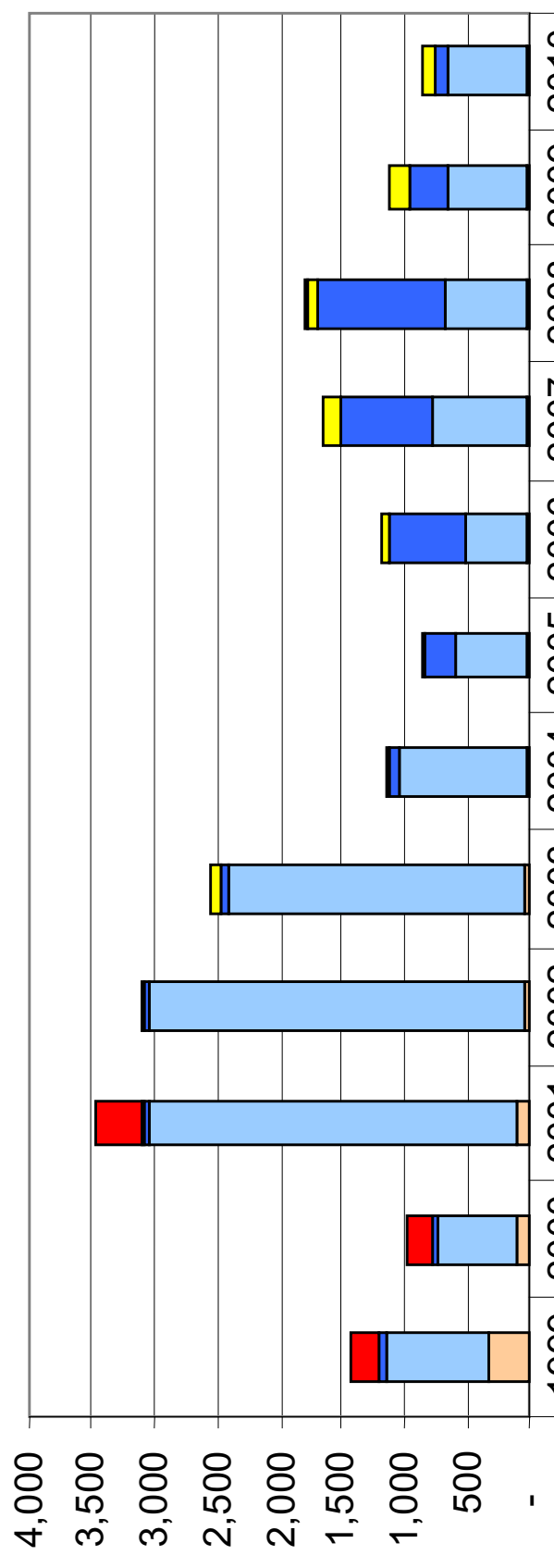

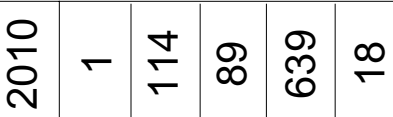

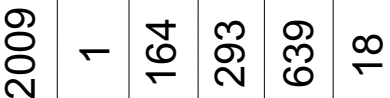

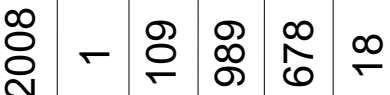

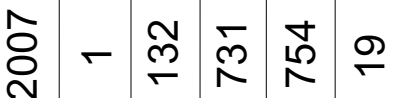

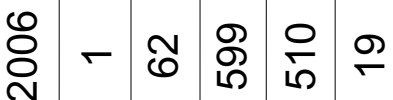

$$
\begin{aligned}
& \text { 总 }- \text { ส }
\end{aligned}
$$

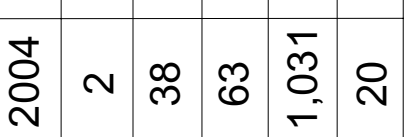

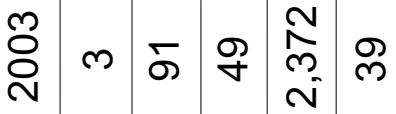

$$
\begin{aligned}
& \text { §ิ స , ๆ }
\end{aligned}
$$

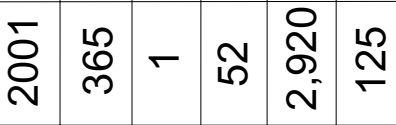

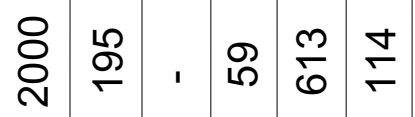

윰 


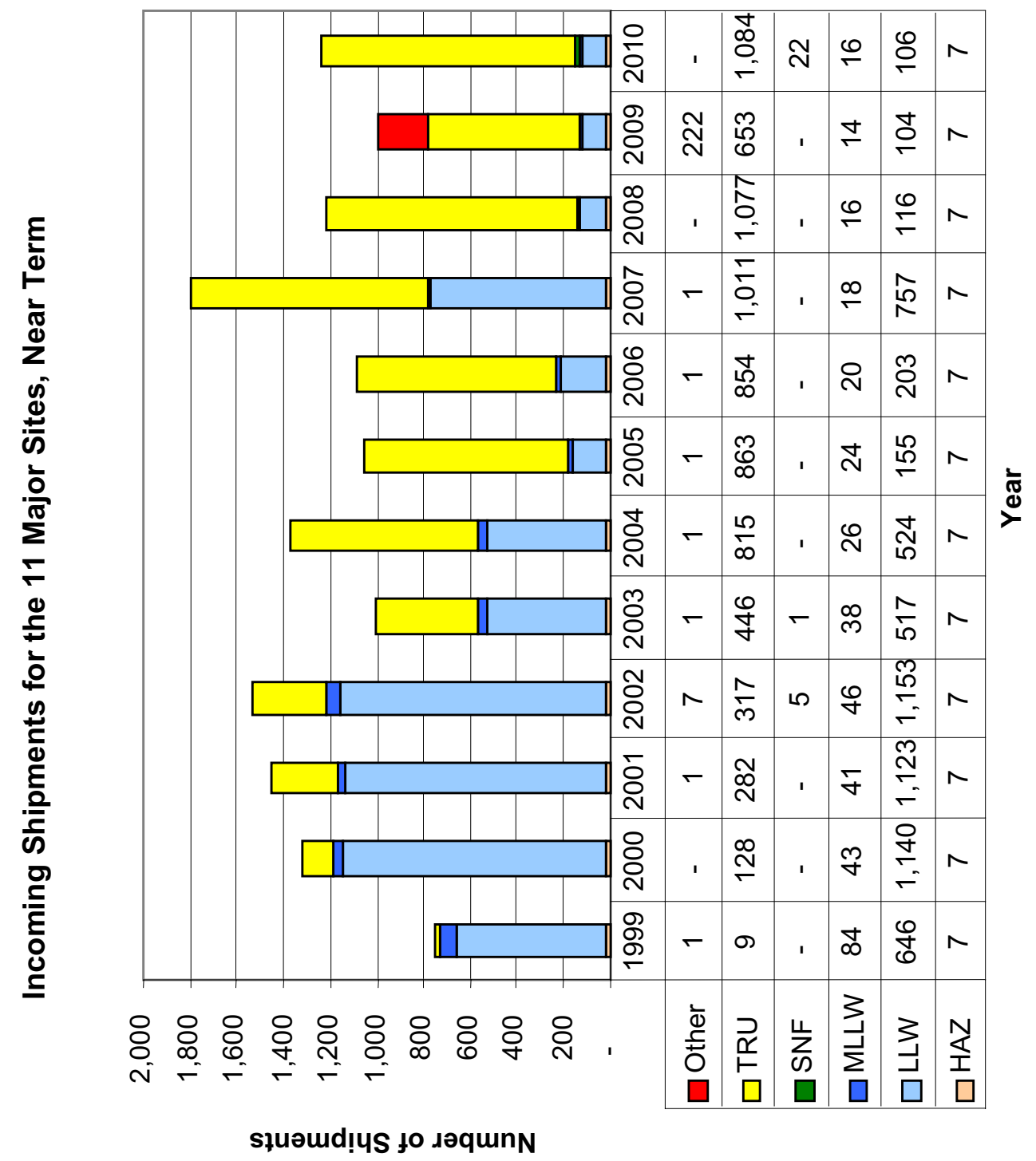




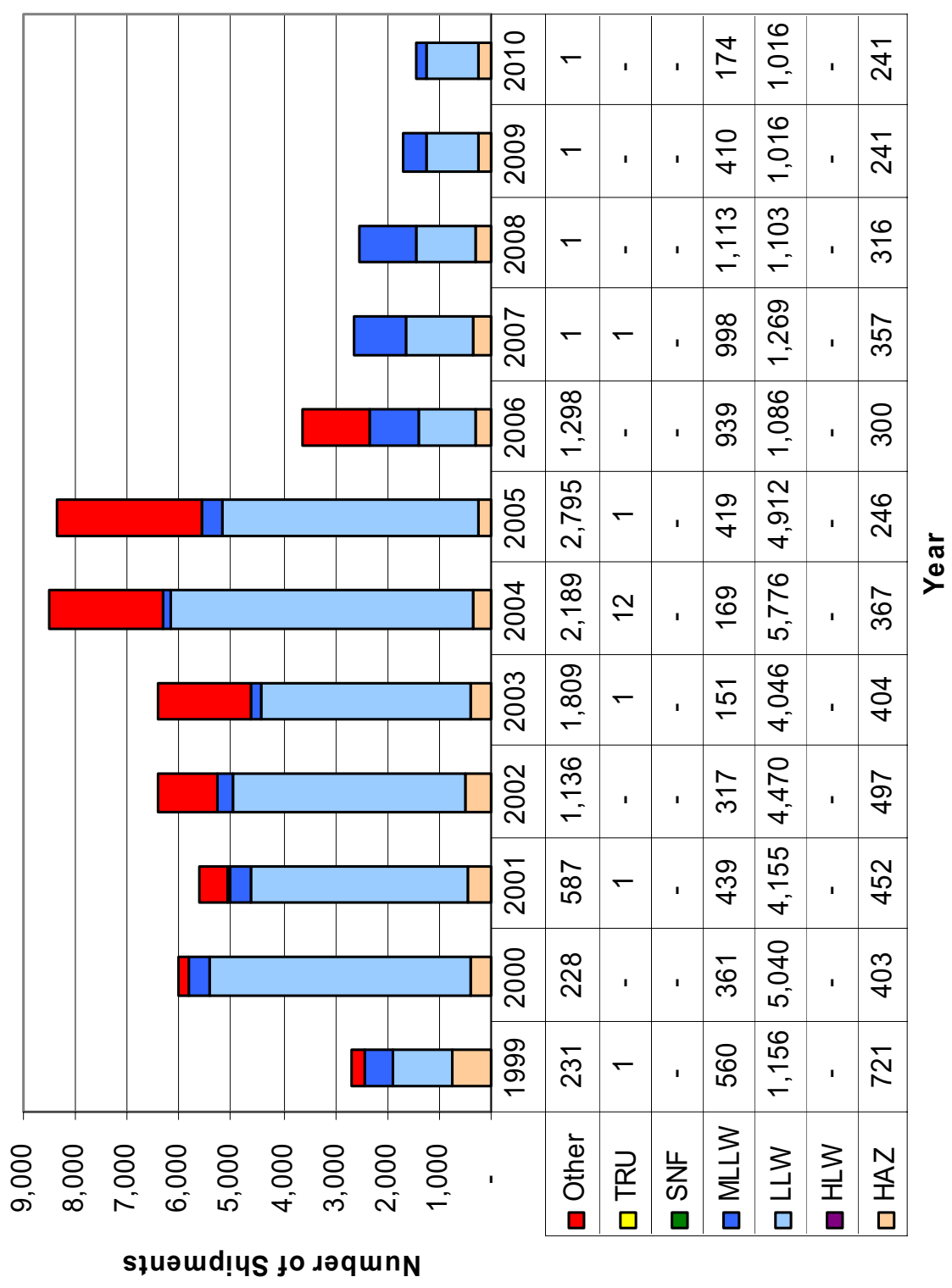


Figure 45. Major Site Shipments Compared with All Other Sites

\section{Comparison of Outgoing Shipments from the 11 Major Sites verses All Other Sites}

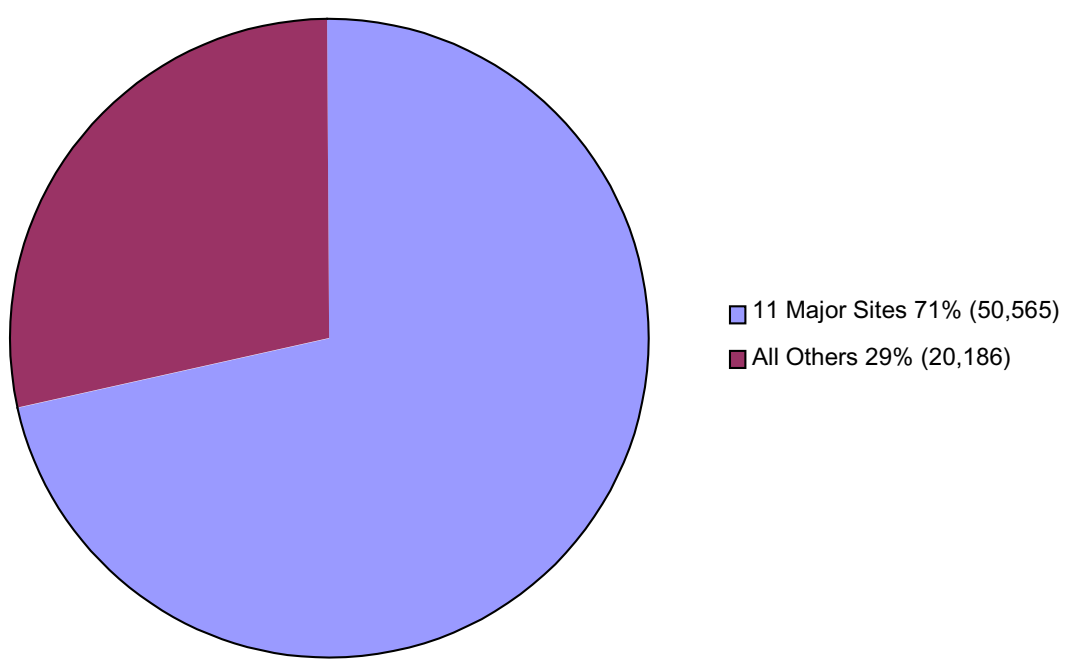

Comparison of Incoming Shipments to the 11 Major Sites verses All Other Sites

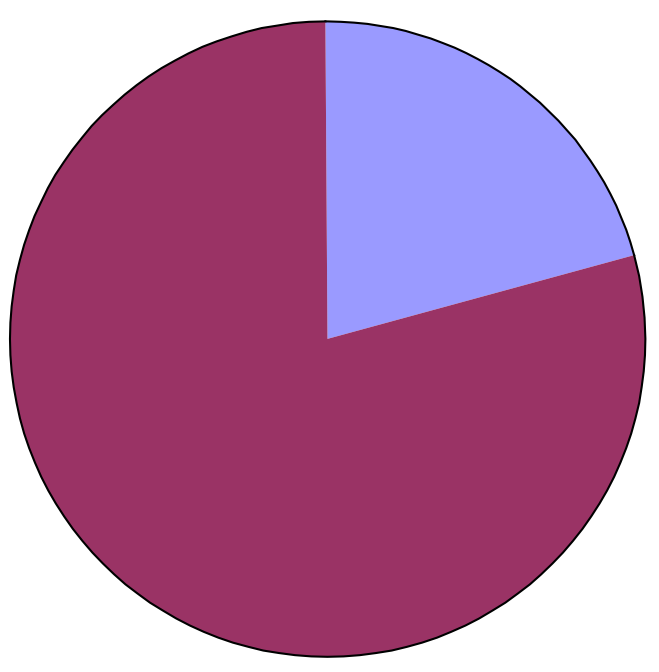

$\square 11$ Major Sites $21 \%(14,817)$

$\square$ All Others $79 \%(55,934)$ 



\section{Appendix C}

Site Specific Volume, Weight and Canister Data

(Disposition Volume/Weight/Canister Data for Stream Data not Reported as Shipments in

Appendix B) 



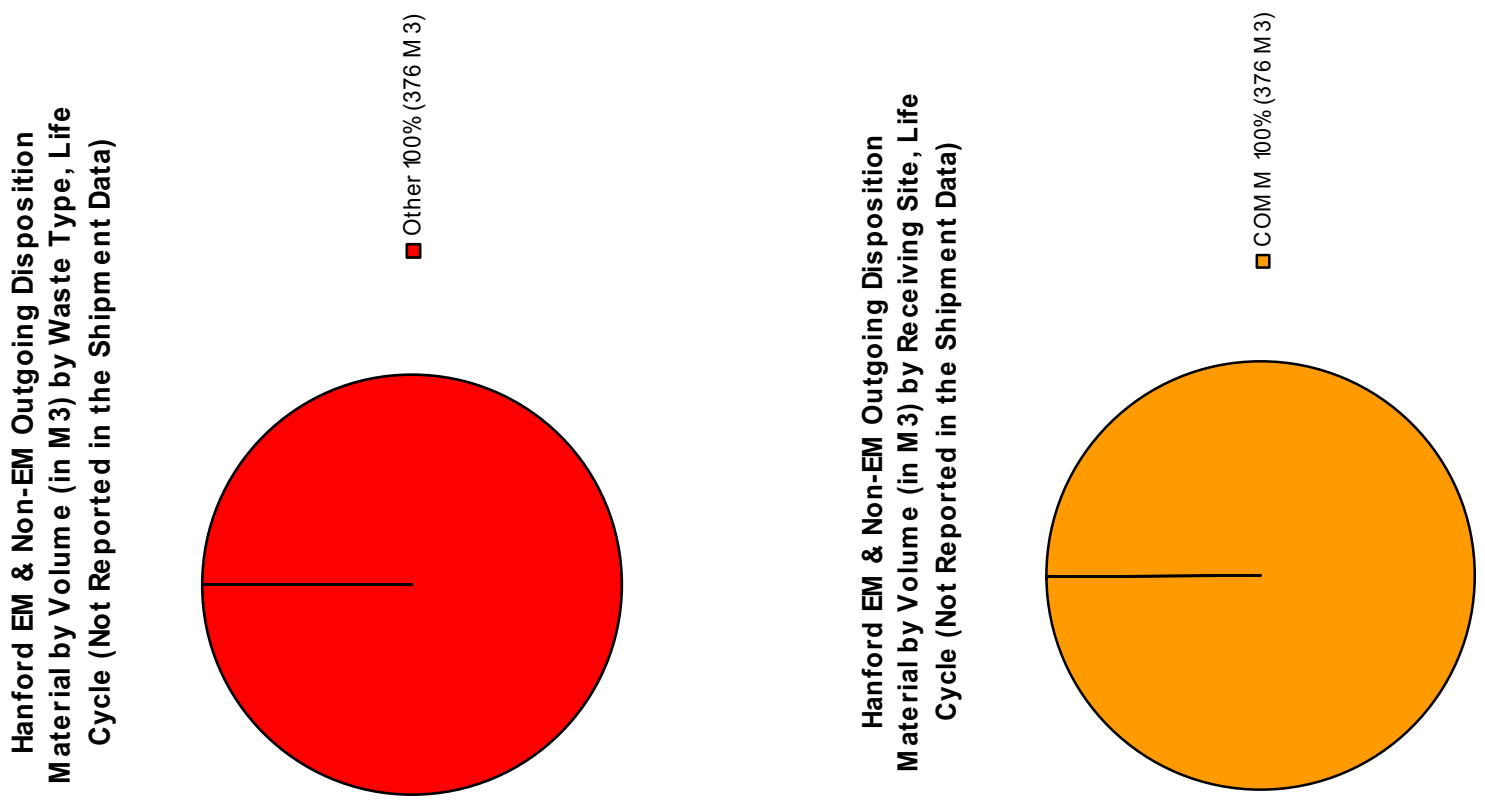

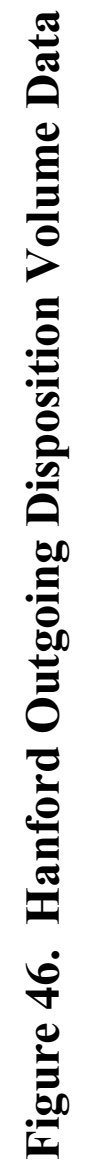

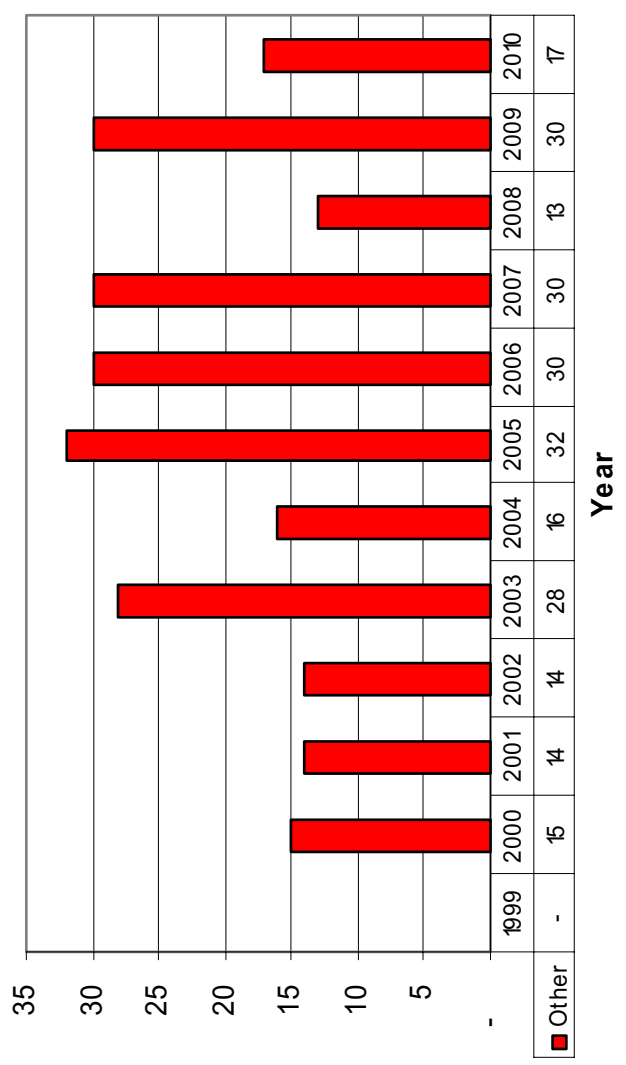

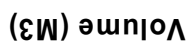



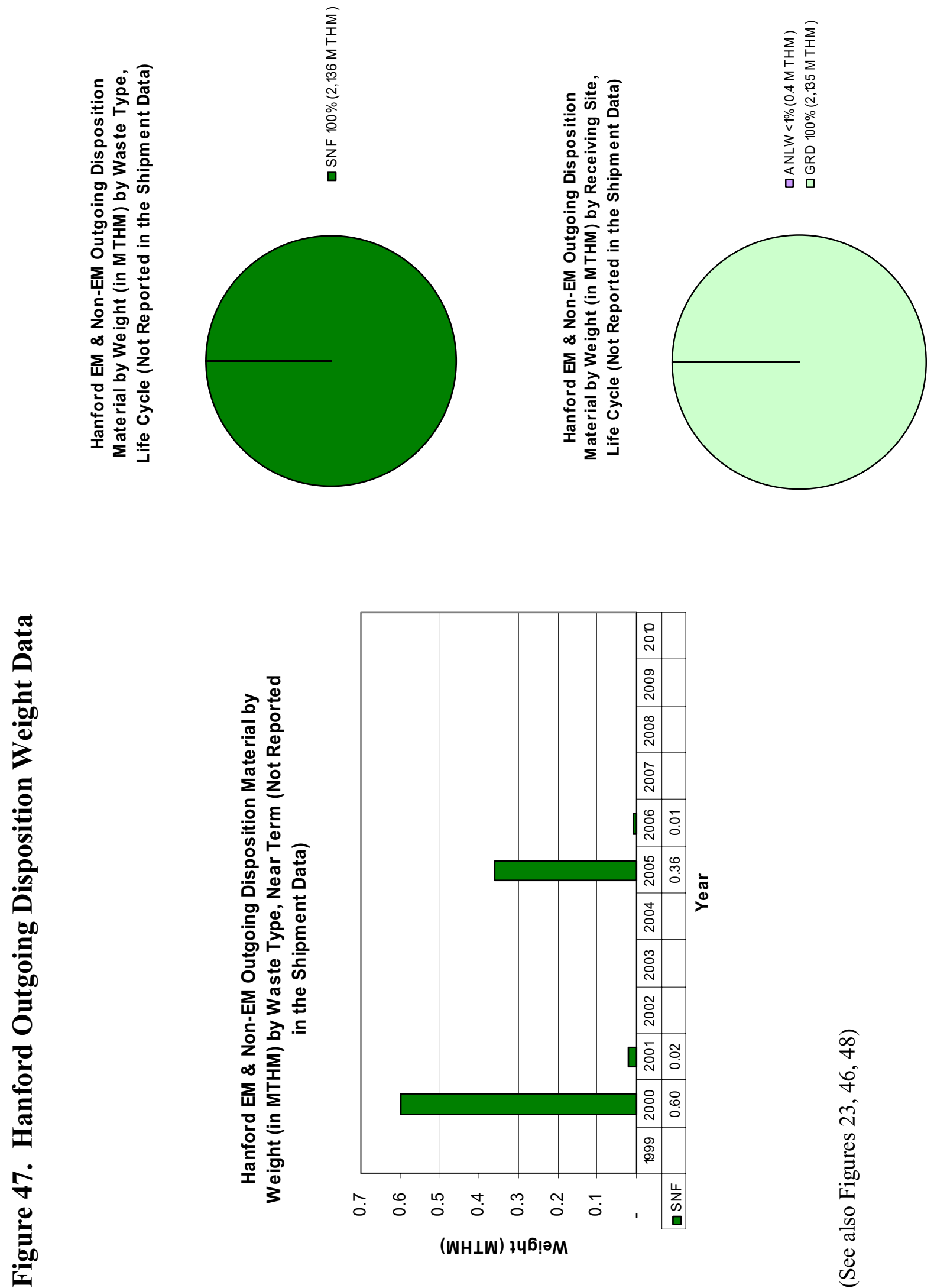

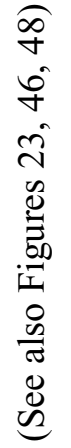



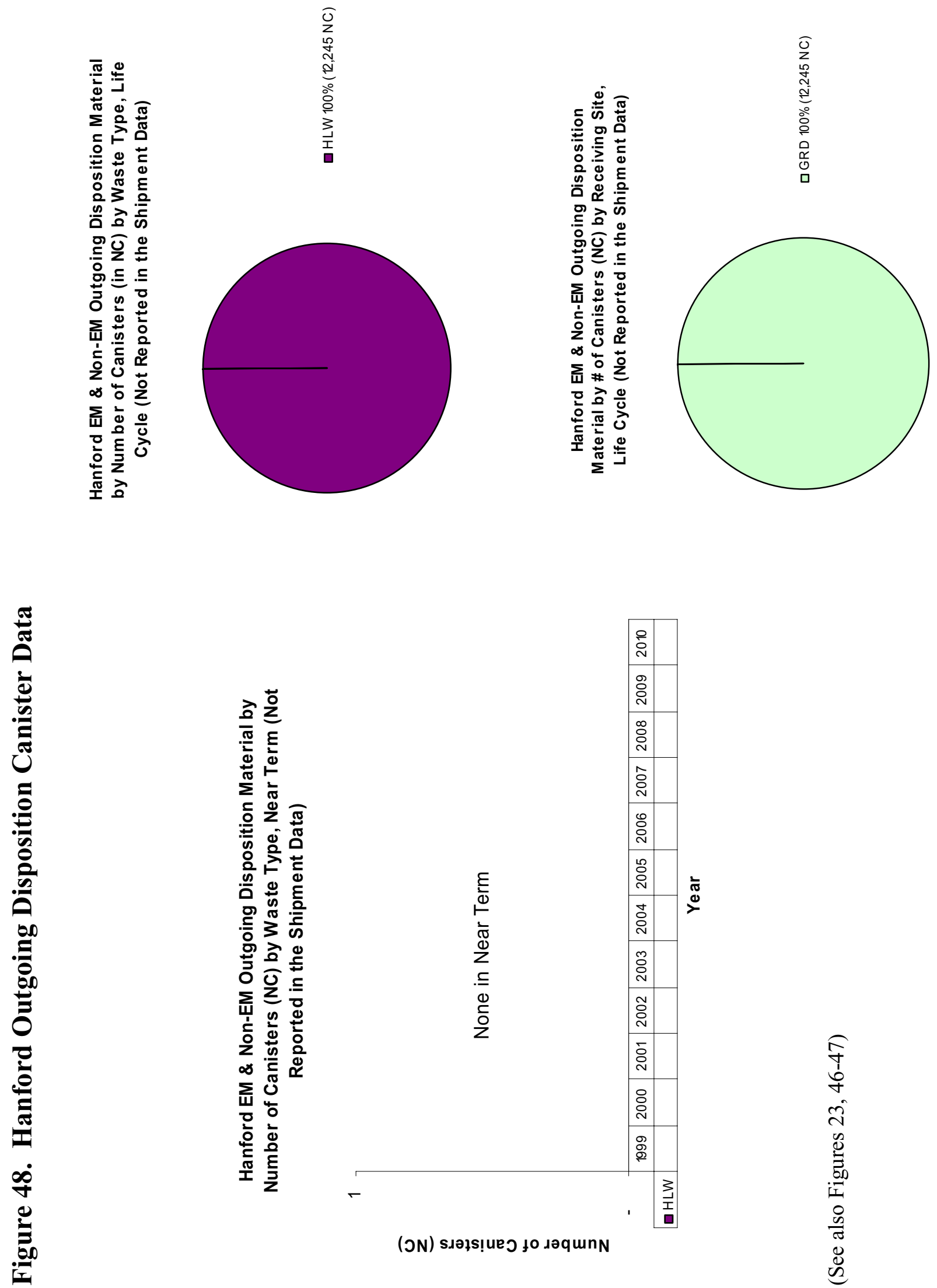

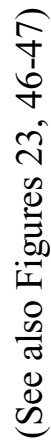



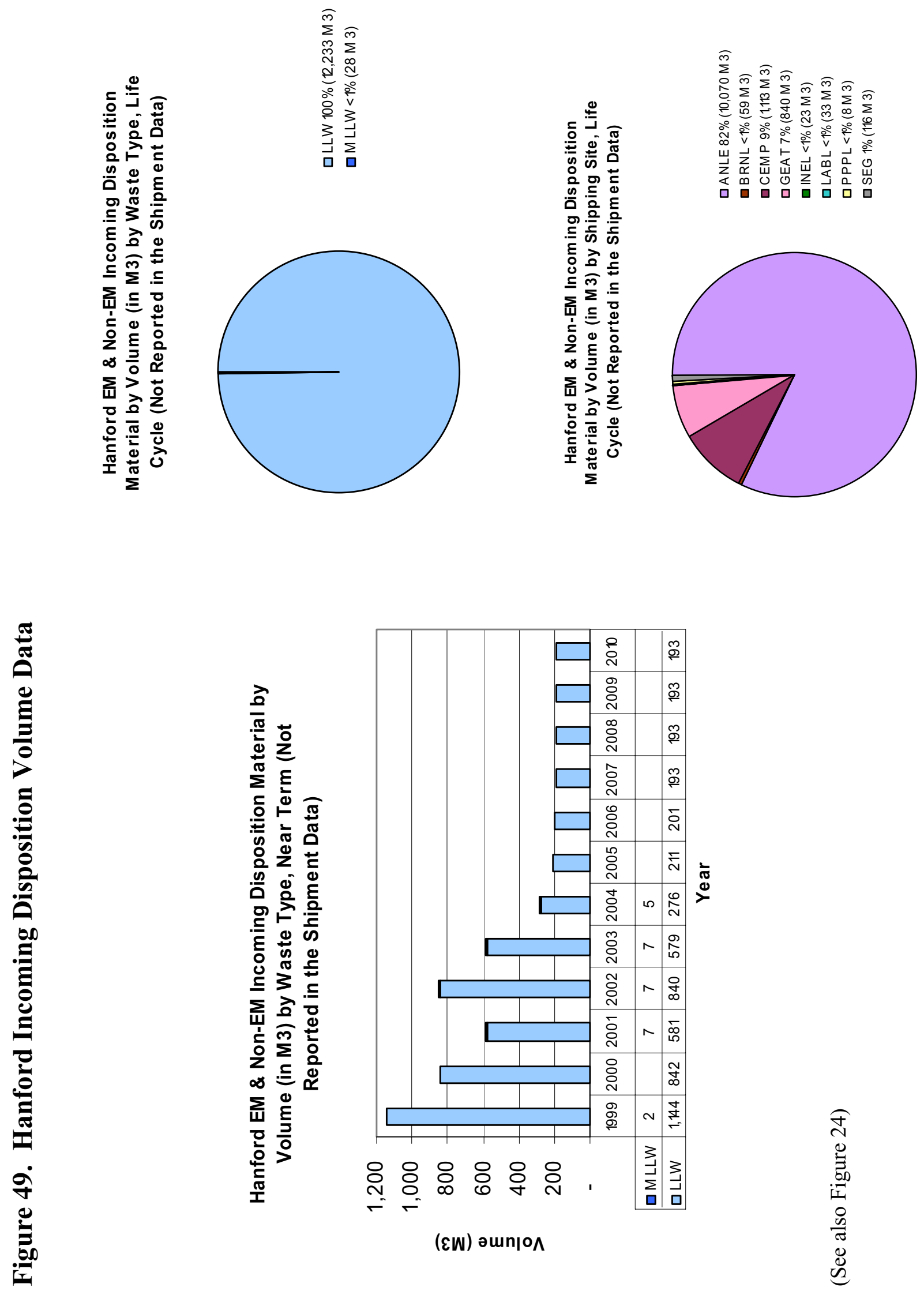

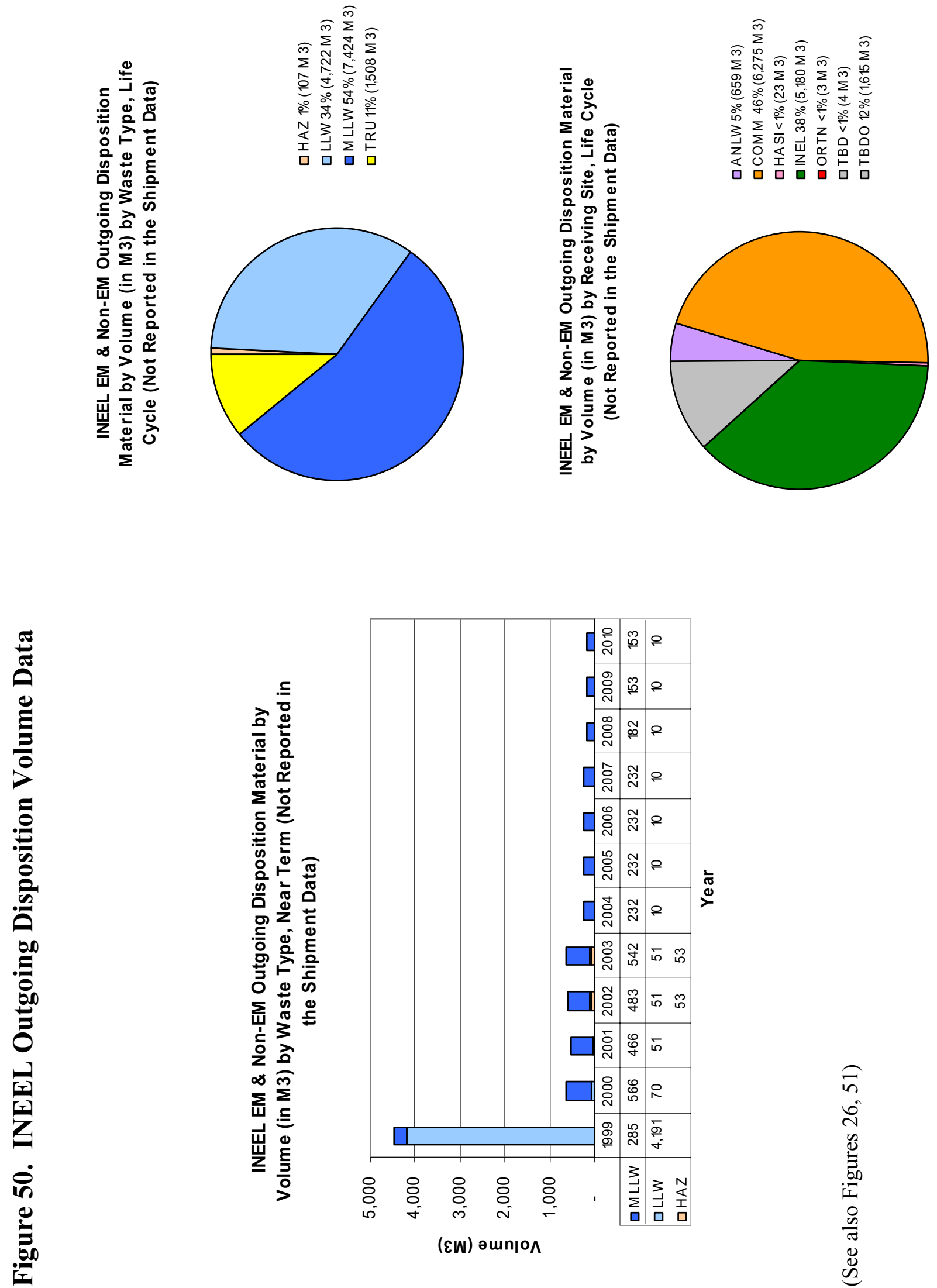

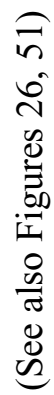



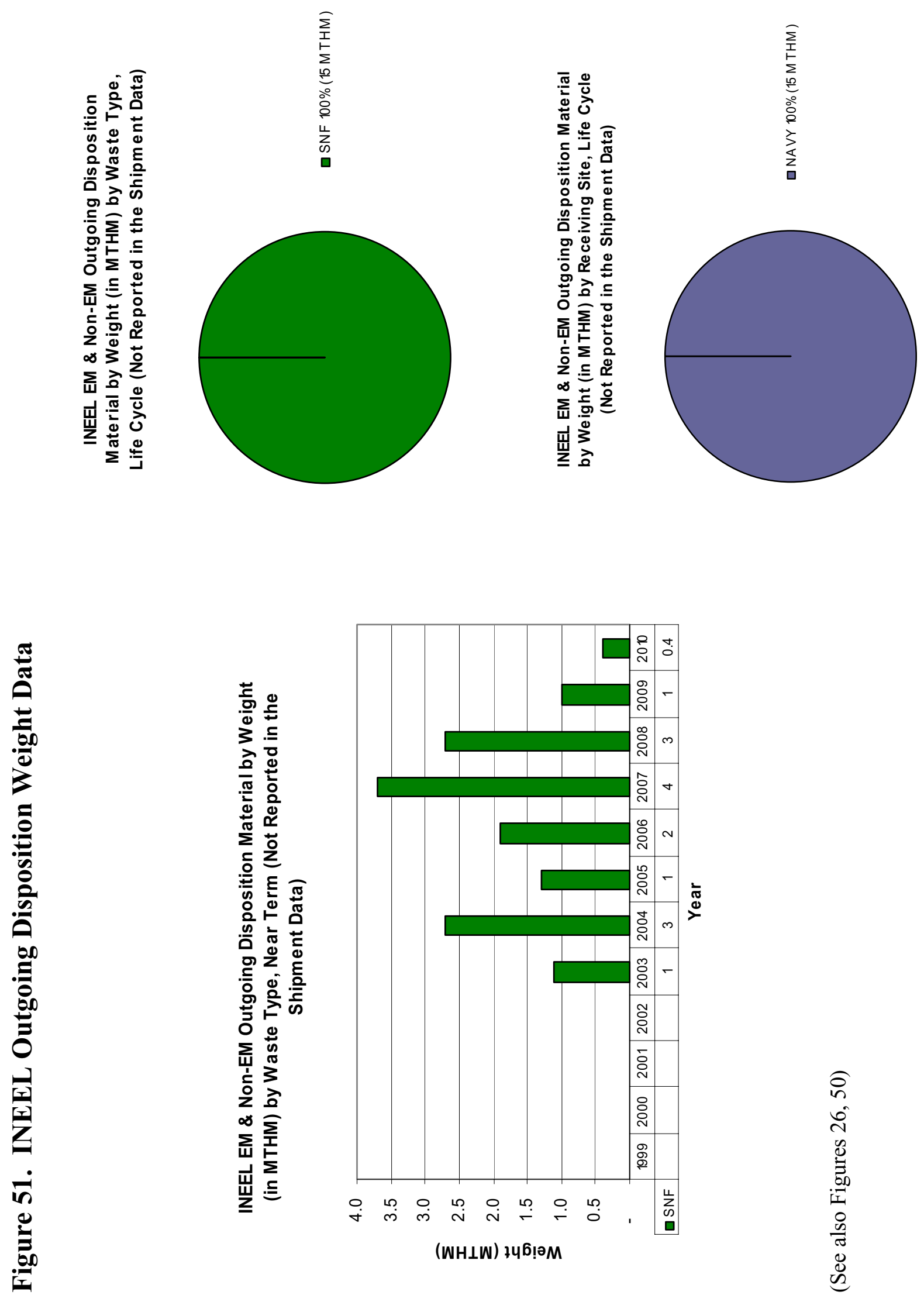

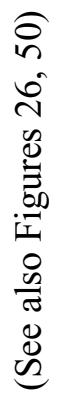



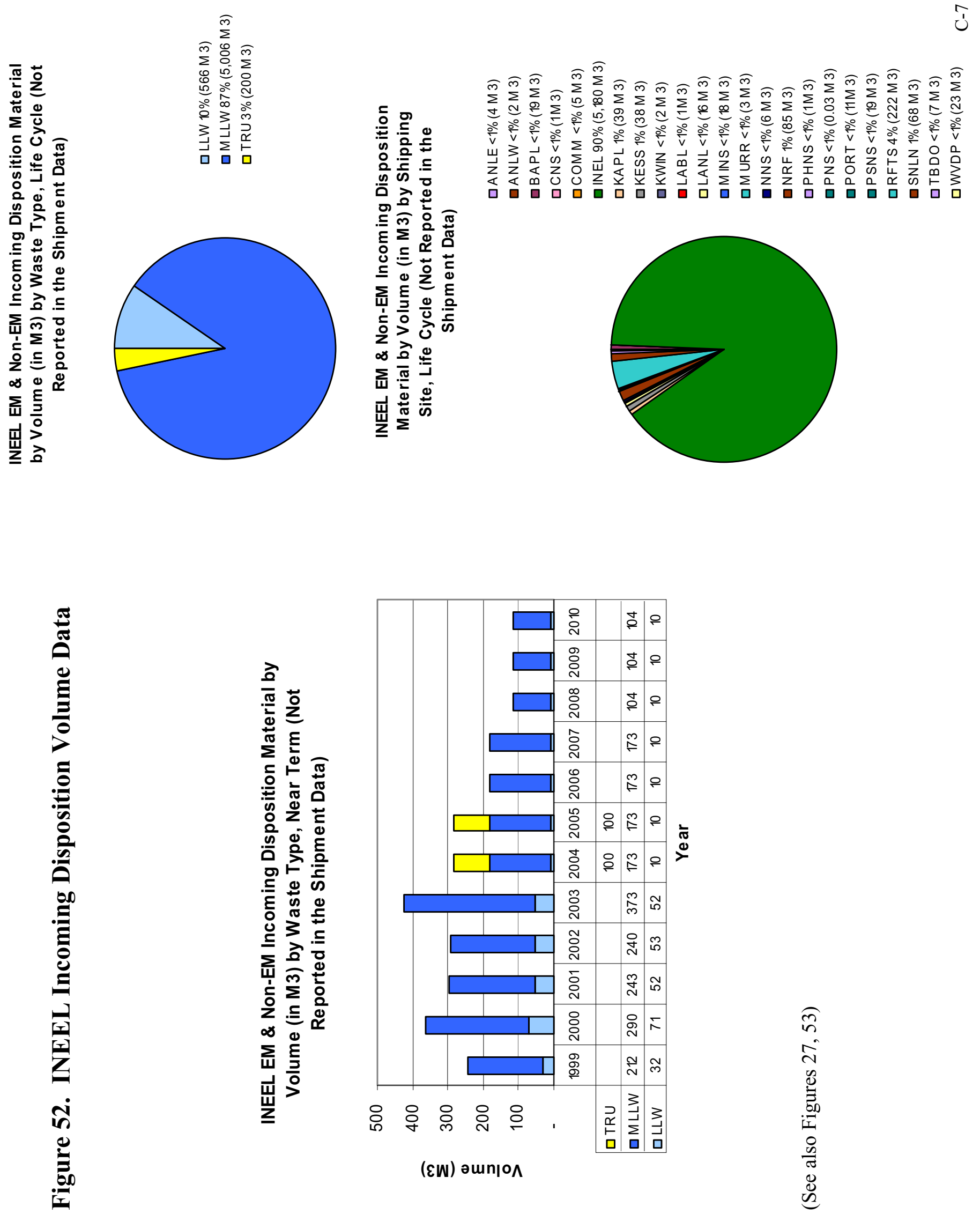

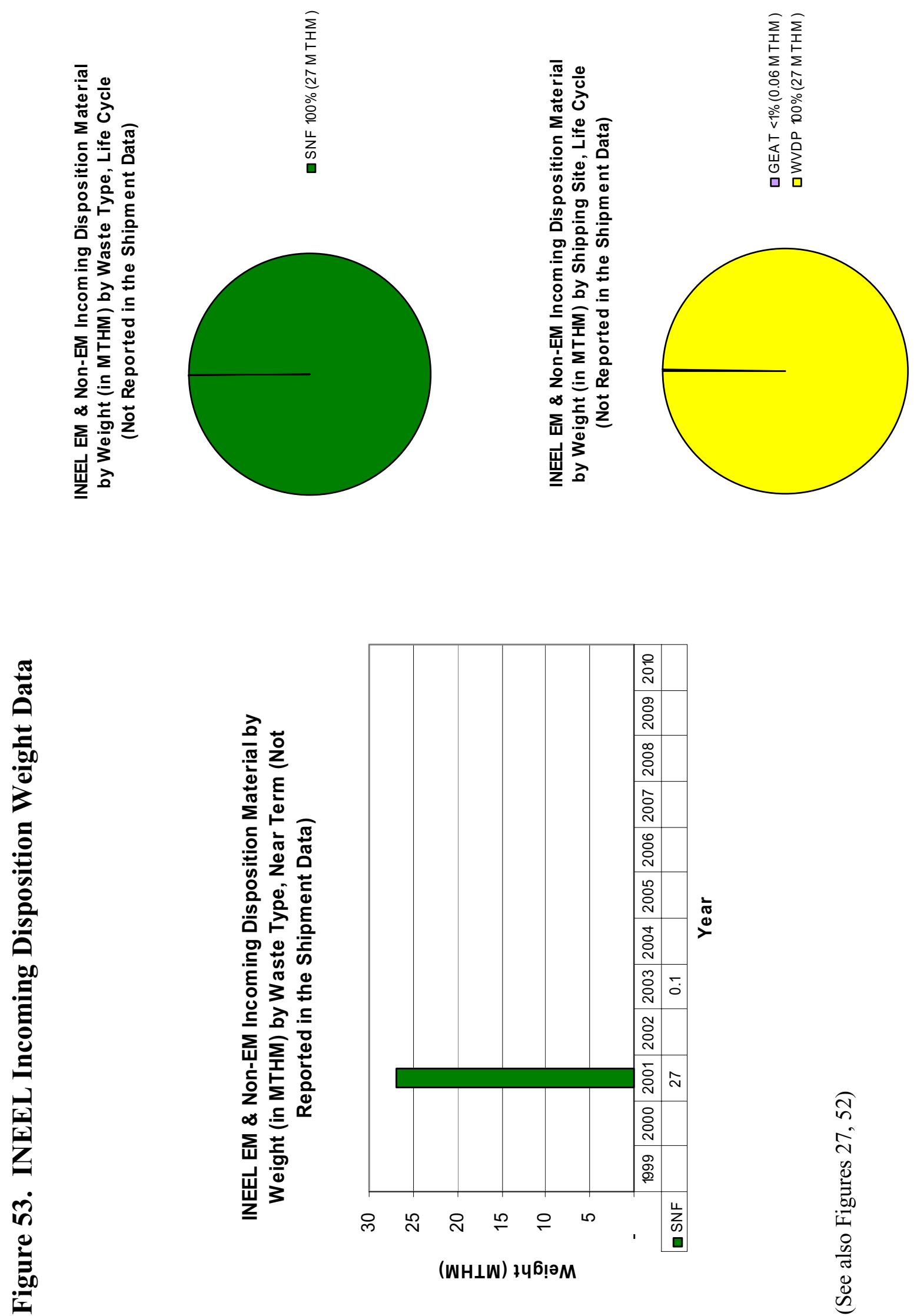

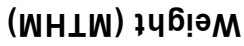

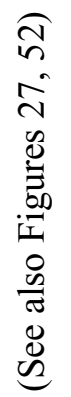



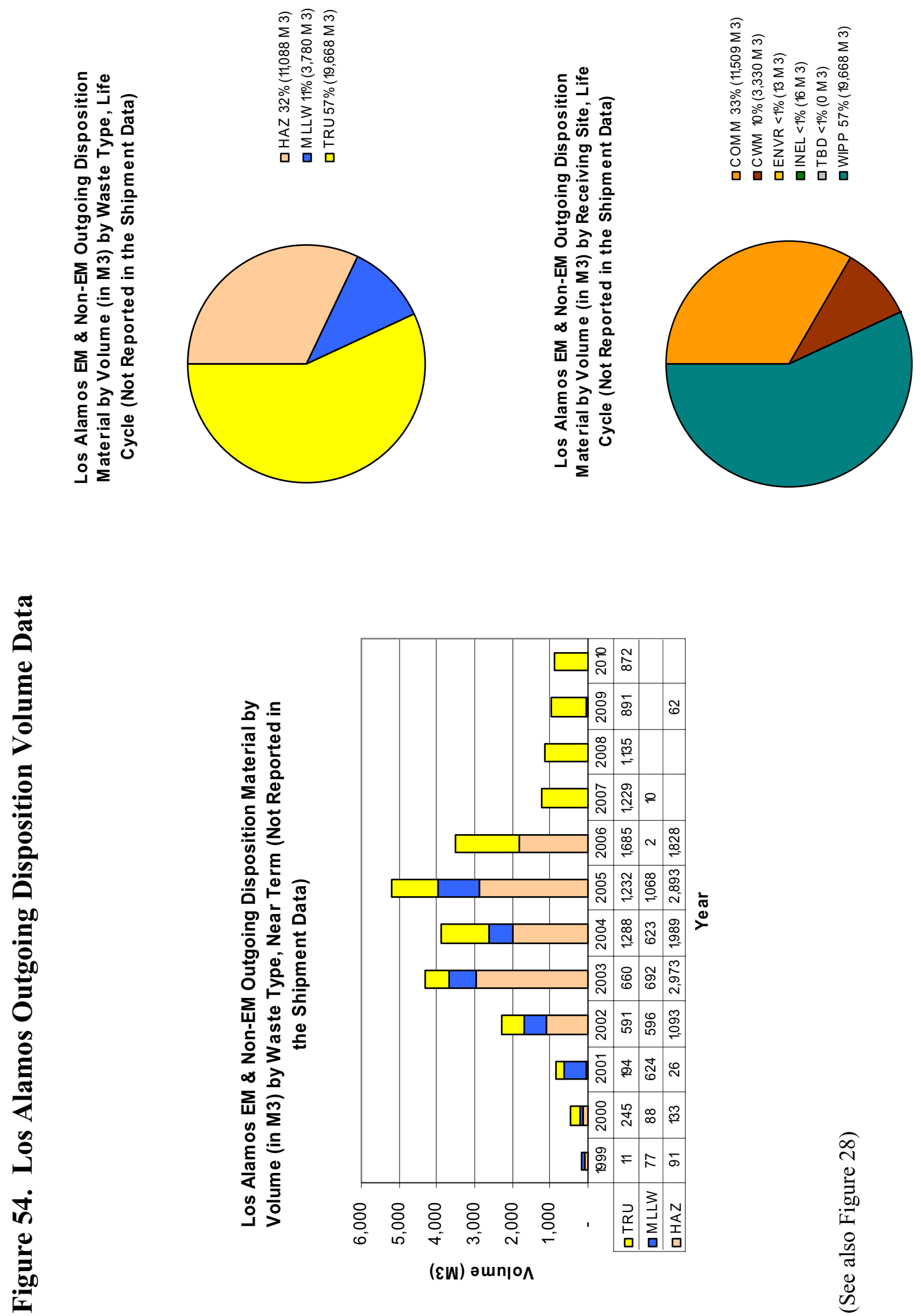

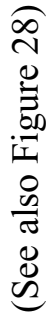



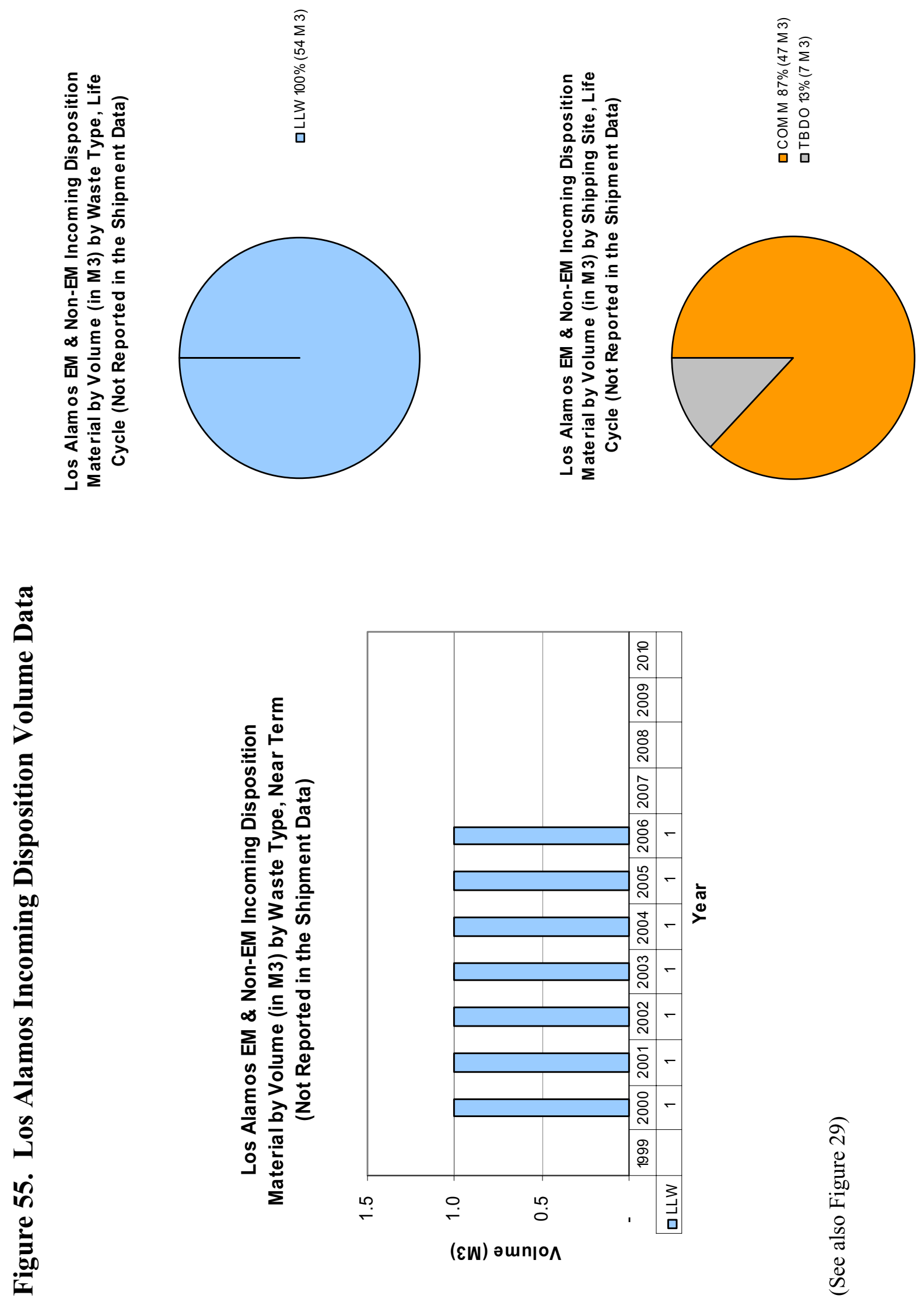

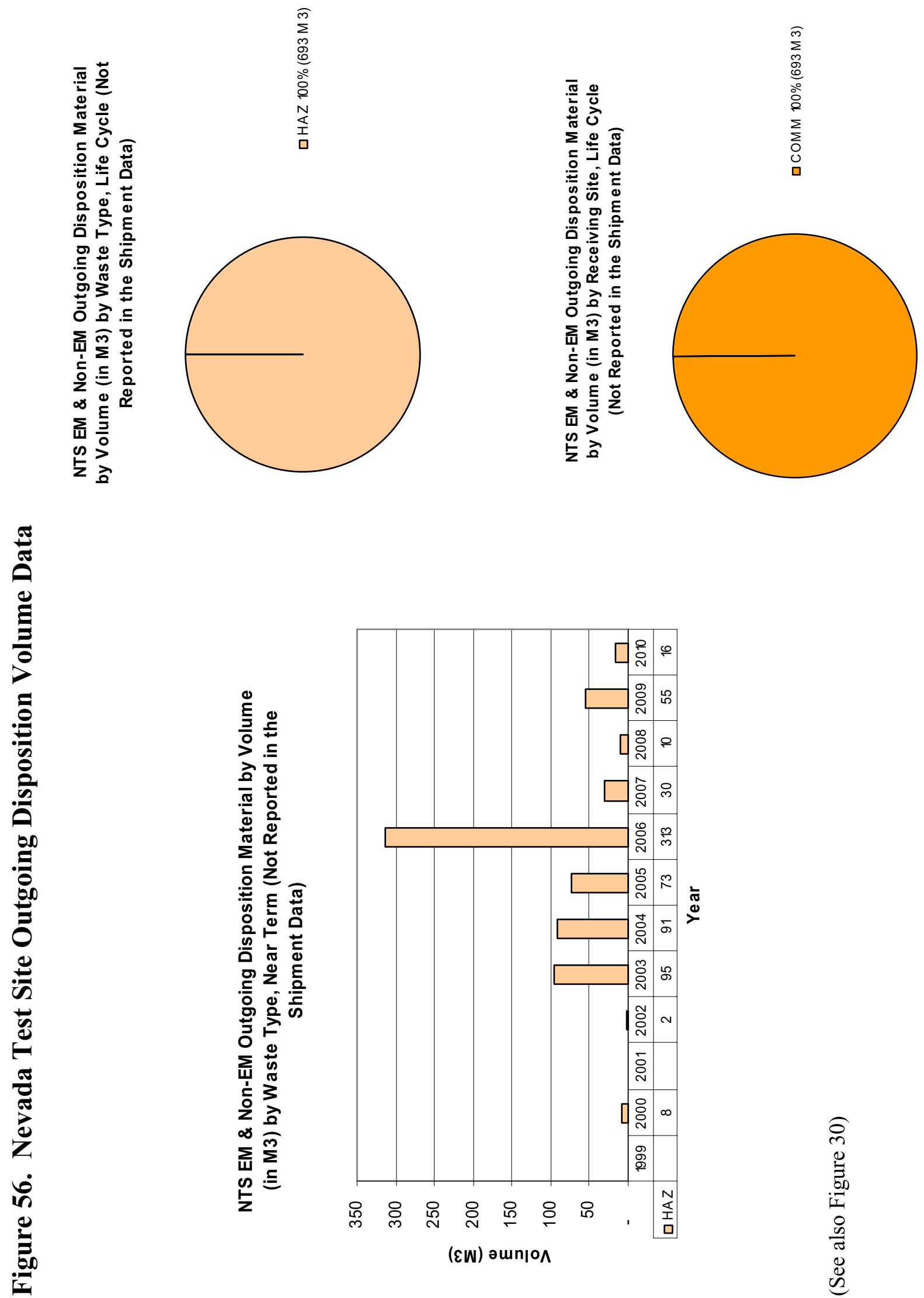

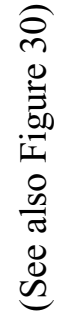



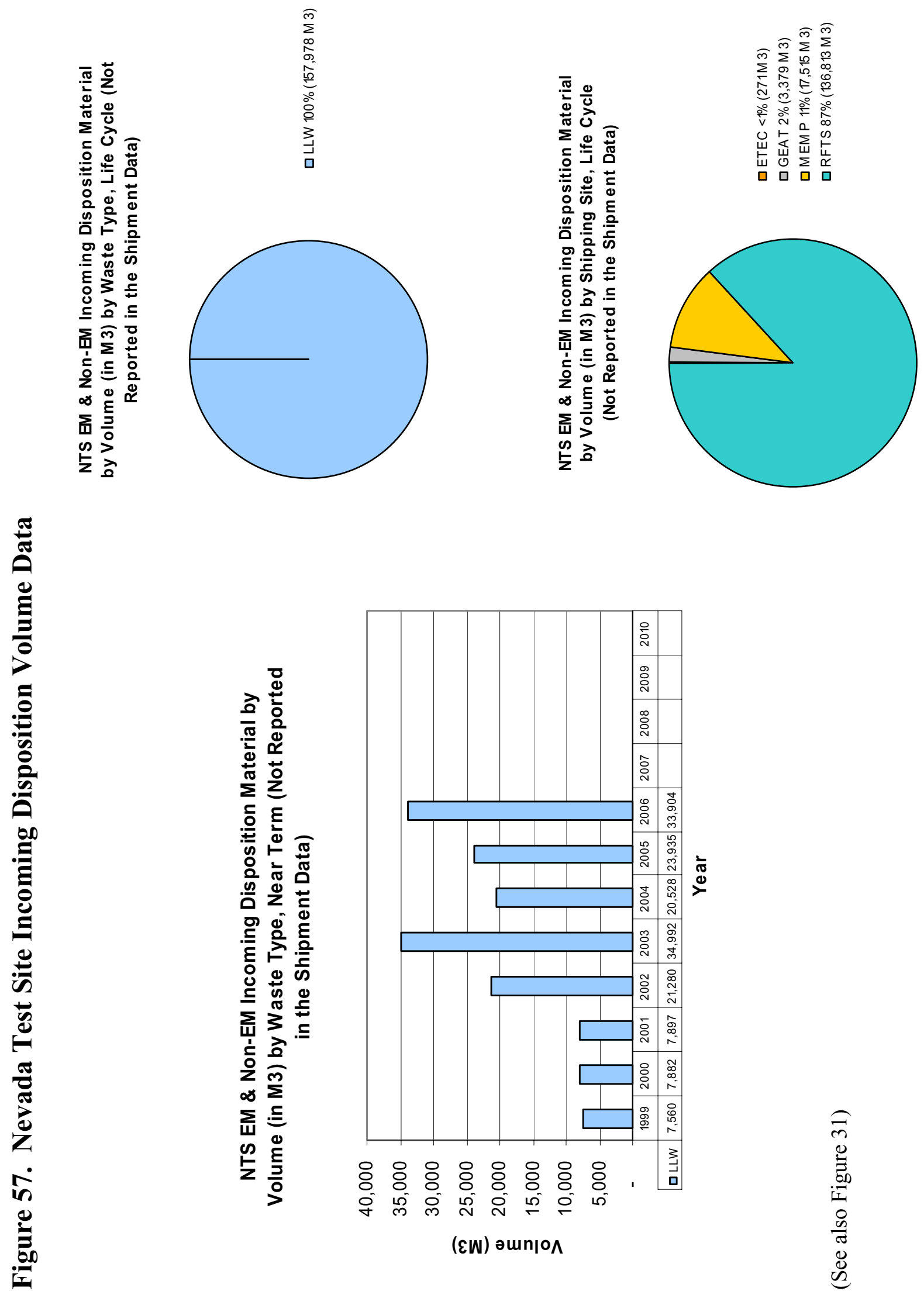

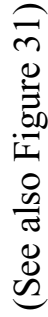



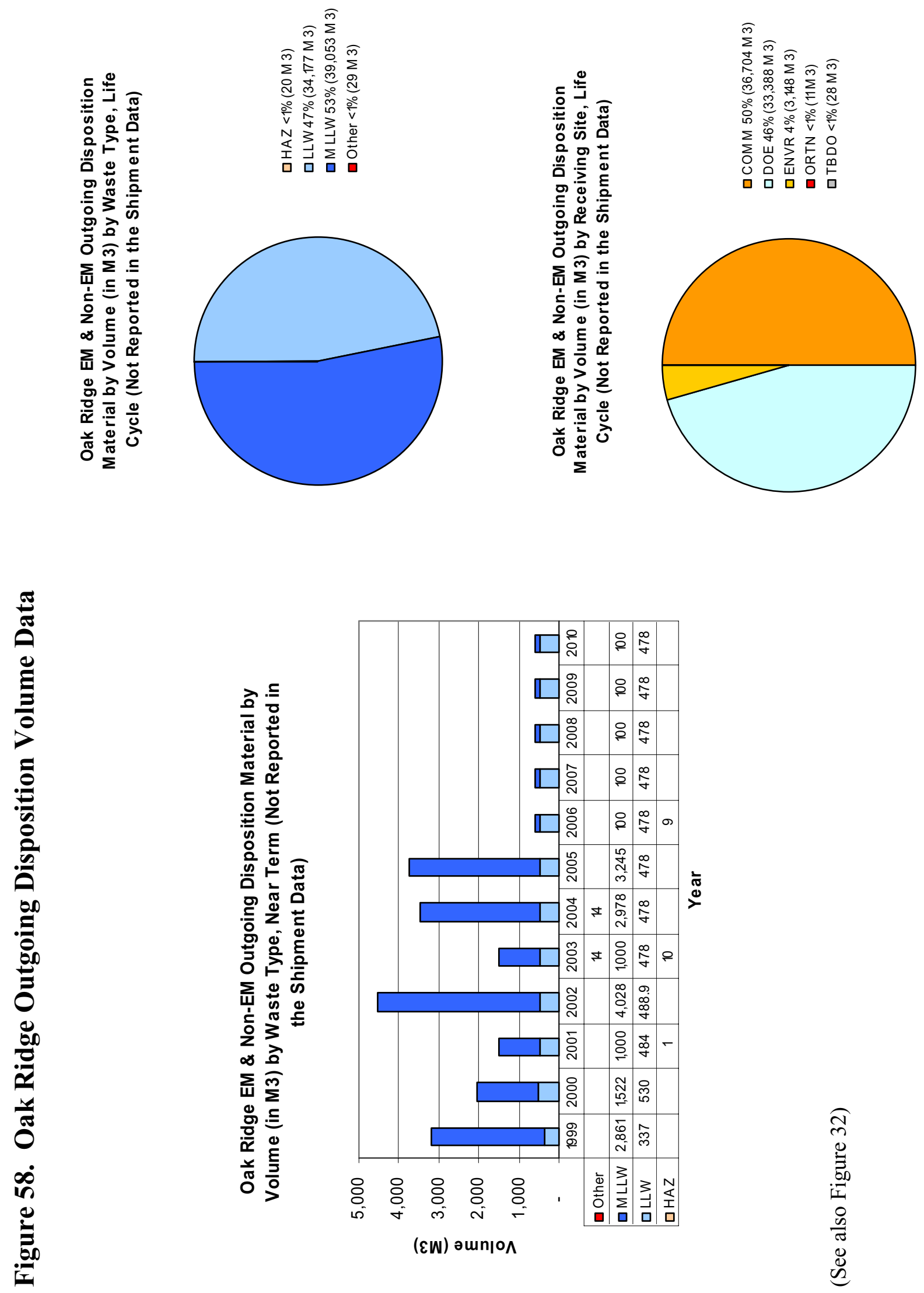

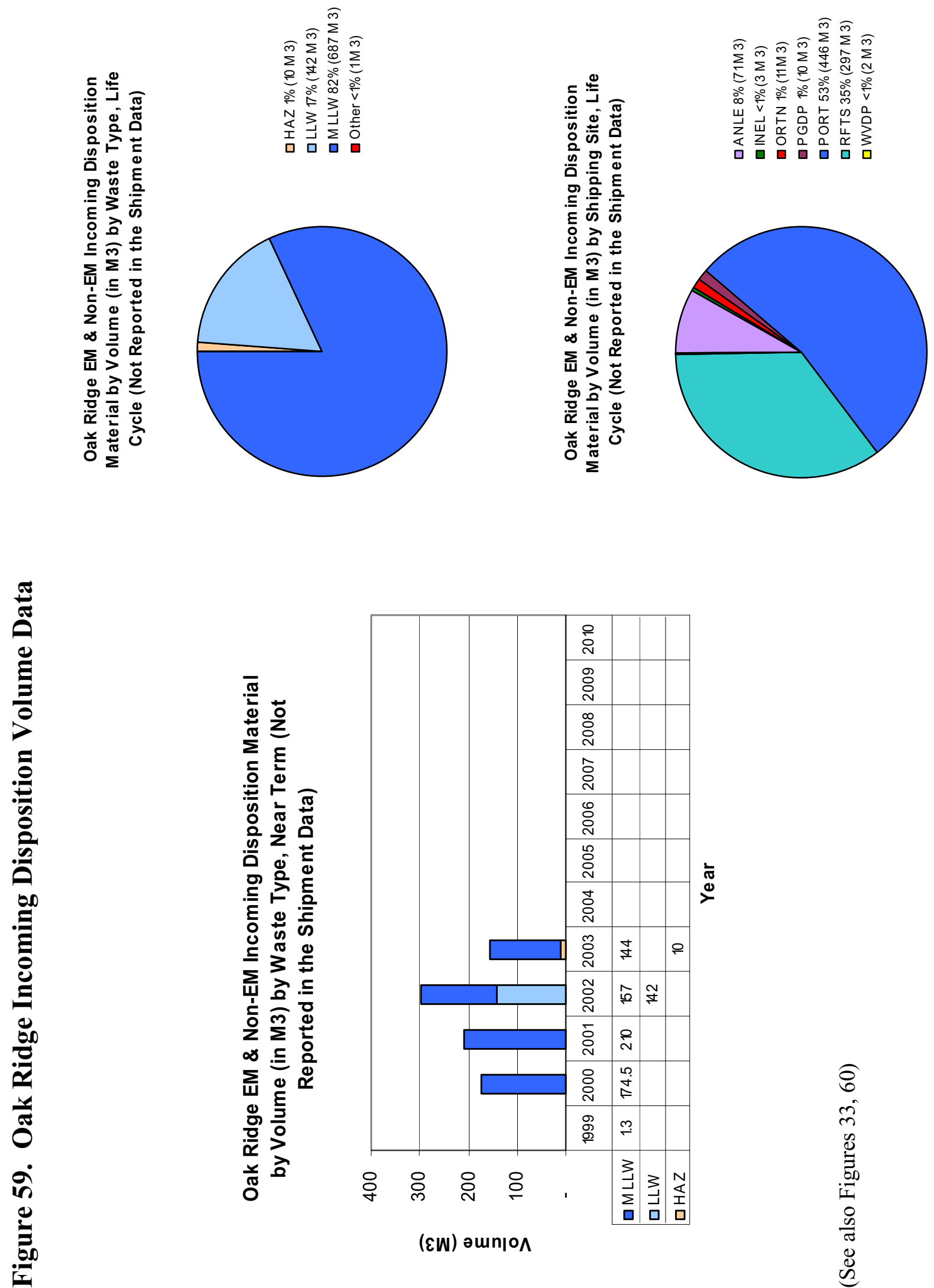

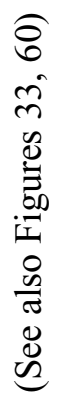



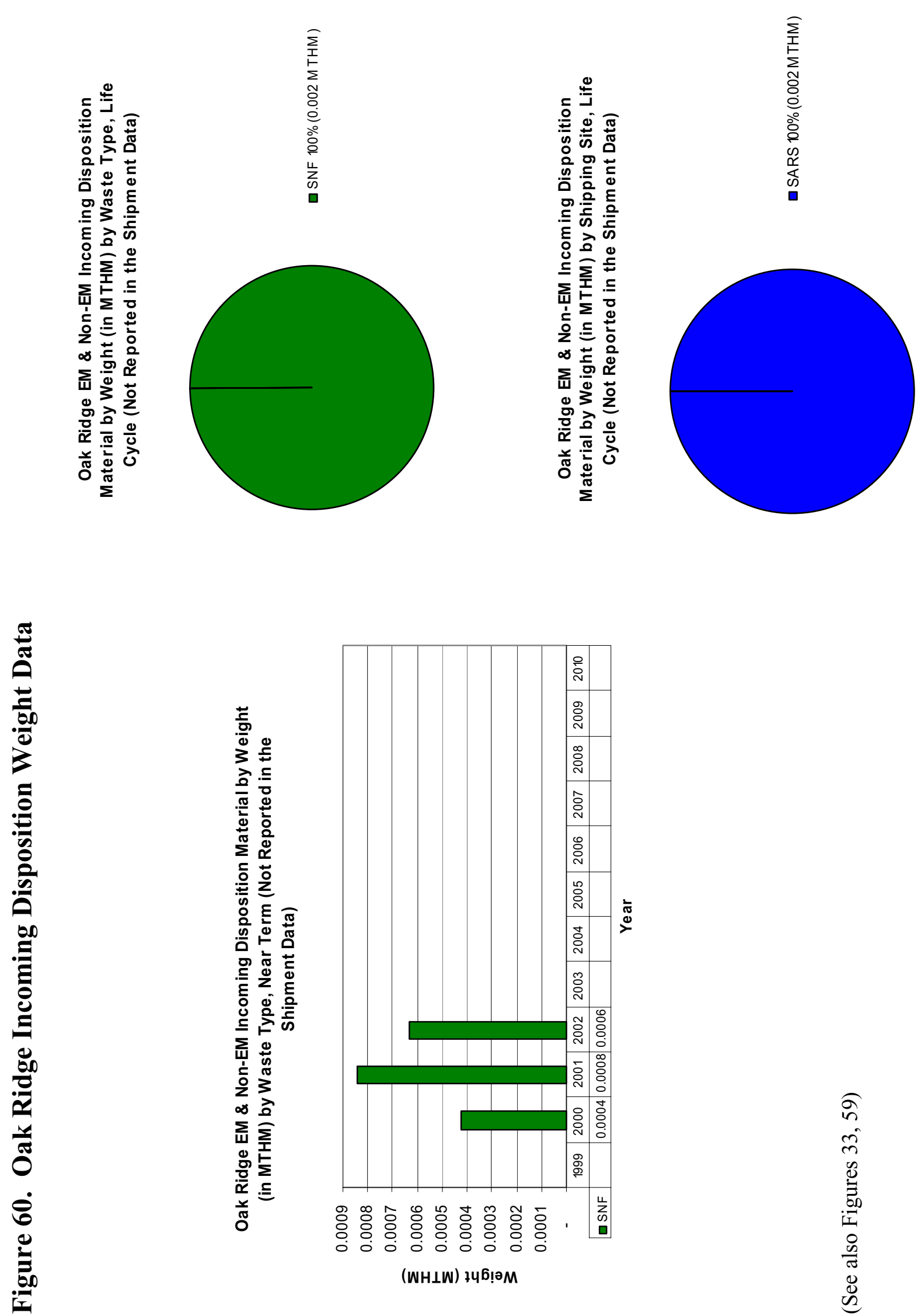

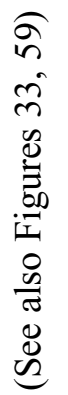



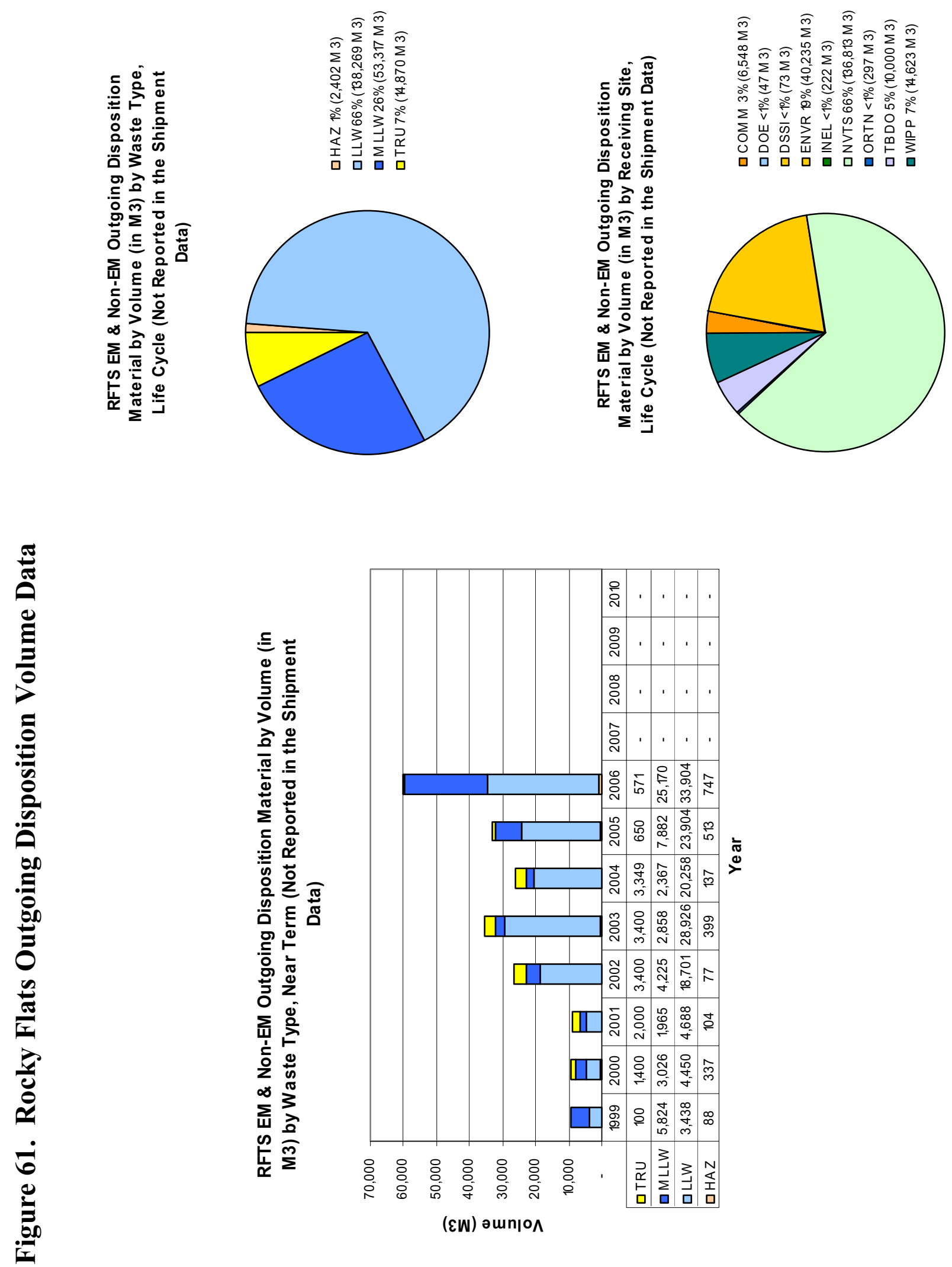


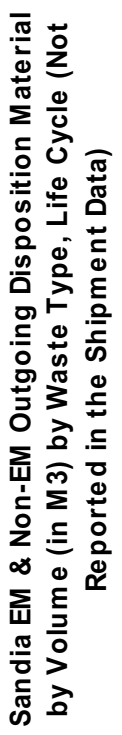

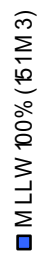

$\widehat{m} \sum_{\Sigma}^{m} \hat{m} \sum^{m}$
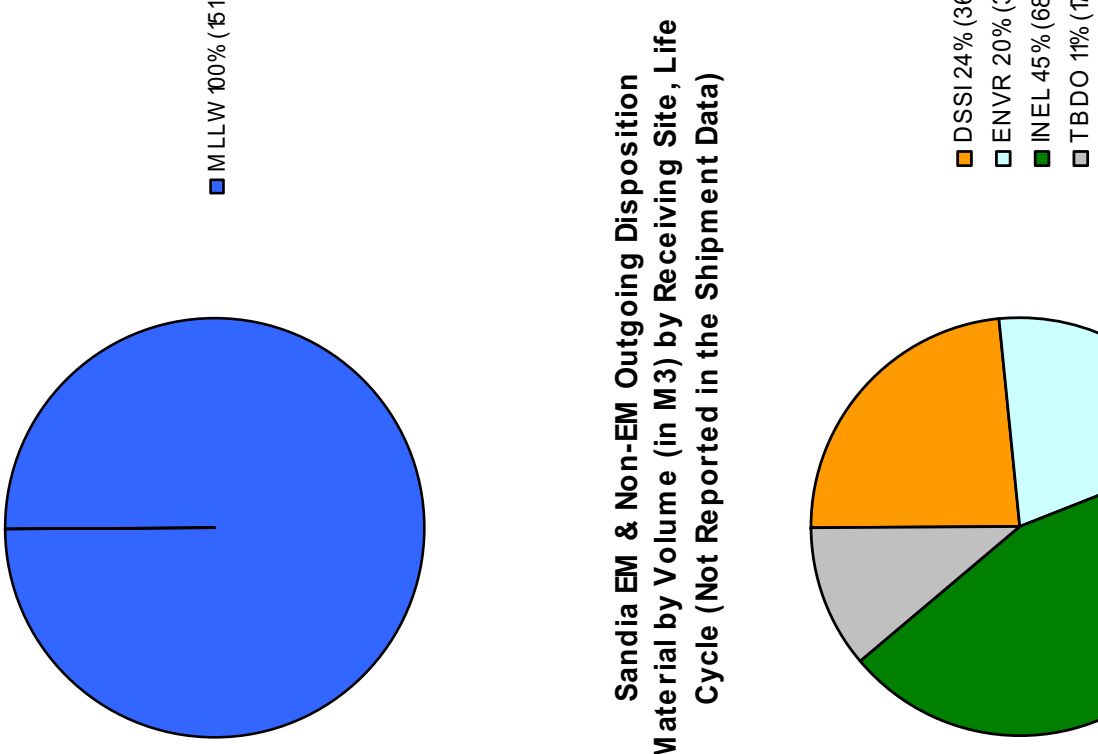

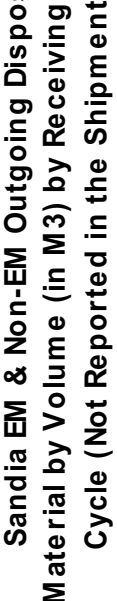

$\frac{1}{0}$
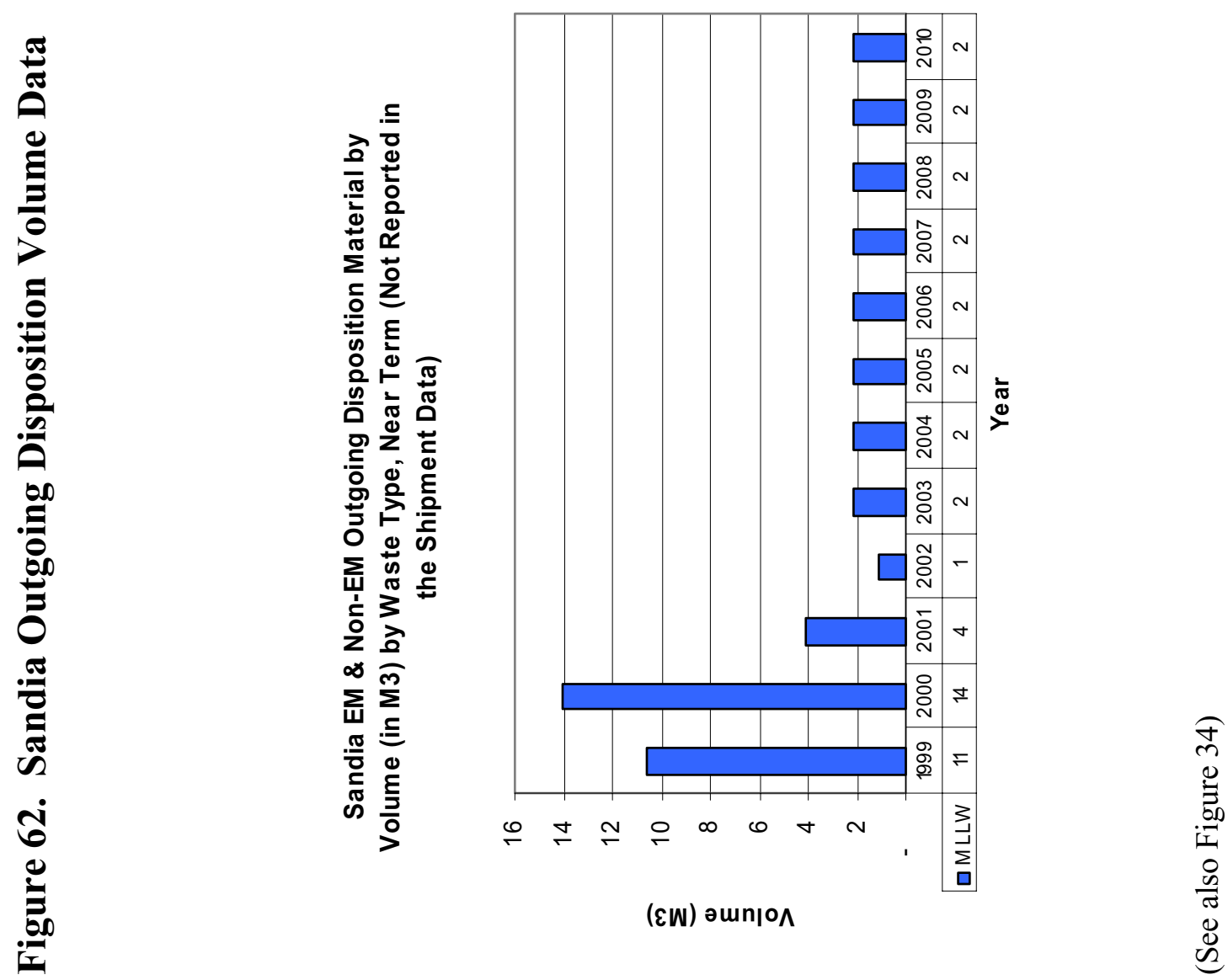

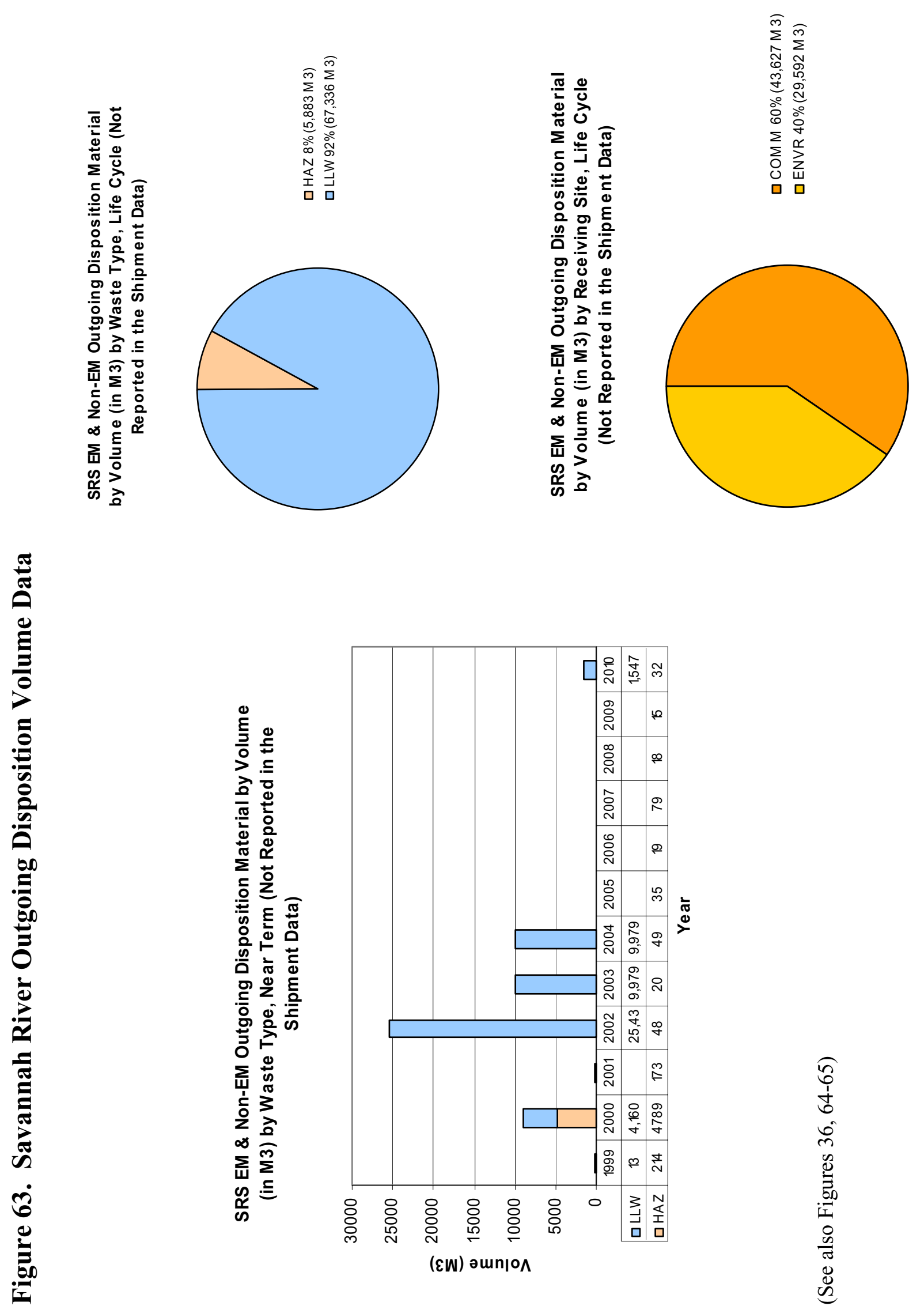

$\widehat{6}$
0
1
0
0
$n$
0
0
0
0
0
0
0
0
0
0
0
0 
즈응

交 $\frac{0}{0}$

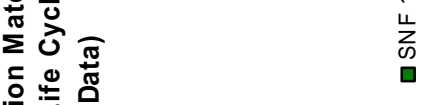

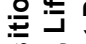

के

क⿺辶

垔

오을

伭全焉

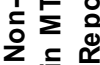

$\infty$

㐫

品

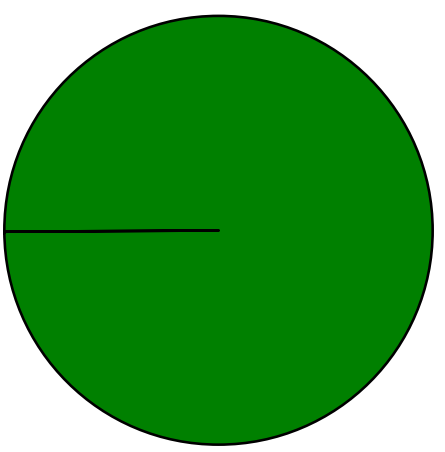

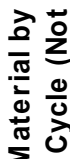

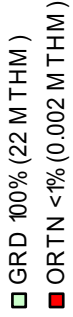

$\frac{9}{3}$
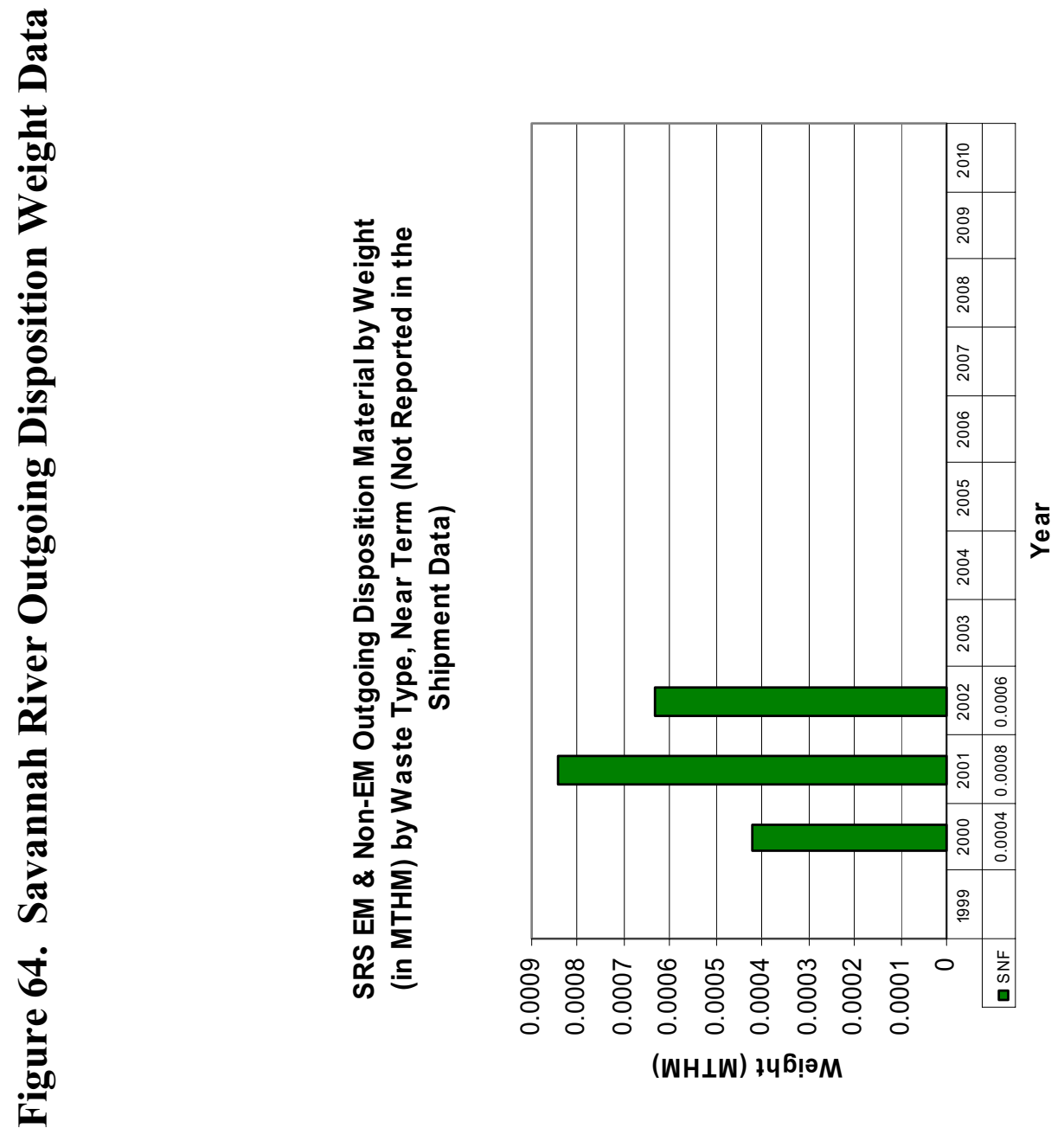

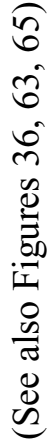



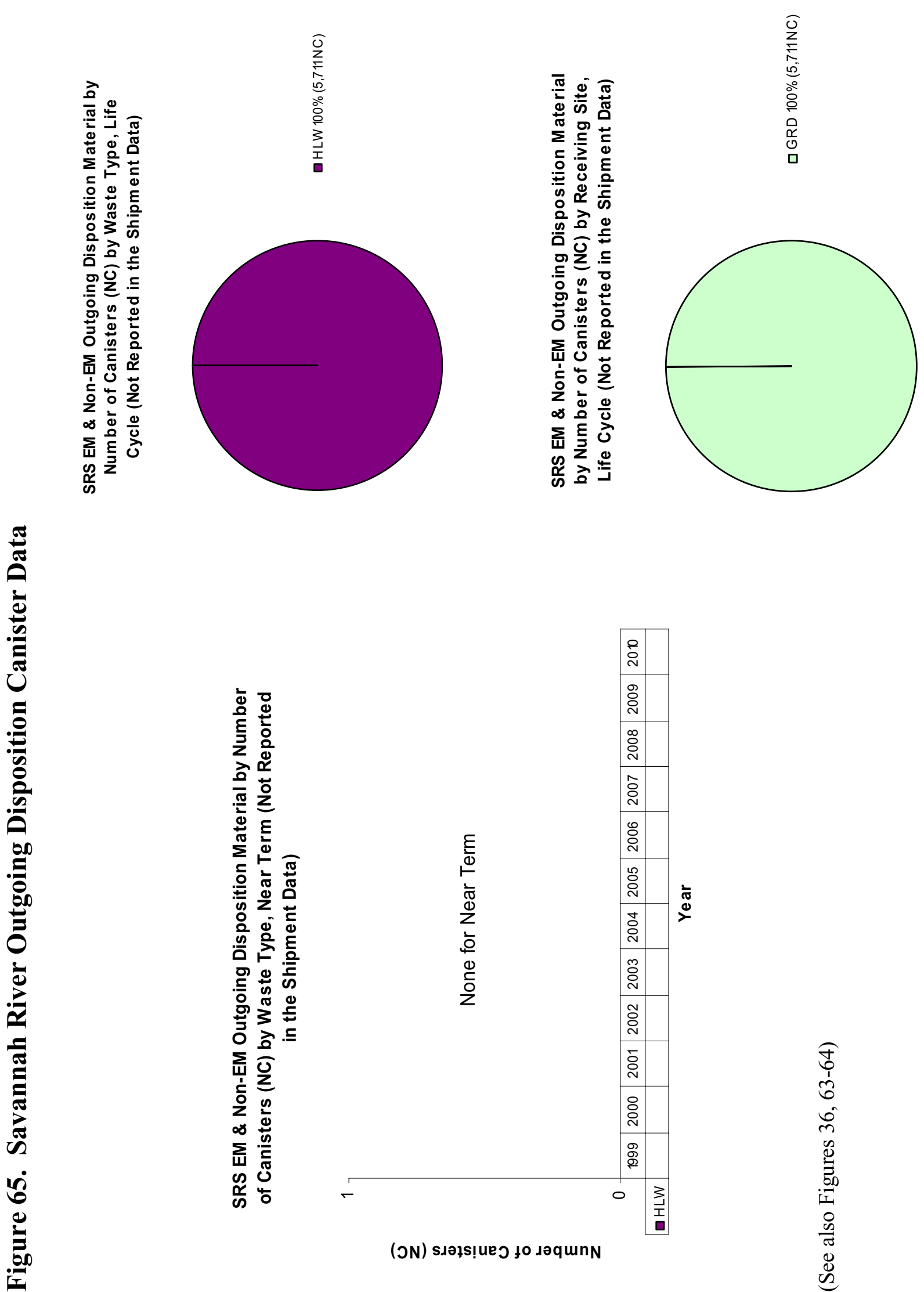

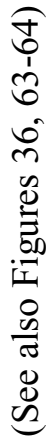



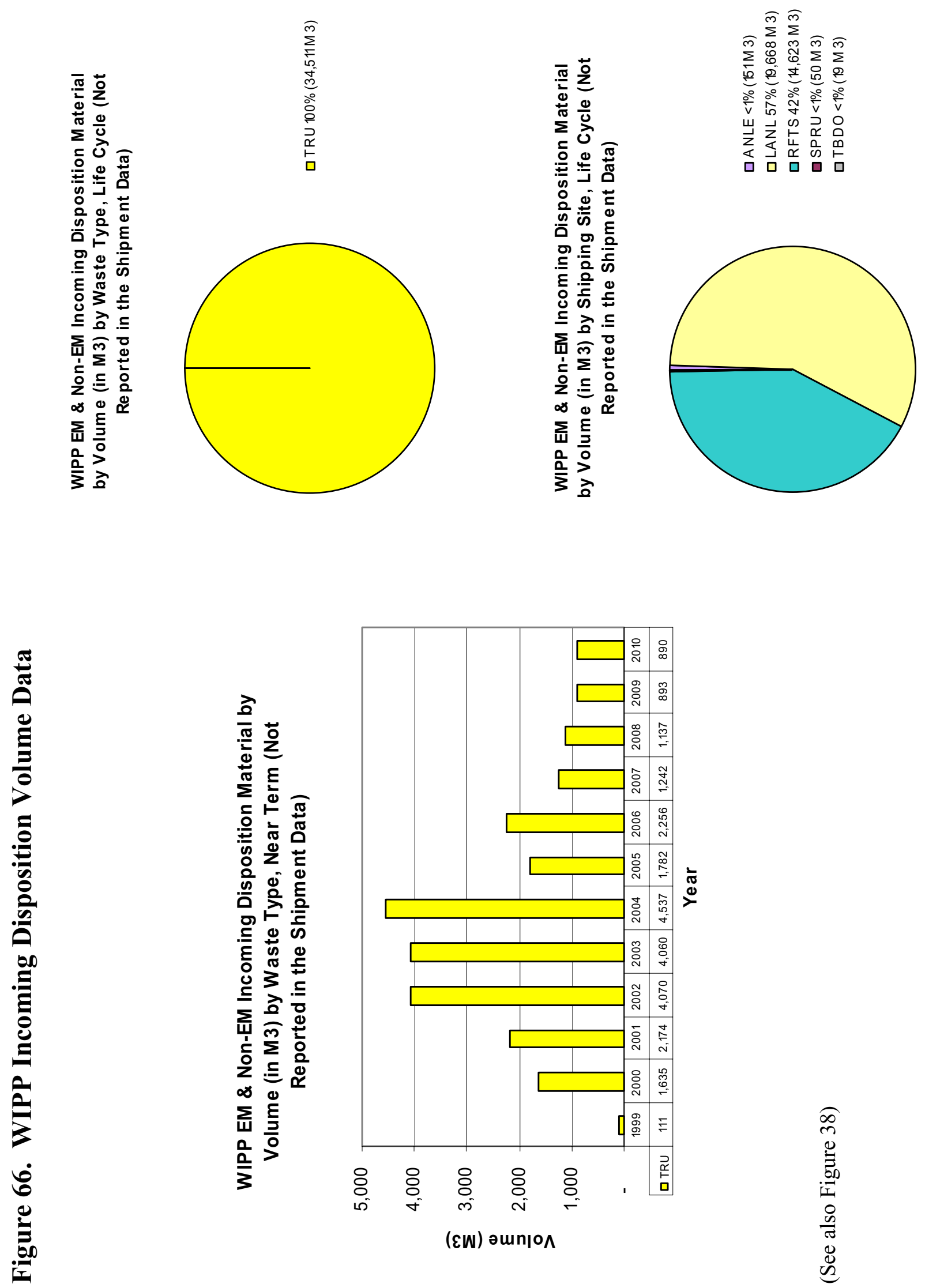

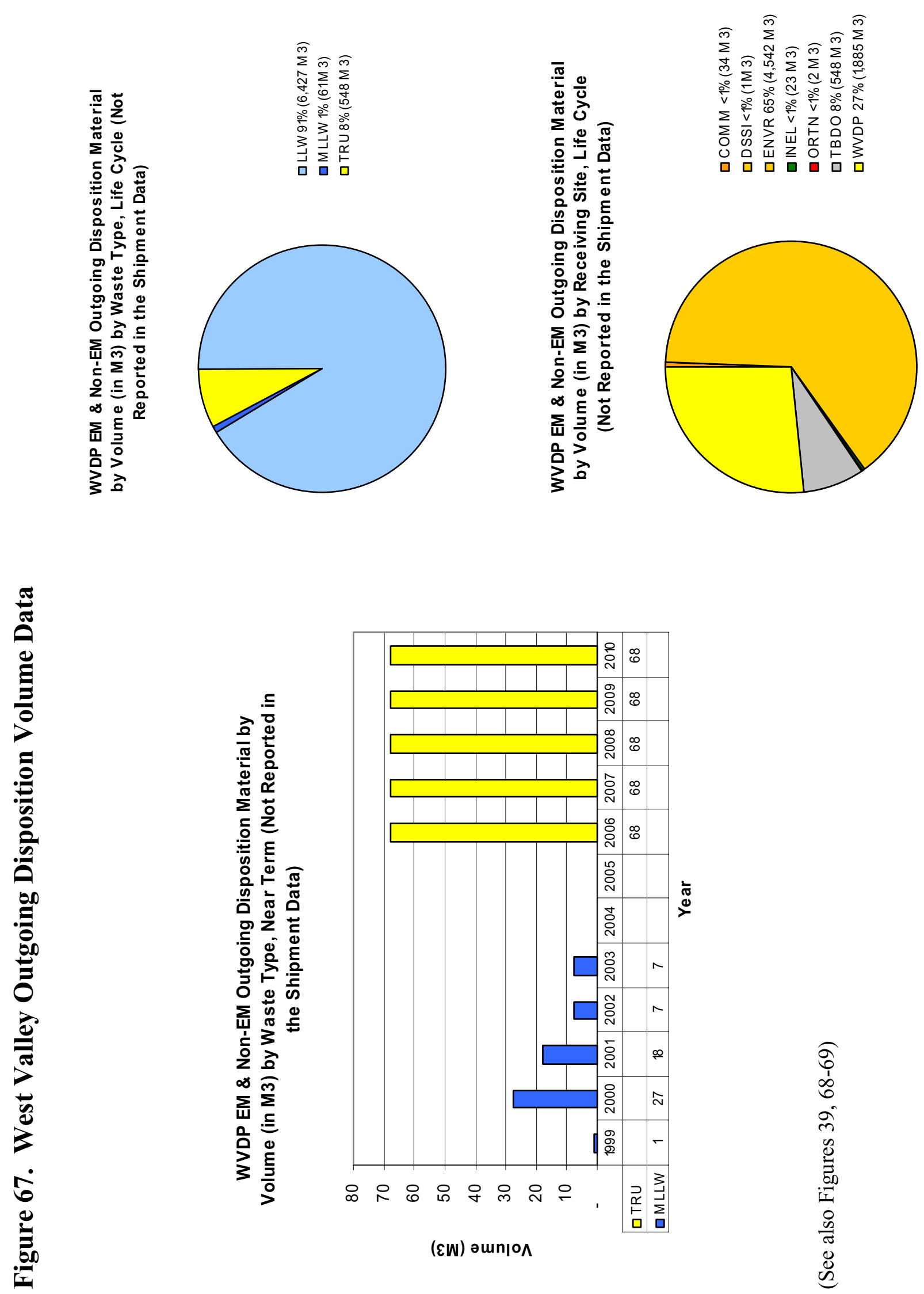


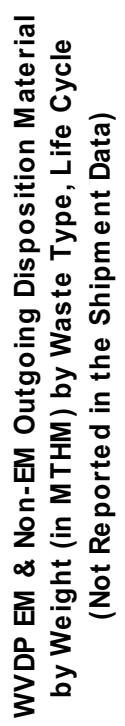

产 $\frac{0}{0}$

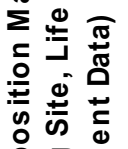

응 올

高

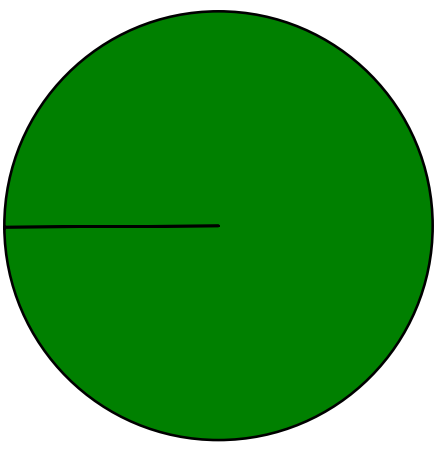

용 क

등 용

온를

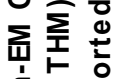

호

$z \leqq \nsubseteq$

会志苍

응

引
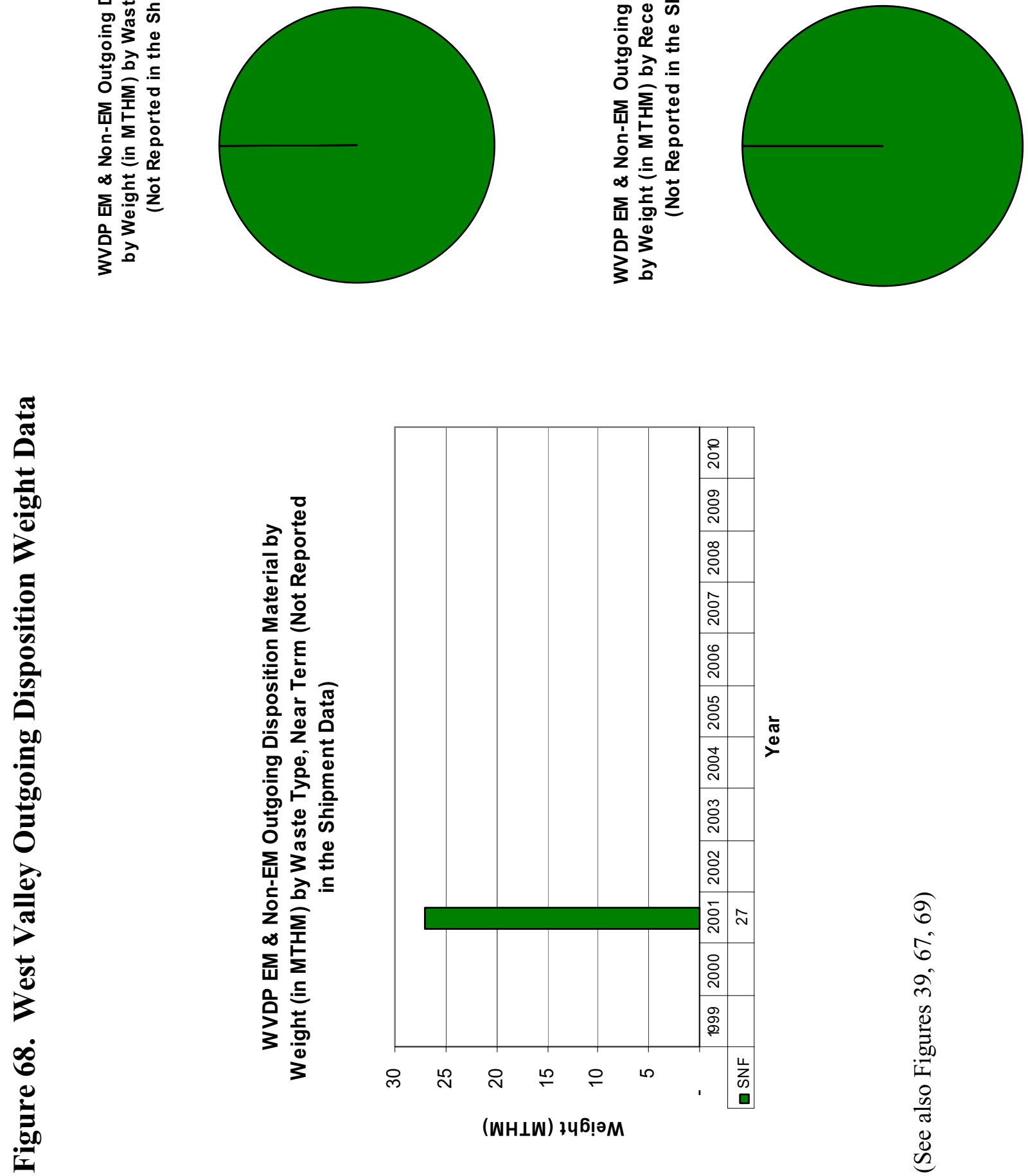

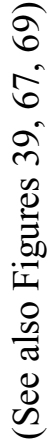



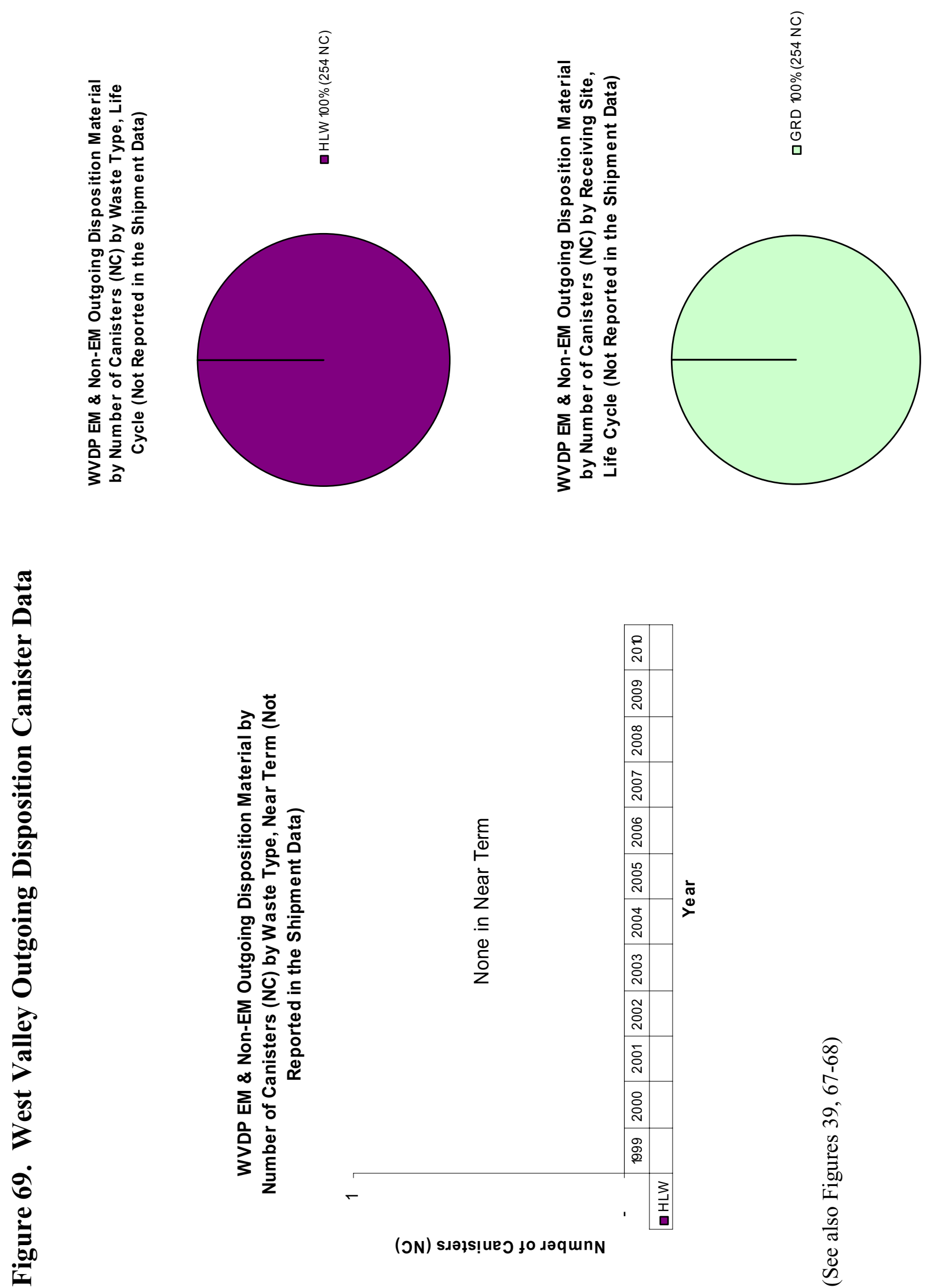

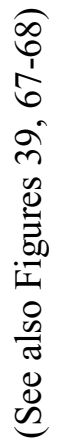



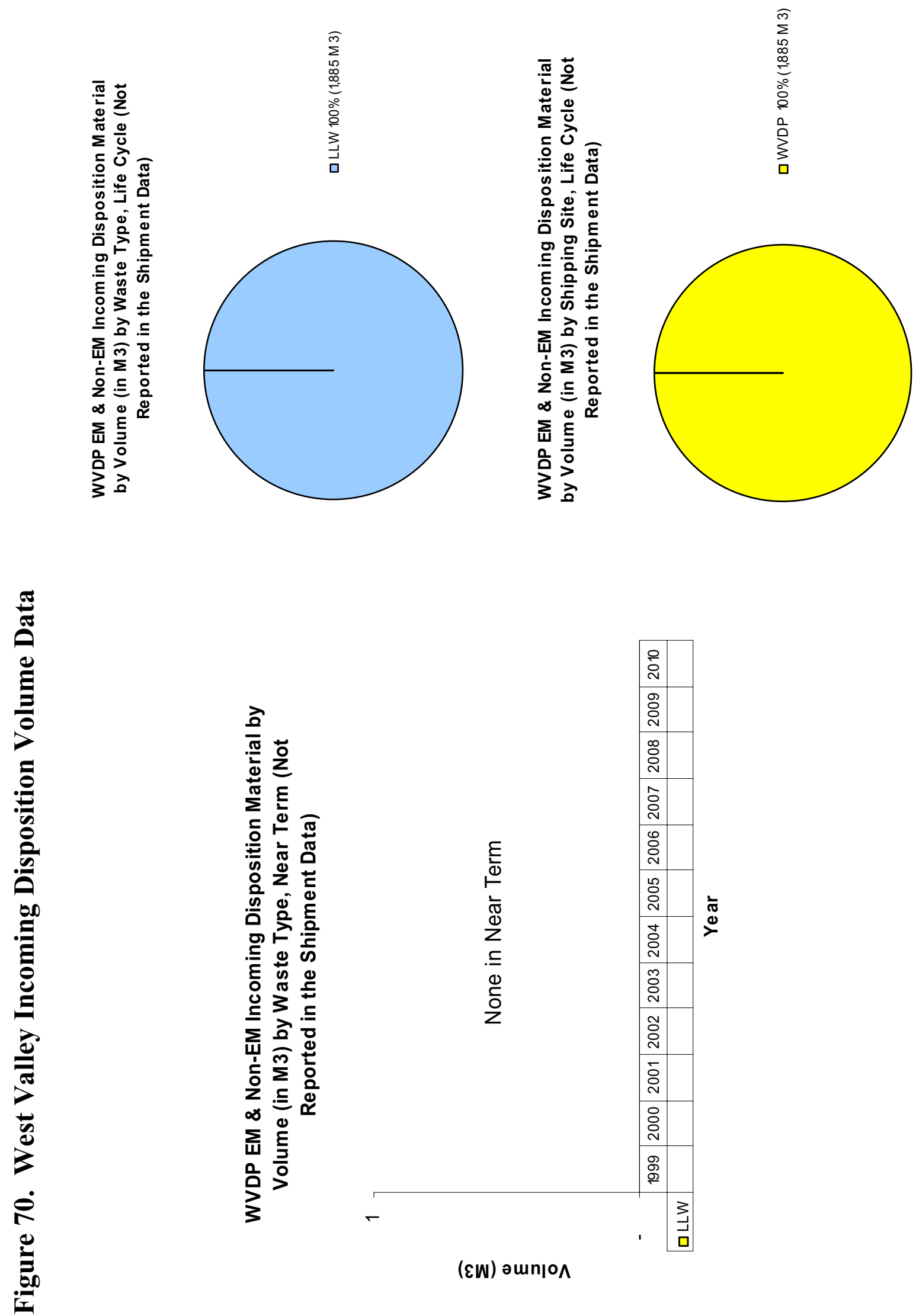

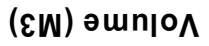




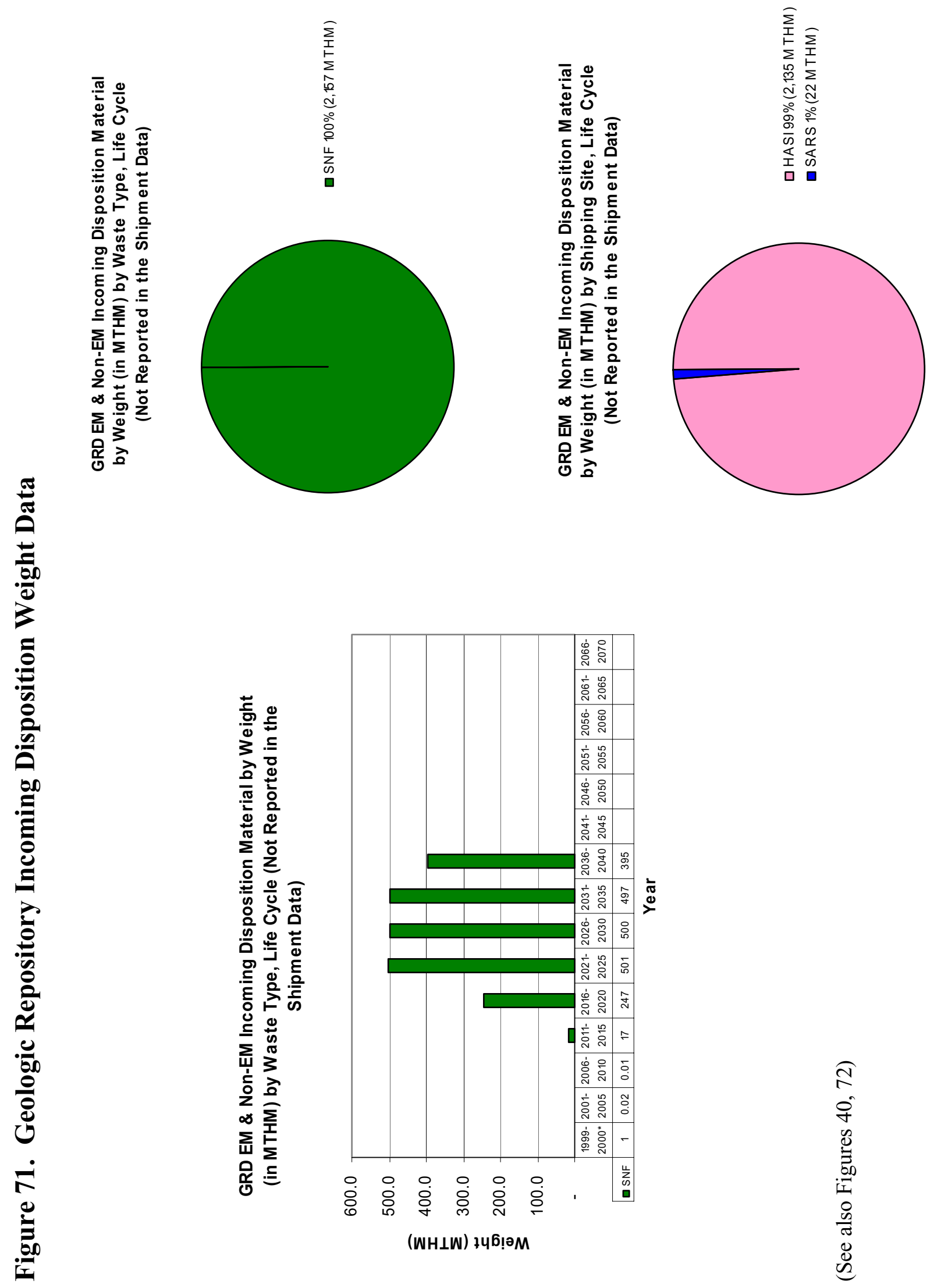


ปั

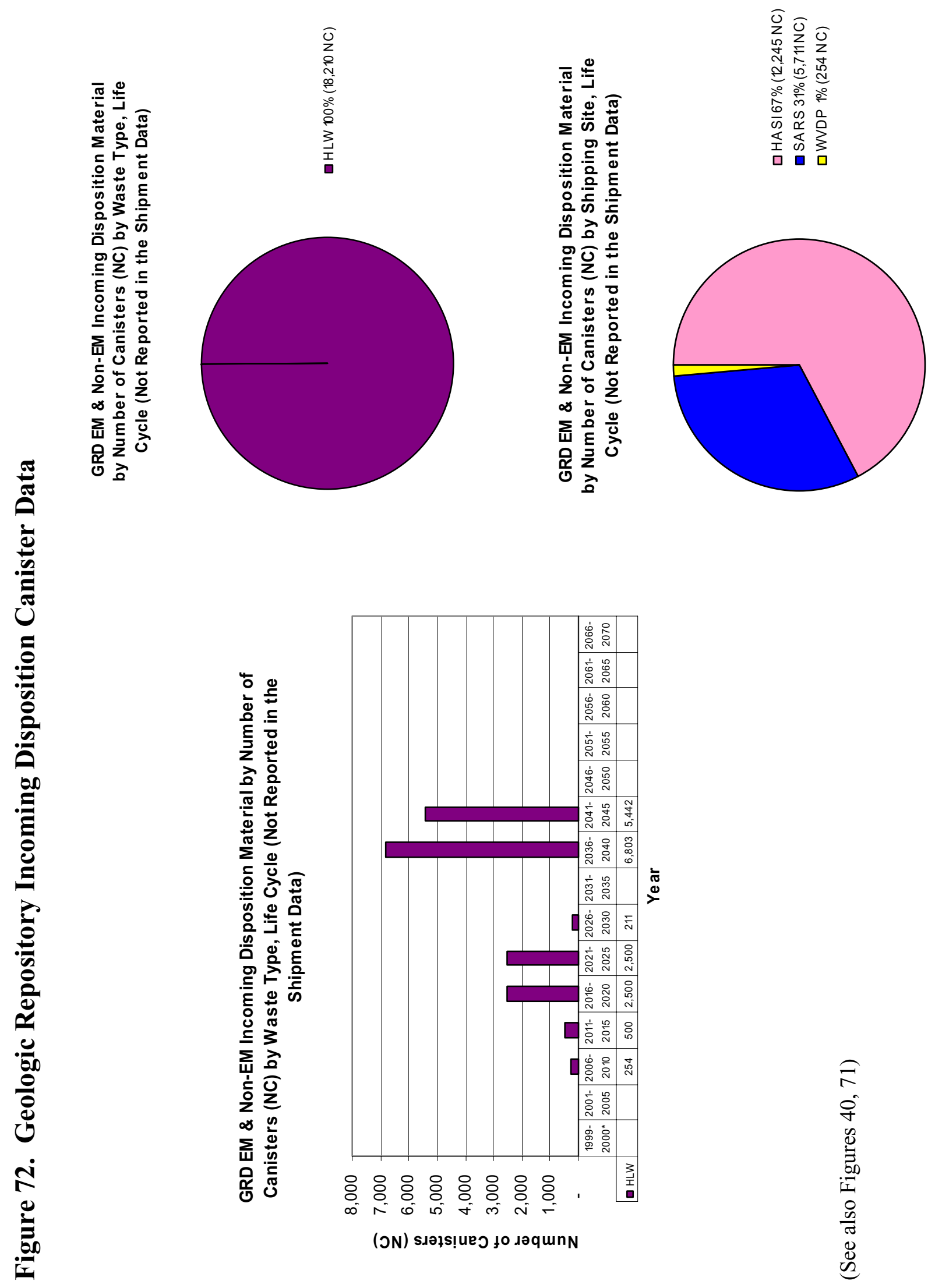



Appendix D

TBD Data 

Figure 73.

\section{Comparison between Shipments to/from "Known" Sites verses Shipments to/from "Unknown" (TBD) Sites, \\ Near Term}

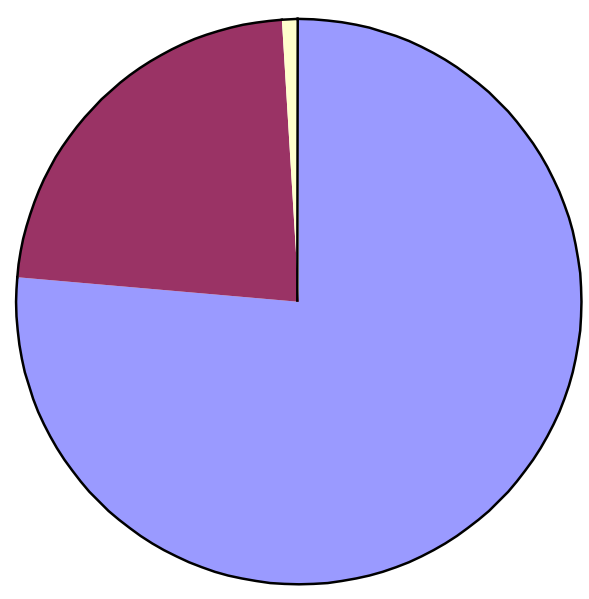

$\square$ Known to Known $76 \%(53,993)$

$\square$ Known to TBD 23\% $(16,185)$

$\square$ TBD to Known $1 \%(563)$

$\square \mathrm{TBD}$ to $\mathrm{TBD}<1 \%(10)$

Figure 74.

Comparison between Shipments to/from "Known" Sites verses Shipments to/from "Unknown" (TBD) Sites,

Life Cycle

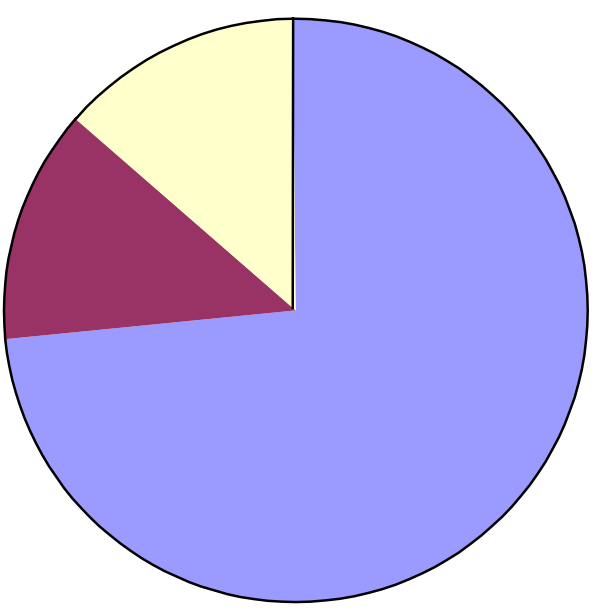

口Known to Known $73 \%(104,417)$

$\square$ Known to TBD $13 \%(18,592)$

$\square$ TBD to Known $14 \%(19,449)$

$\square \mathrm{TBD}$ to $\mathrm{TBD}<1 \%(16)$ 



\section{Appendix E}

\section{Transportation Baseline Schedule Example Graphics}





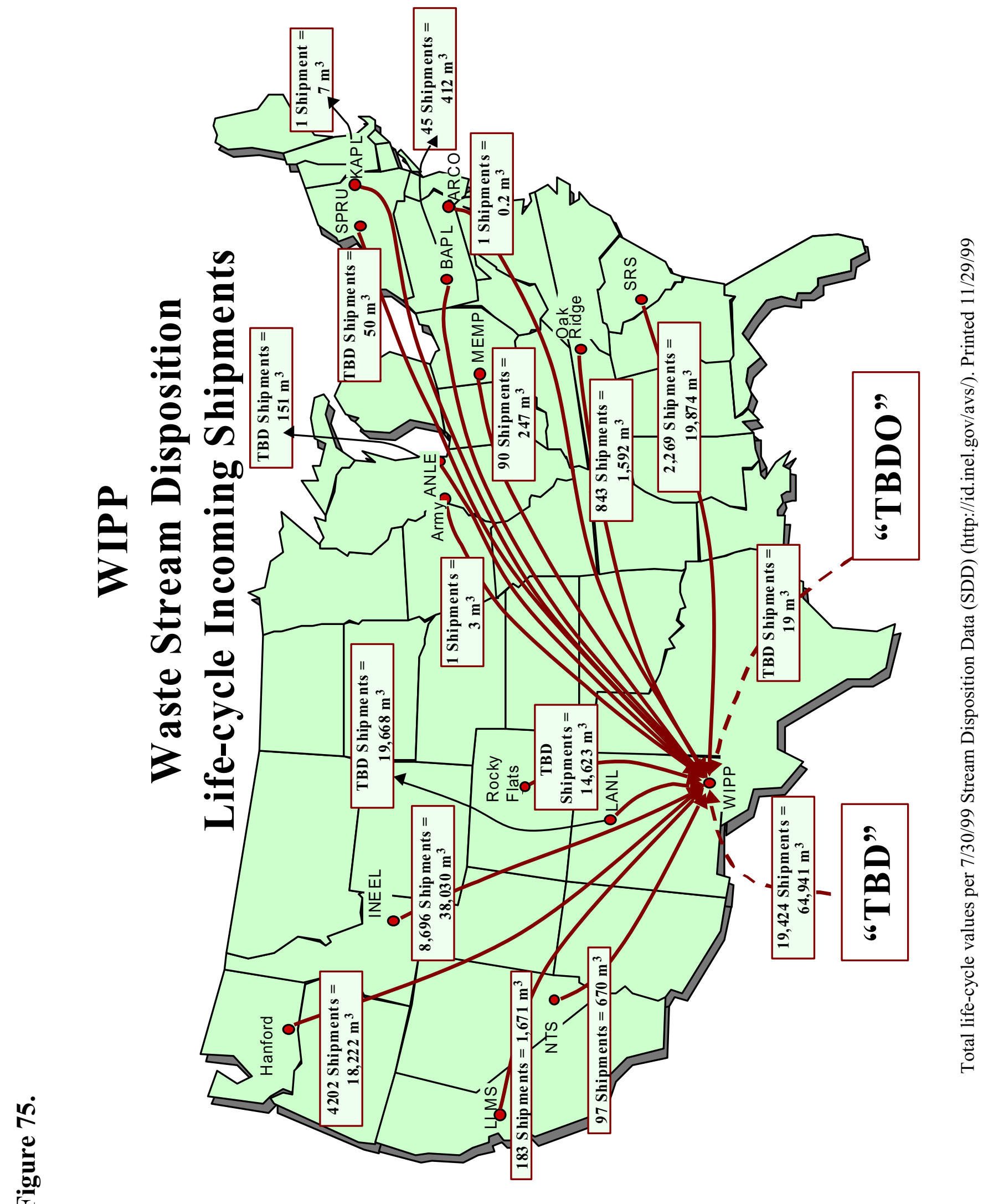



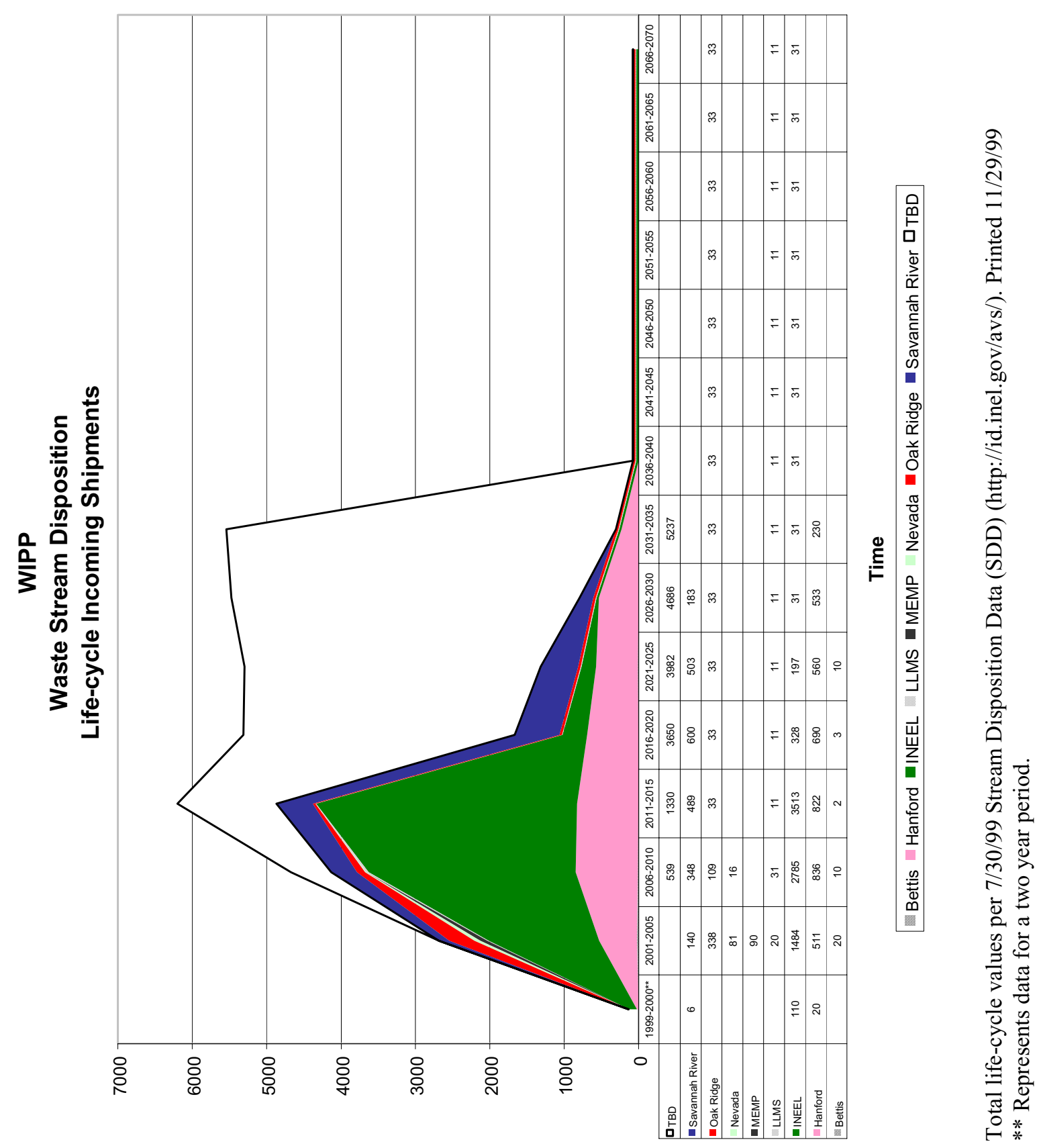

$\underset{1}{0}$ 

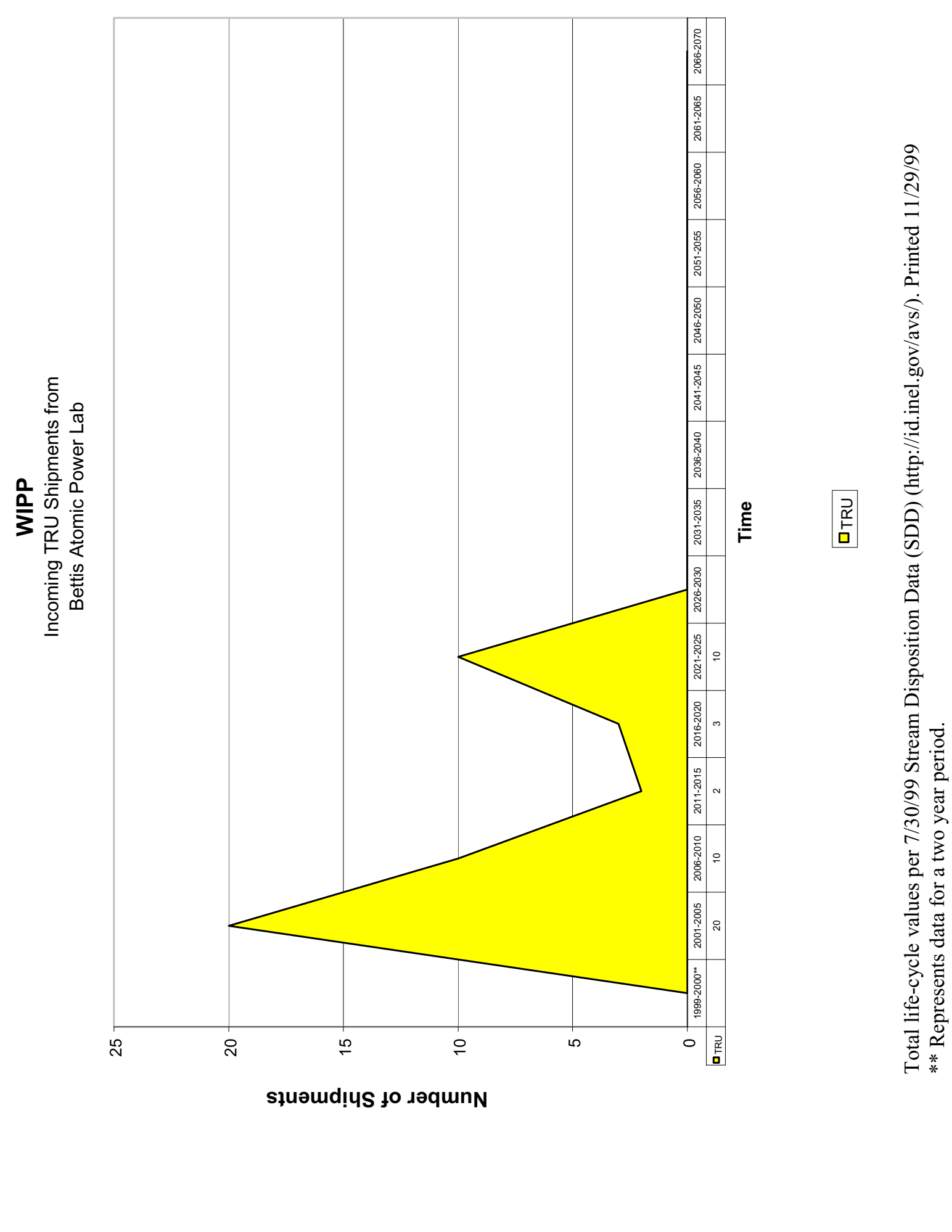

N 

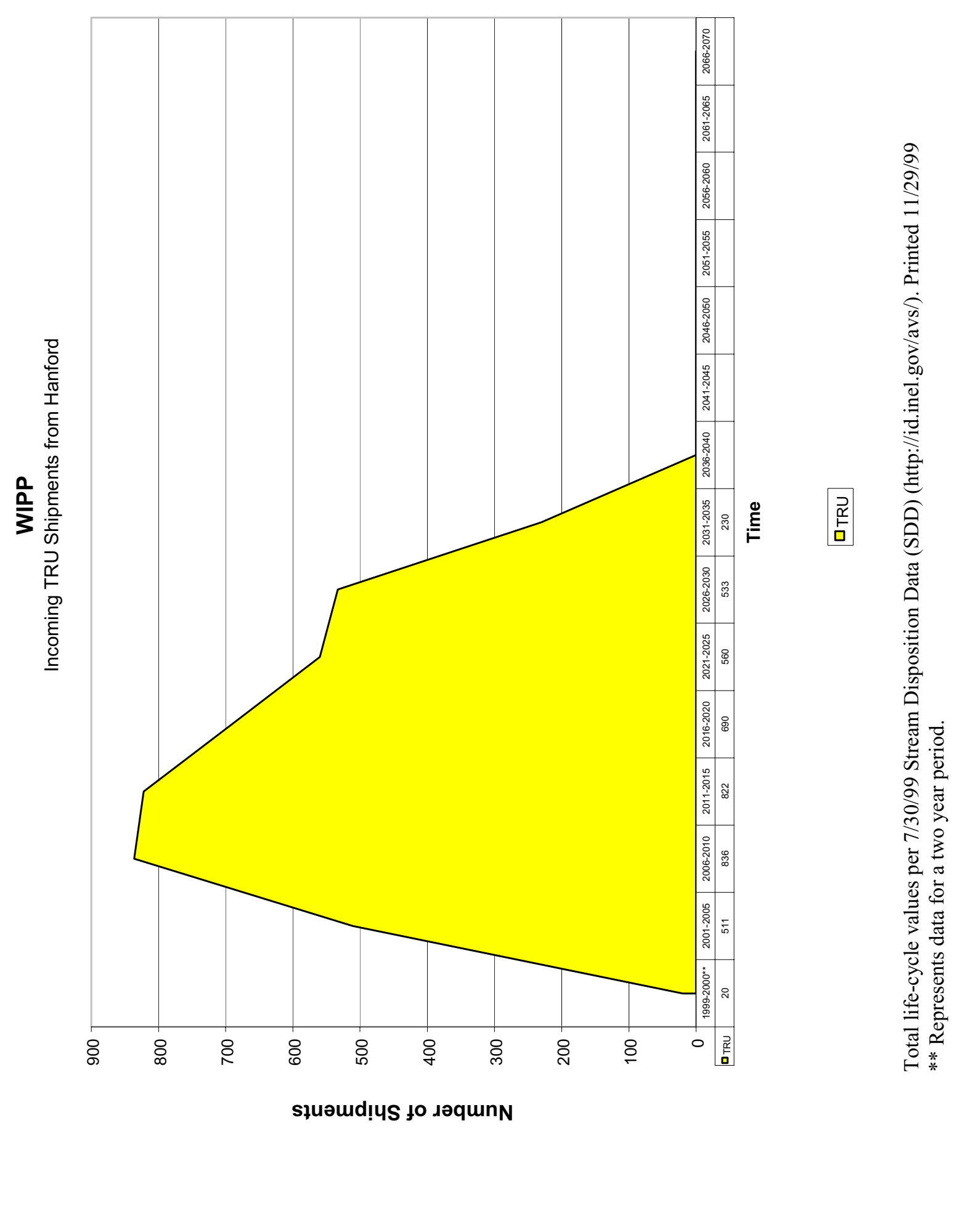

赵 

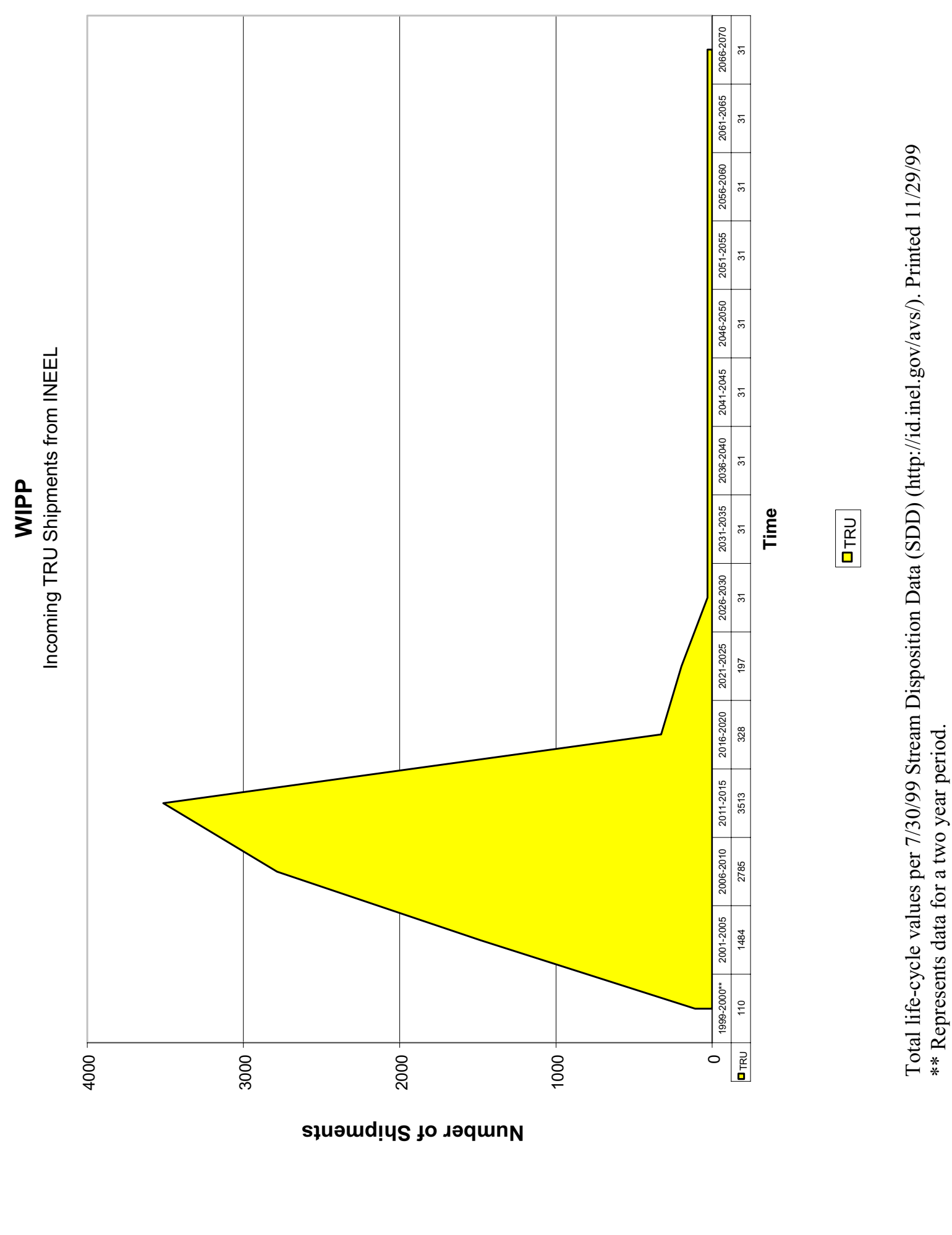

 

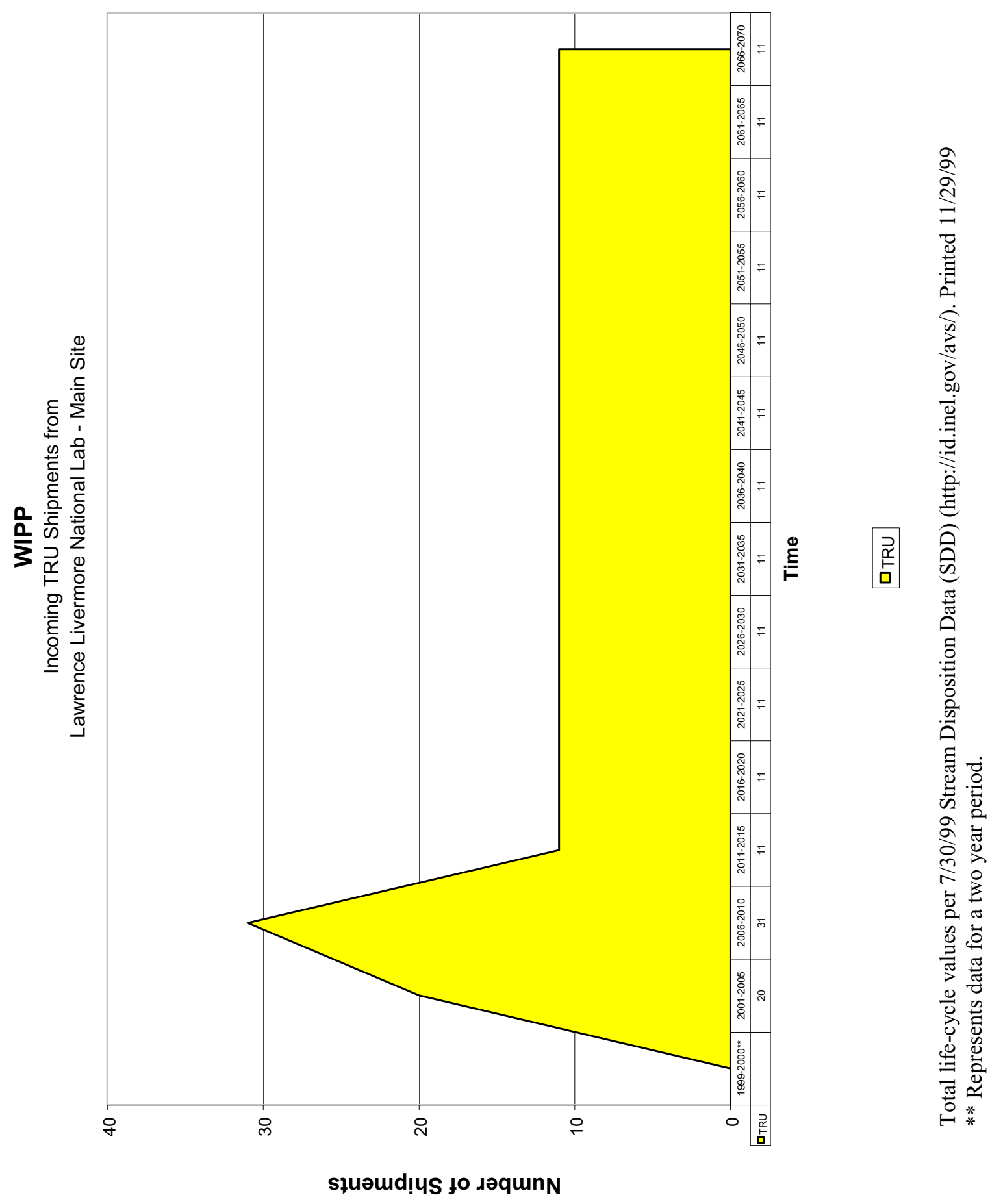

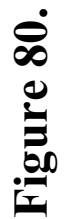


I

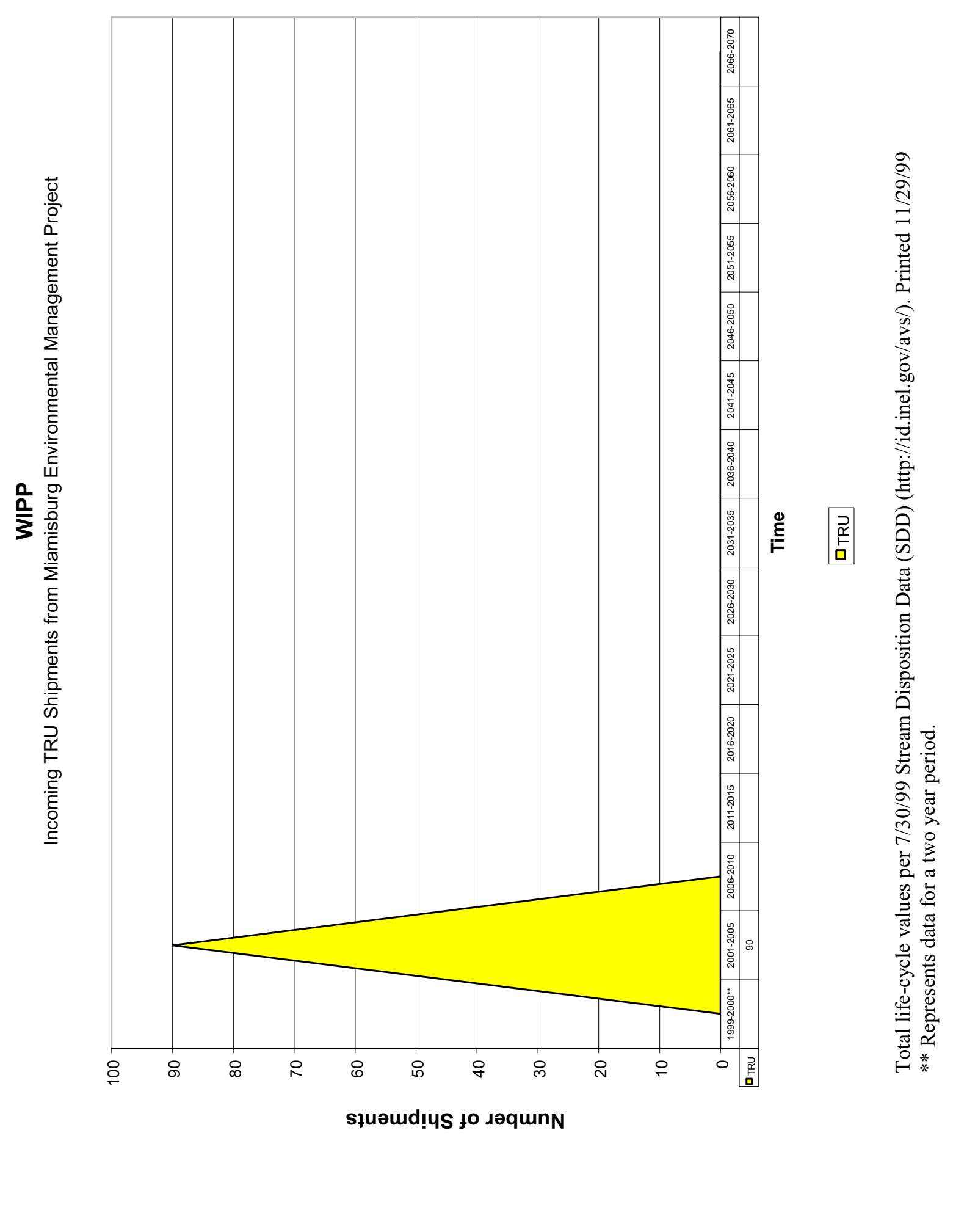



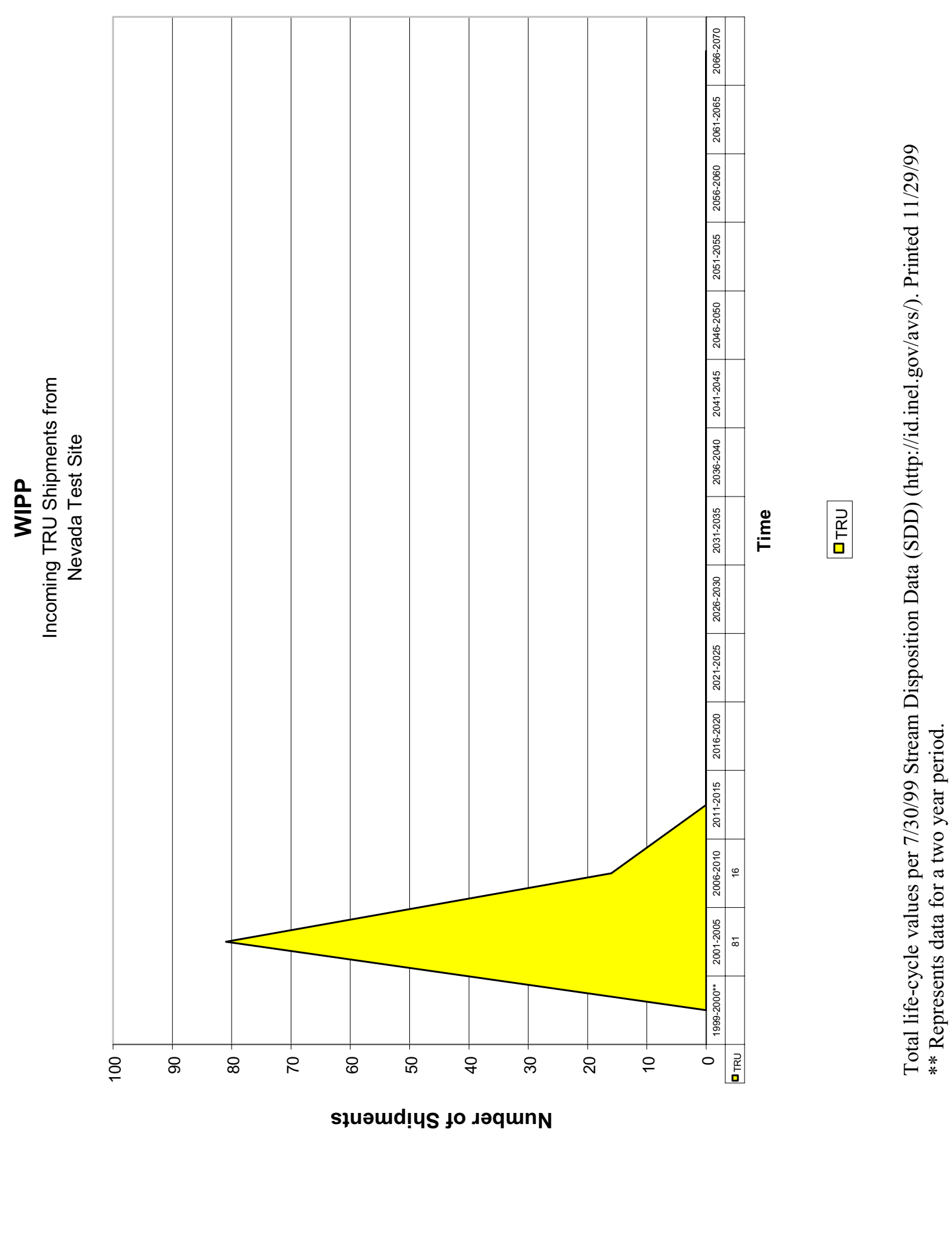

๙ీ 

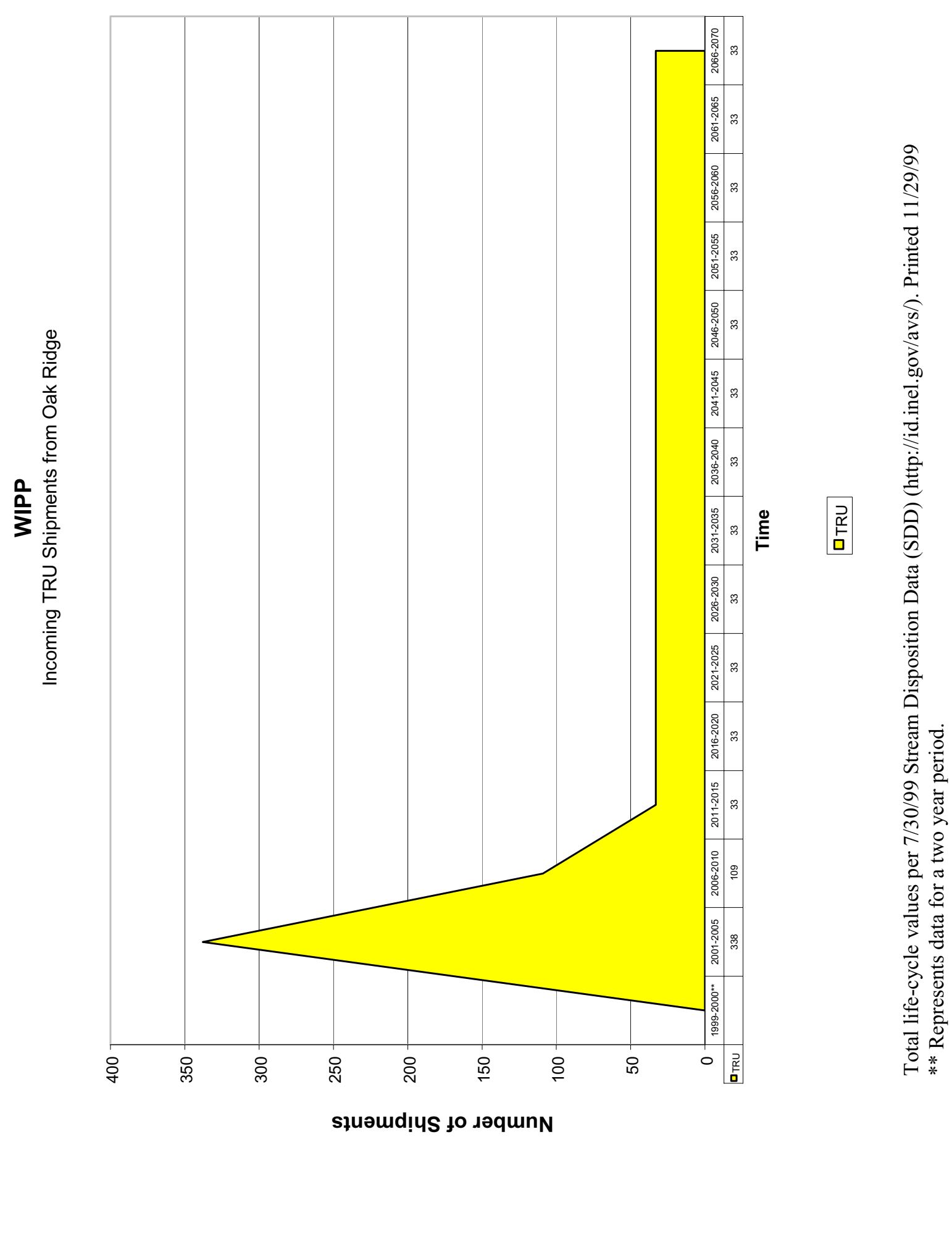

$\infty_{0}^{\infty}$ 

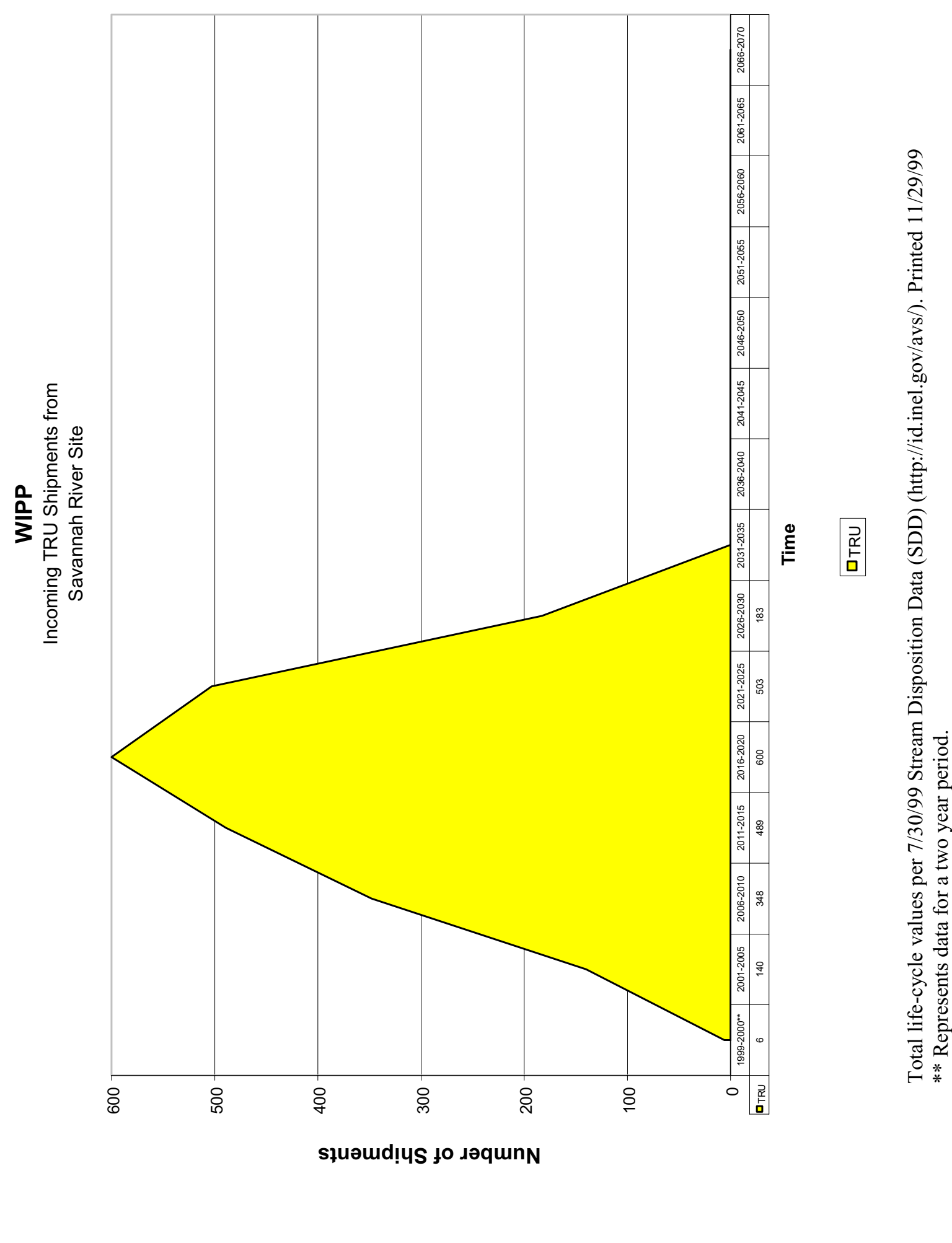

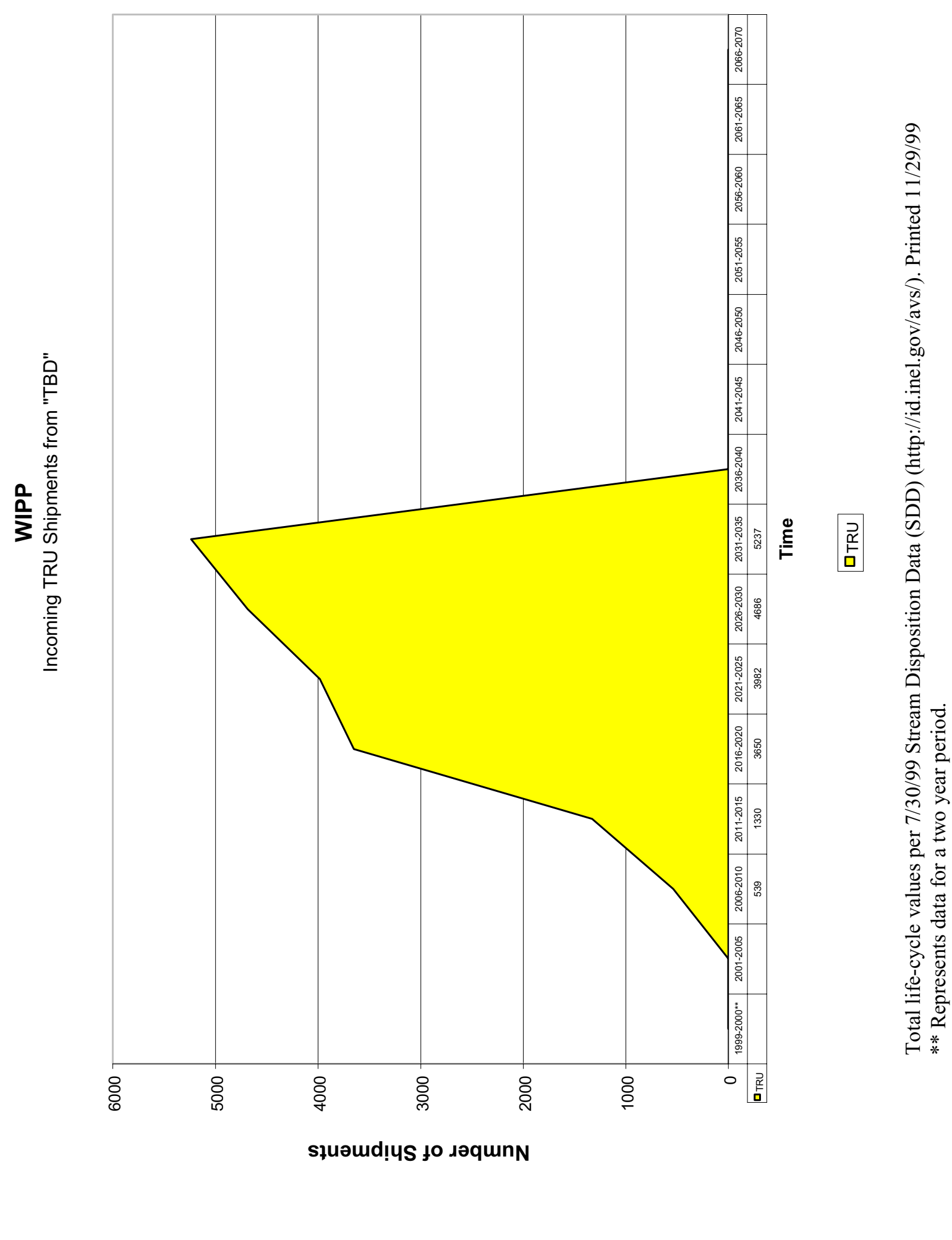


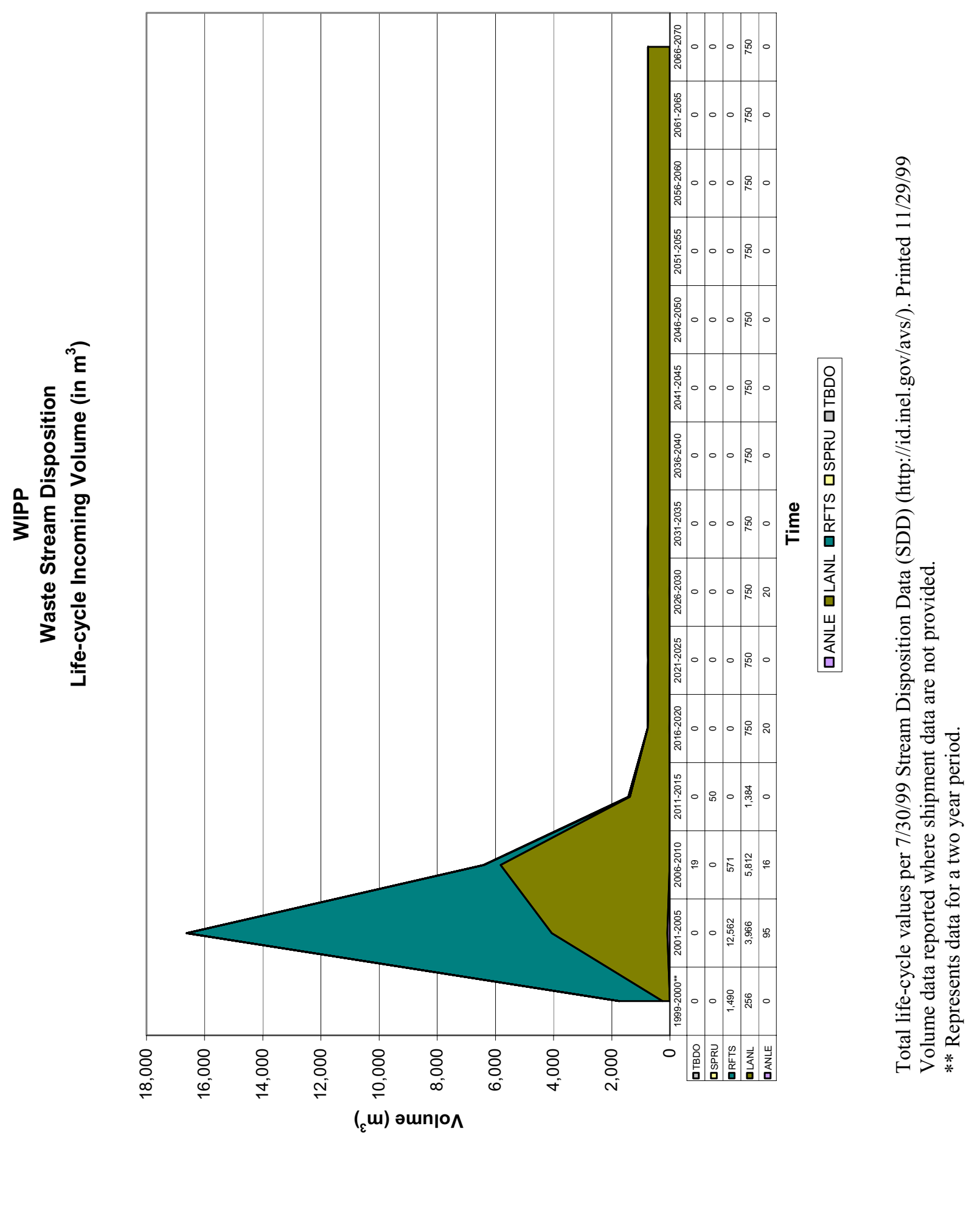


$\frac{n}{1}$
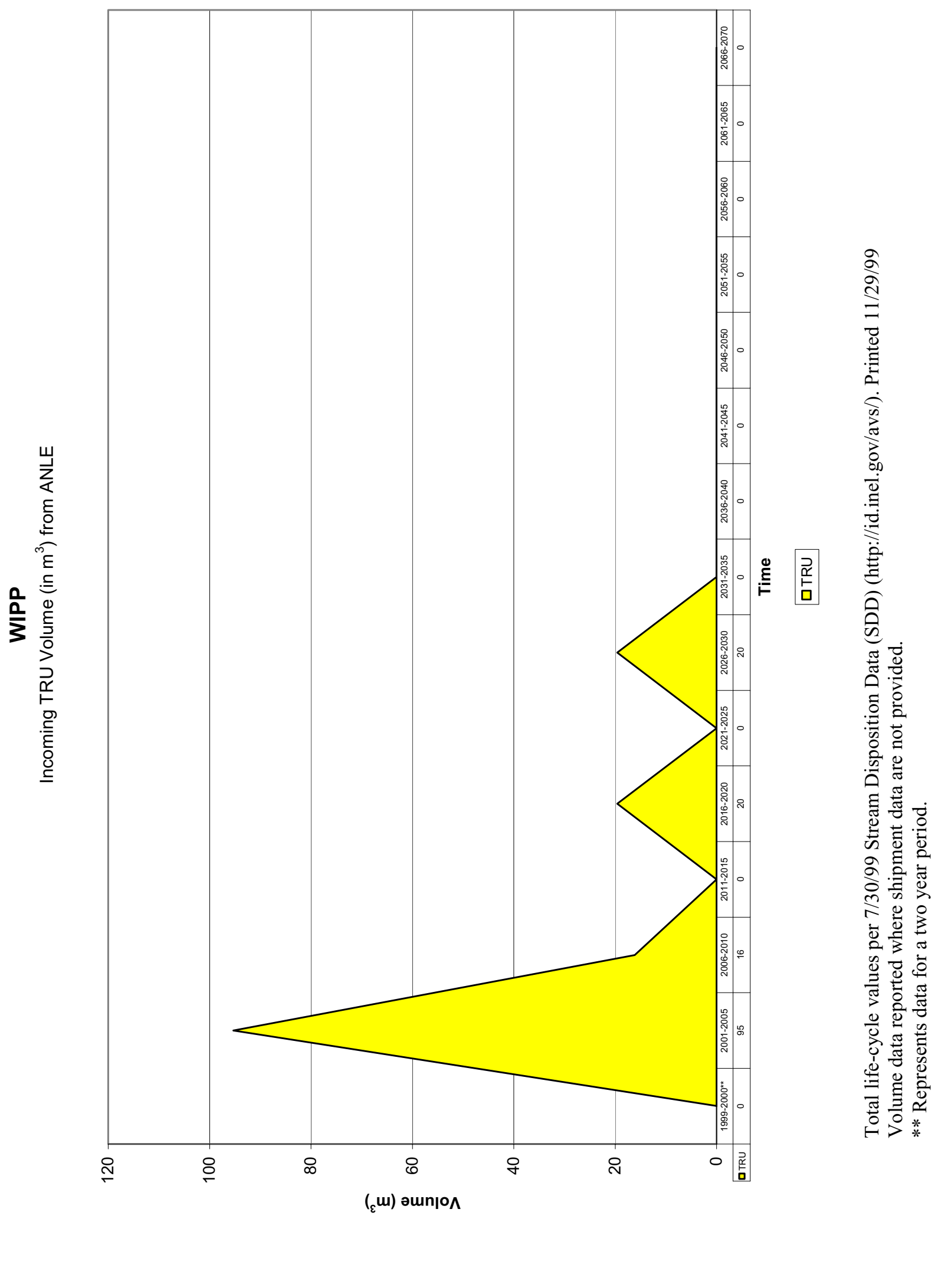
$\frac{7}{4}$

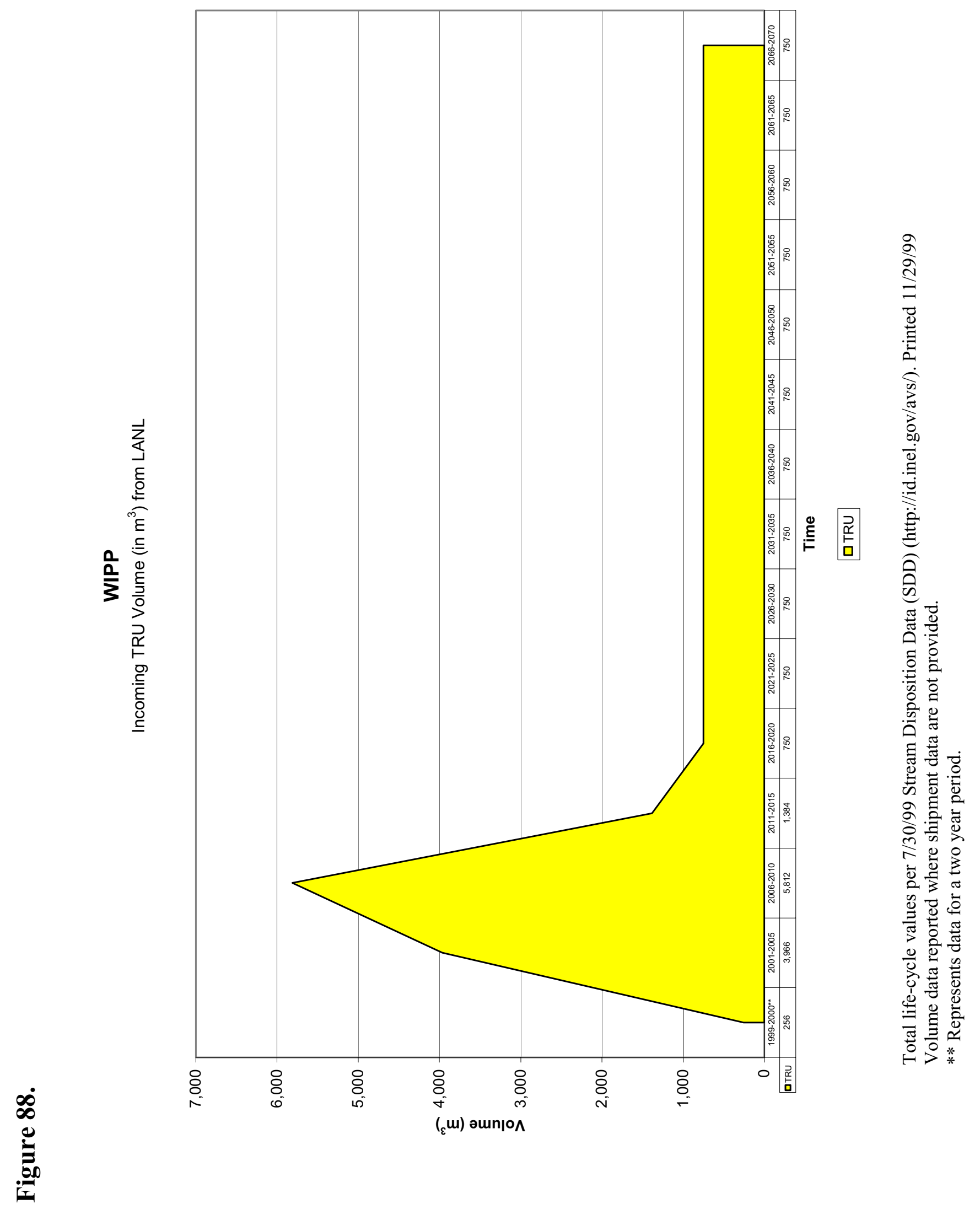


向
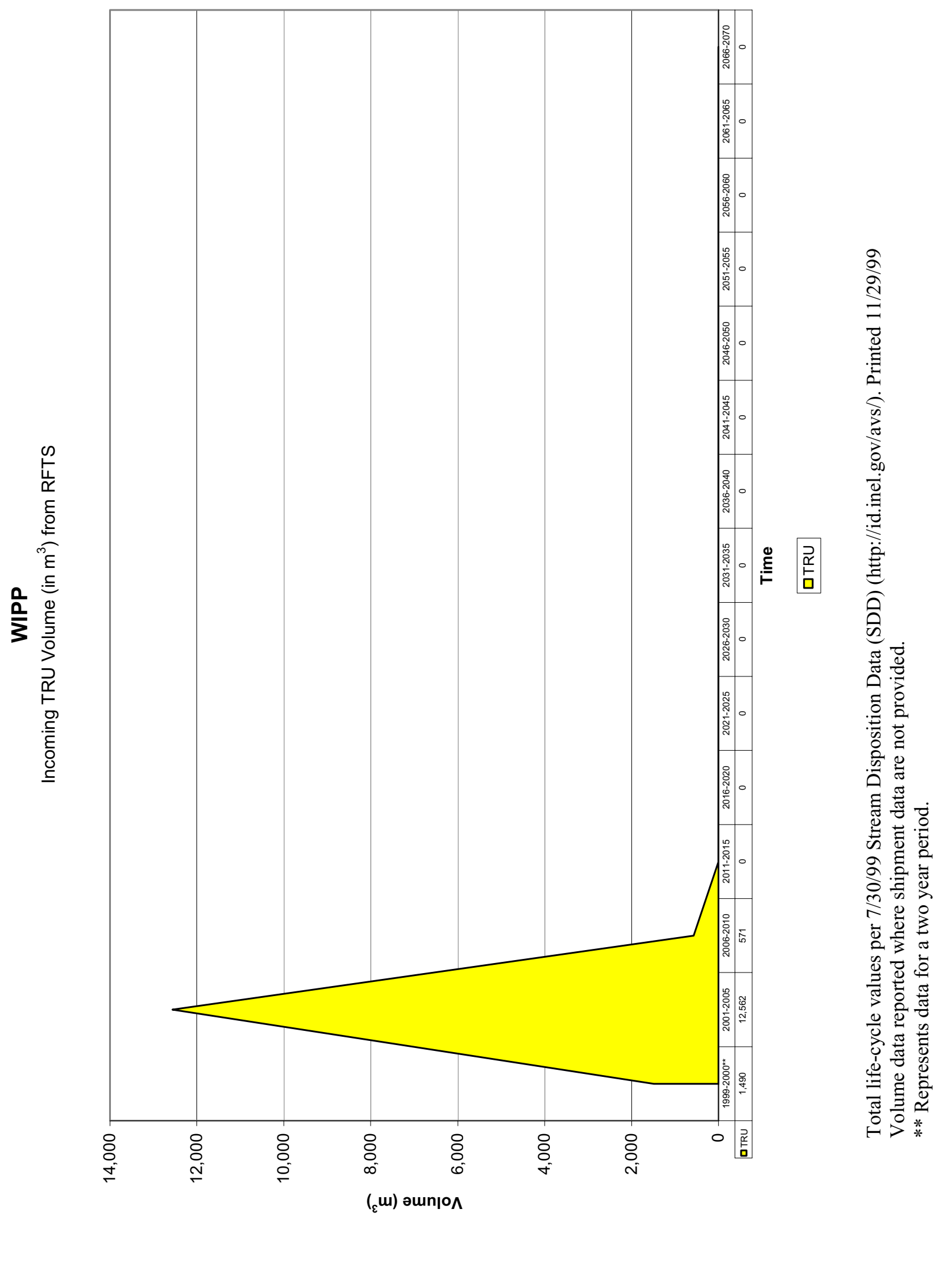

8
0
0
0
0 
$\frac{0}{1}$

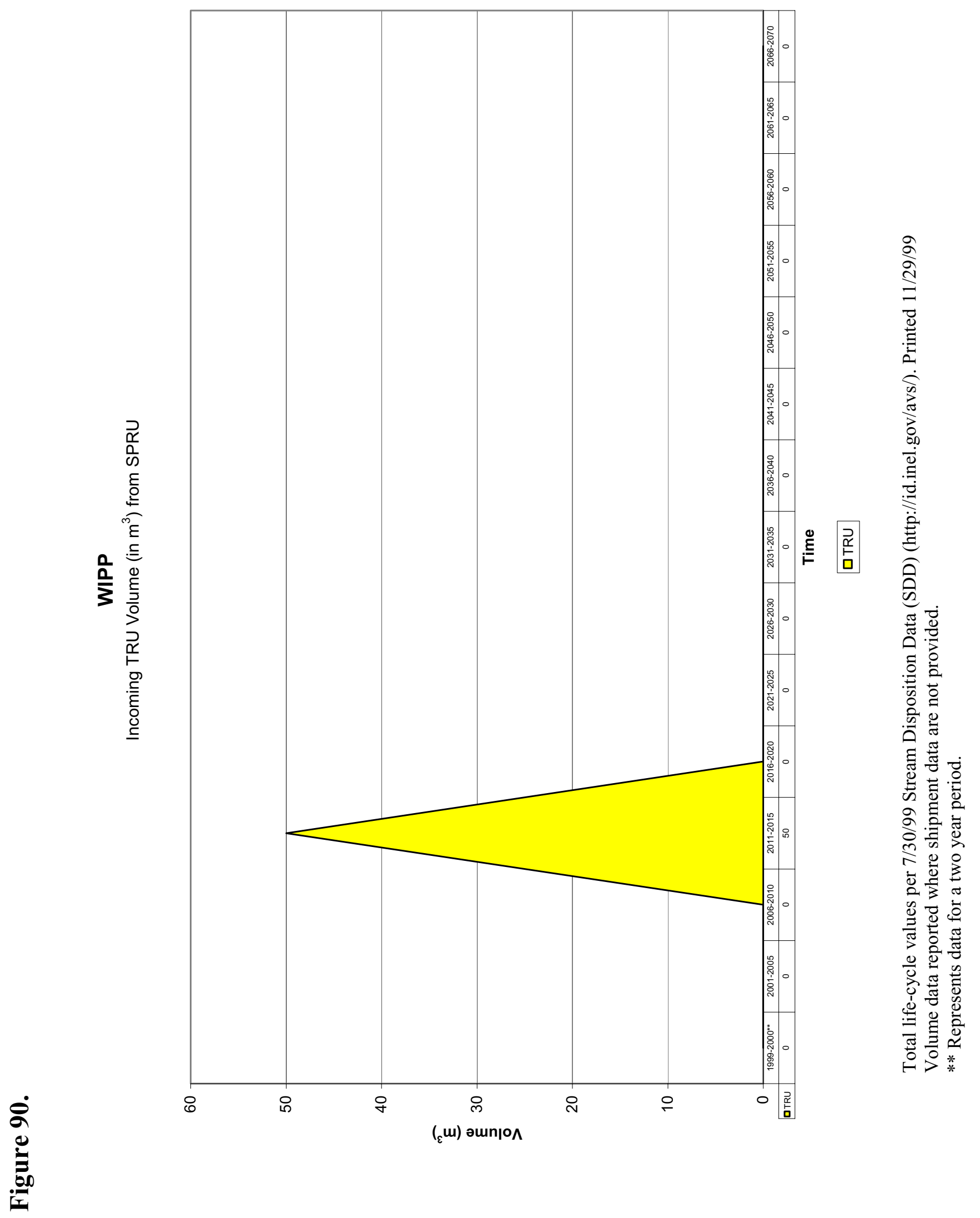


$\frac{5}{4}$

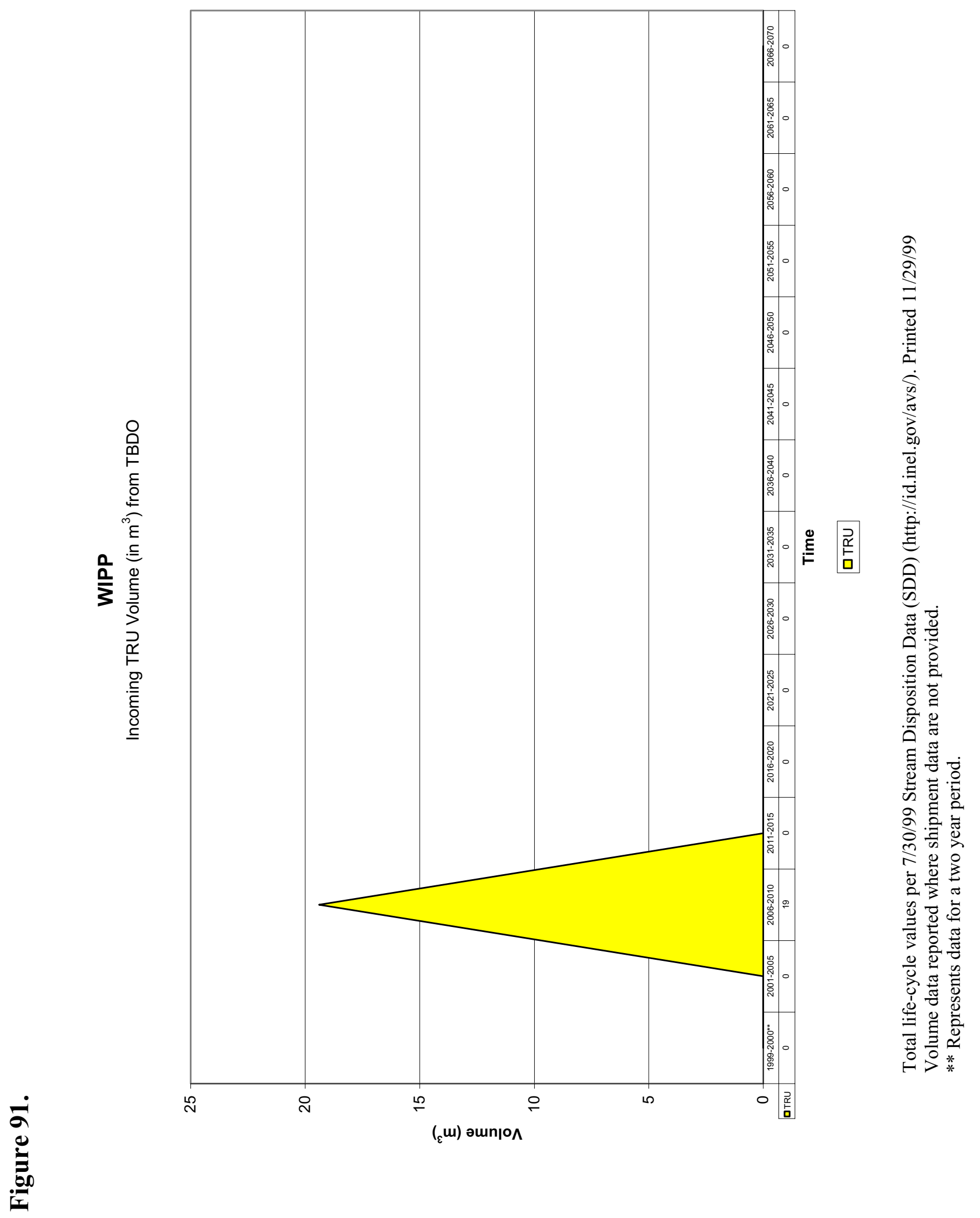





\section{Appendix F}

\section{Data Analysis Examples 1 - Repository Receipts Model 2 - Packaging Analysis}





\section{Figure 92.}

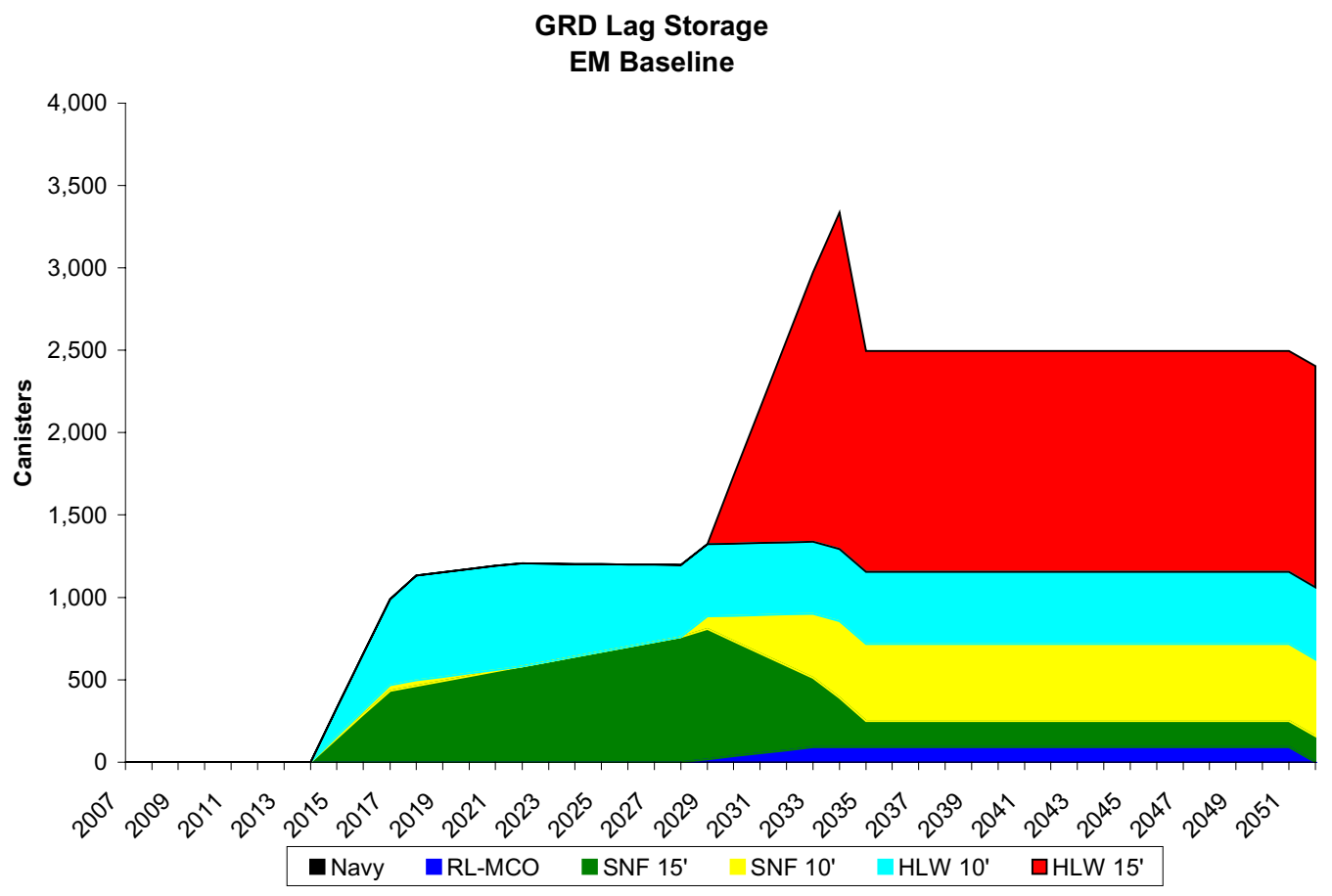

Figure 93.

GRD Lag Storage

Alternative "B"

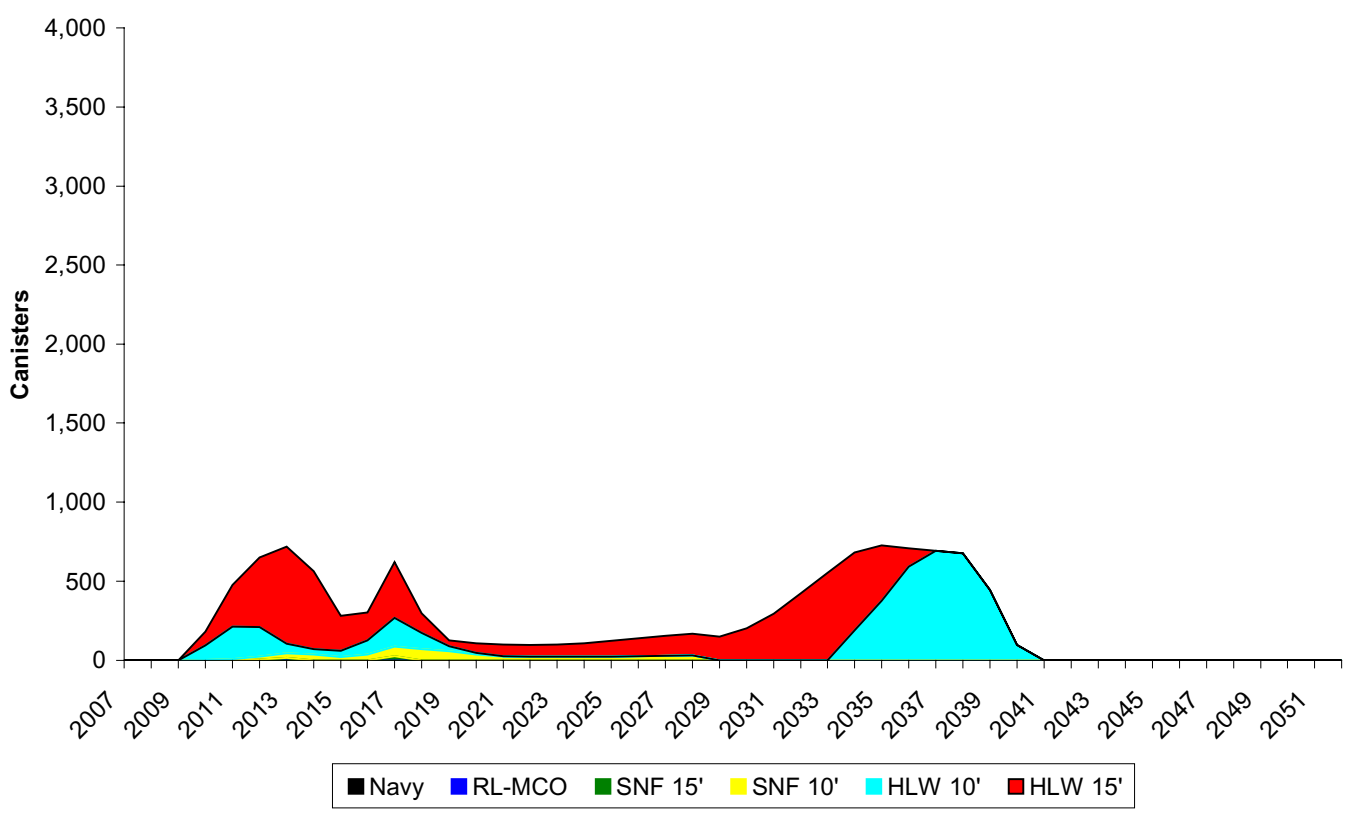




\section{Figure 94.}

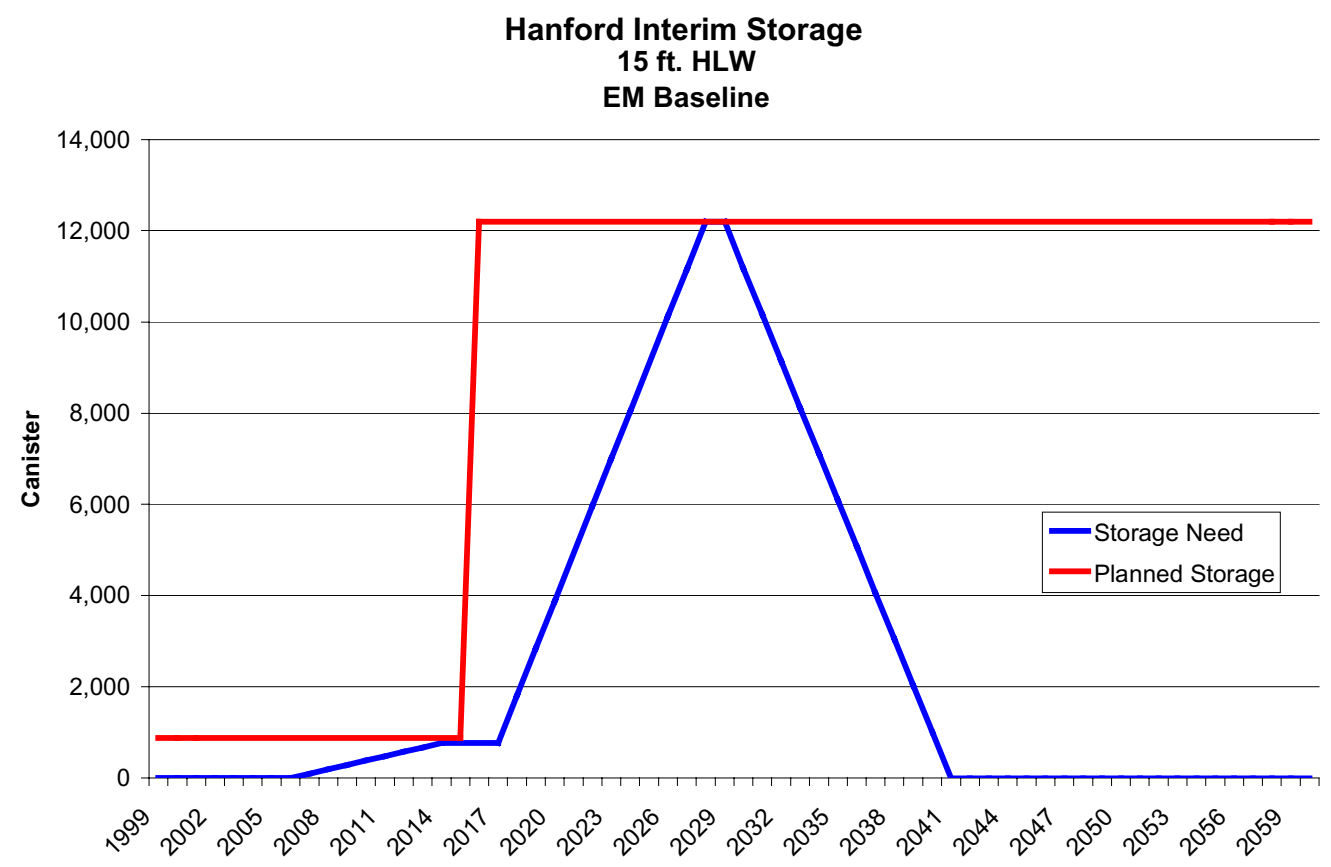

\section{Figure 95.}

Hanford Interim Storage

$15 \mathrm{ft}$. HLW

Alternative "B"

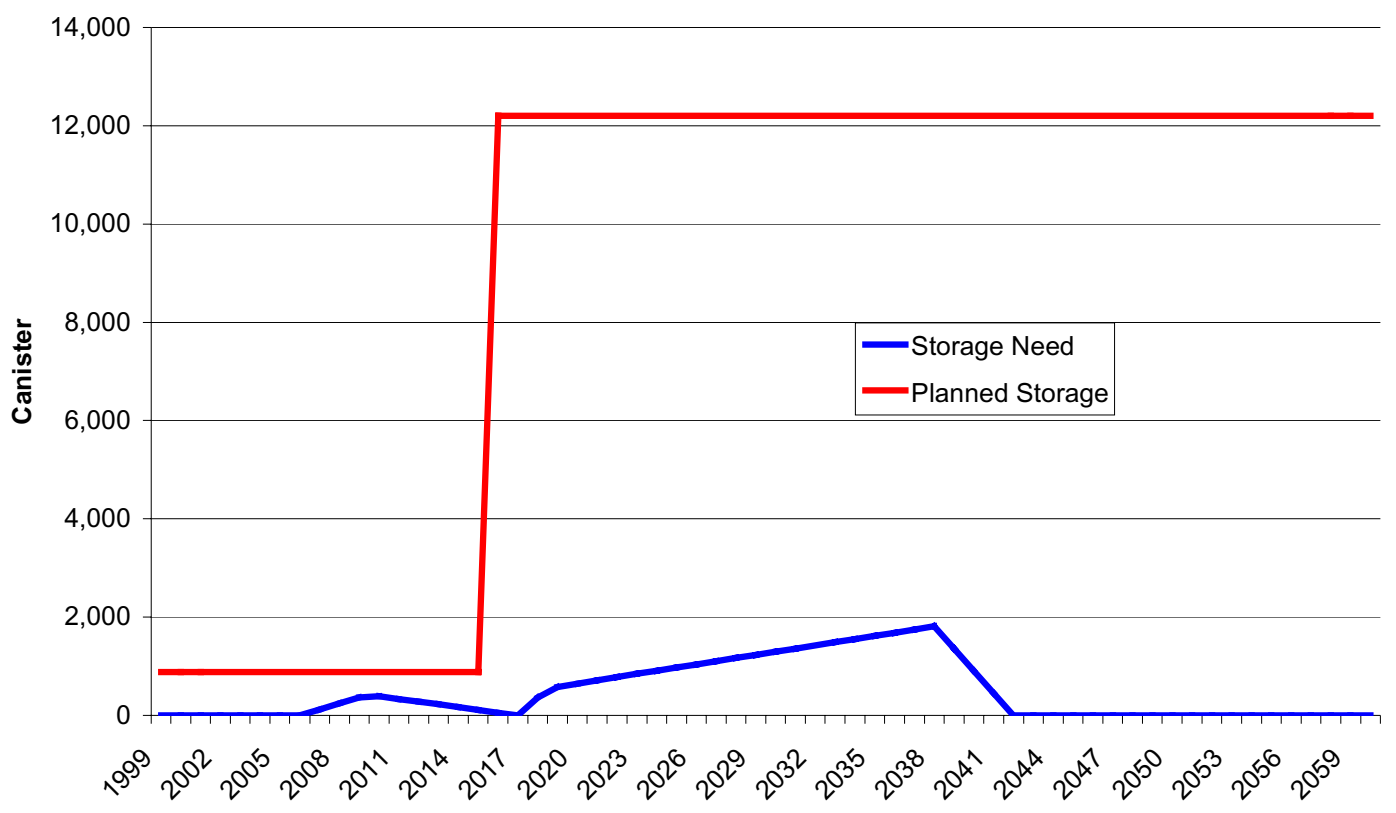




\section{Figure 96.}

Complex-wide Number of Type B Packagings by Waste Type, Near Term

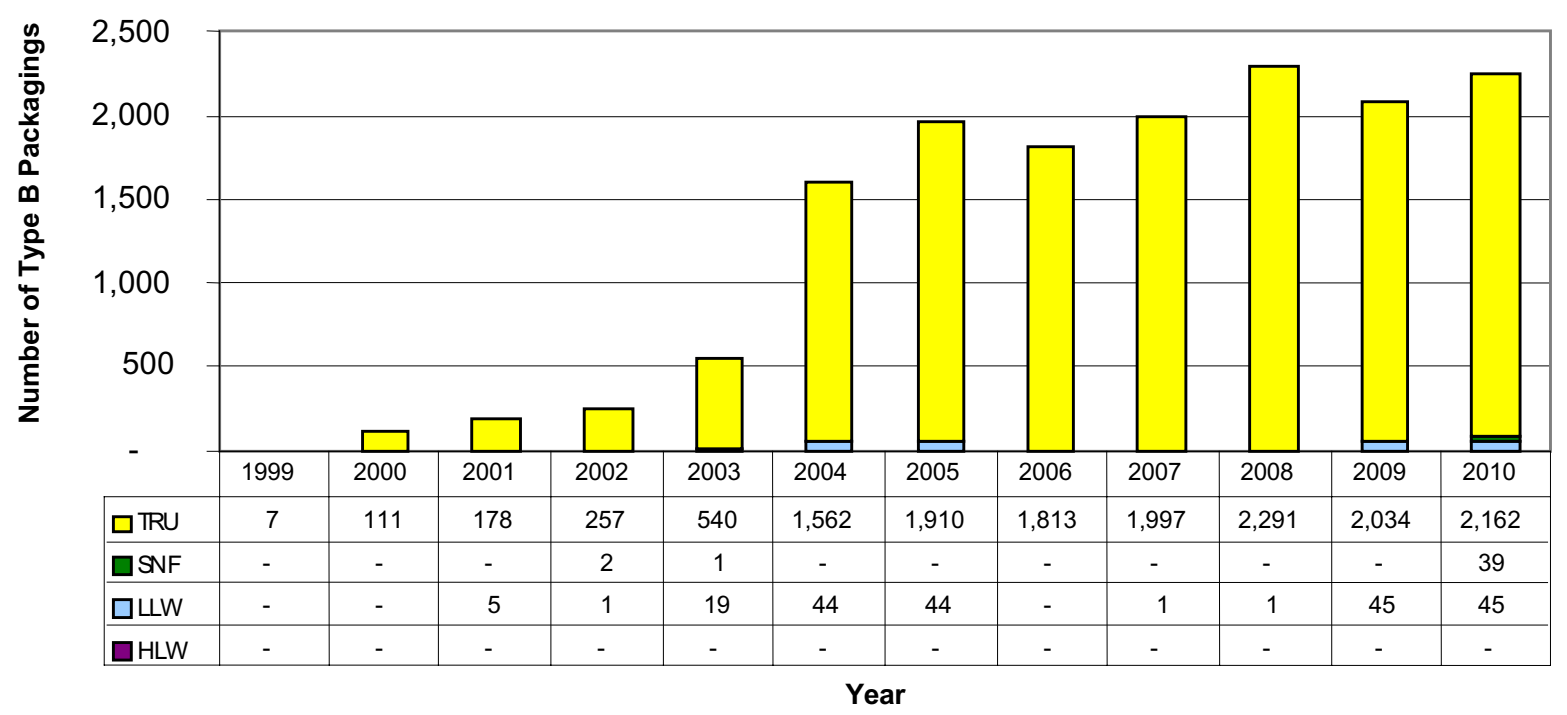

Figure 97.

Complex-wide Number of Type B Packagings by Waste Type, Life Cycle

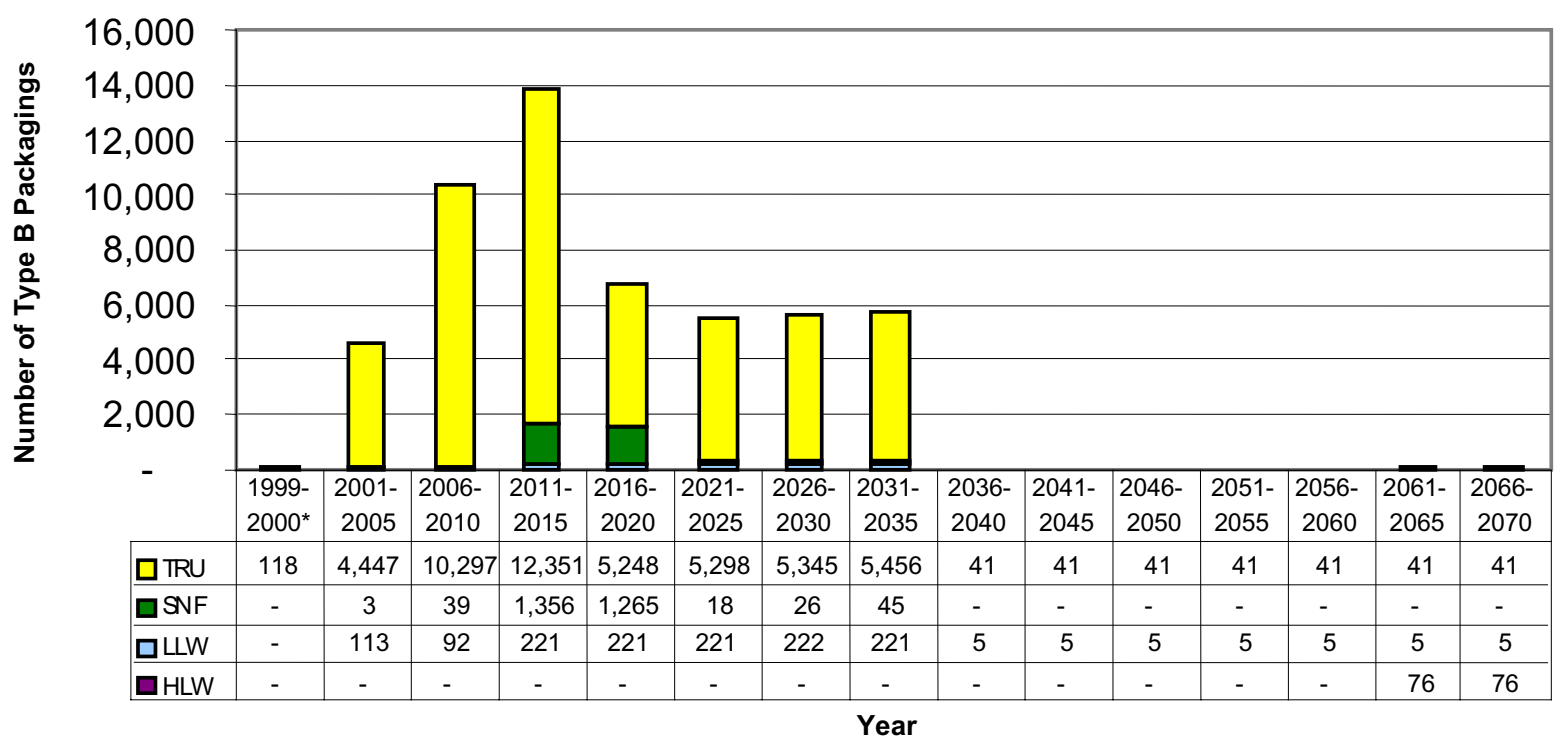

*Two years only 




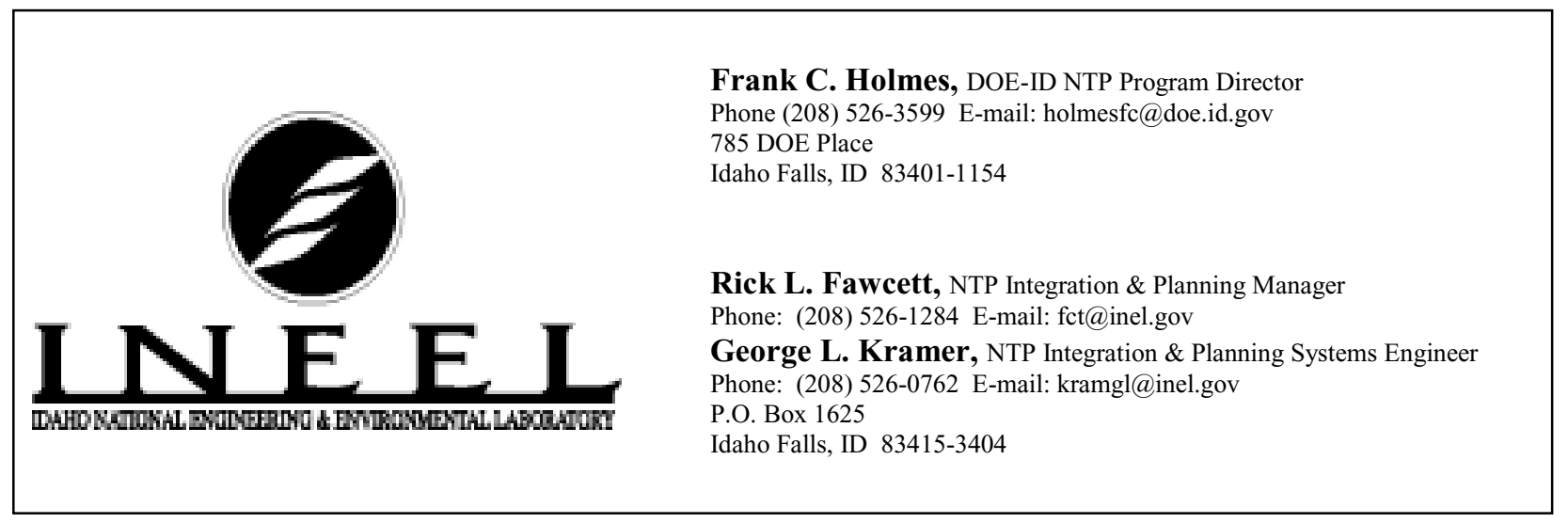

